\title{
Catecholaminergic connectivity to the inner ear, central auditory and vocal motor circuitry in the plainfin midshipman fish, Porichthys notatus
}

\author{
Paul M. Forlano ${ }^{1,2,3,6}$, Spencer D. Kim¹, Zuzanna M. Krzyminska1 ${ }^{1}$, and Joseph A. \\ Sisneros ${ }^{4,5,6}$ \\ 1Department of Biology, Brooklyn College, City University of New York, Brooklyn, NY 11210 \\ ${ }^{2}$ Programs in Neuroscience, Ecology, Evolutionary Biology and Behavior, and Behavioral and \\ Cognitive Neuroscience, The Graduate Center, City University of New York, Brooklyn, NY 11210 \\ ${ }^{3}$ Aquatic Research and Environmental Assessment Center, Brooklyn College, Brooklyn, NY \\ ${ }^{4}$ Departments of Psychology and Biology, University of Washington, Seattle, WA, 98195 \\ ${ }^{5}$ Virginia Merrill Bloedel Hearing Research Center, Seattle \\ ${ }^{6}$ Marine Biological Laboratory, Woods Hole, MA 02543
}

\section{Abstract}

\begin{abstract}
Although the neuroanatomical distribution of catecholaminergic (CA) neurons has been well documented across all vertebrate classes, few studies have examined CA connectivity to physiologically and anatomically identified neural circuitry that controls behavior. The goal of this study was to characterize CA distribution in the brain and inner ear of the plainfin midshipman fish (Porichthys notatus) with particular emphasis on their relationship with anatomically labeled circuitry that both produces and encodes social acoustic signals in this species. Neurobiotin labeling of the main auditory endorgan, the saccule, combined with tyrosine hydroxylase immunofluorescence (TH-ir) revealed a strong CA innervation of both the peripheral and central auditory system. Diencephalic TH-ir neurons in the periventricular posterior tuberculum, known to be dopaminergic, send ascending projections to the ventral telencephalon and prominent descending projections to vocal-acoustic integration sites, notably the hindbrain octavolateralis efferent nucleus, as well as onto the base of hair cells in the saccule via nerve VIII. Neurobiotin backfills of the vocal nerve in combination with TH-ir revealed CA terminals on all components of the vocal pattern generator which appears to largely originate from local TH-ir neurons but may include diencephalic projections as well. This study provides strong evidence for catecholamines
\end{abstract}

\footnotetext{
Corresponding author: Paul M. Forlano, Department of Biology, Brooklyn College, City University of New York, 2900 Bedford Ave, Brooklyn, NY 11210, phone: (718) 951-5000 x6252, fax: (718) 951-4659, pforlano@ brooklyn.cuny.edu.

CONFLICT OF INTEREST STATEMENT

We have no known or potential conflicts of interest.

ROLE OF AUTHORS

All authors had full access to all the data in the study and take responsibility for the integrity of the data and the accuracy of the data analysis. Study concept and design: PMF. Acquisition of data: PMF, DSK, ZMK, JAS. Analysis and interpretation of data: PMF, DSK, ZMK. Drafting of the manuscript: PMF. Critical revision of the manuscript for important intellectual content: PMF and JAS. Obtained funding: PMF and JAS.
} 
as important neuromodulators of both auditory and vocal circuitry and acoustic-driven social behavior in midshipman fish. This first demonstration of TH-ir terminals in the main endorgan of hearing in a non-mammalian vertebrate suggests a conserved and important anatomical and functional role for dopamine in normal audition.

\section{Keywords}

dopaminergic neurons; noradrenergic neurons; posterior tuberculum; saccule; vocal pattern generator; octavolateralis efferent nucleus

\section{INTRODUCTION}

Catecholamines are a highly conserved group of neurochemicals that are known to function as important modulators of motivation, reward, arousal, sensory and motor systems and reproduction (Berridge, 2008; Hurley et al., 2004; Joshua et al., 2009; Riters, 2012; Salamone and Correa, 2012). The neuroanatomical distribution of catecholaminergic (CA) neuronal groups, which include dopamine (DA) and noradrenaline (NA), is well characterized across all major vertebrate taxa, and with a few exceptions, is largely conserved. Like other vertebrates, teleosts exhibit brainstem CA cell groups in the area postrema (AP), vagal lobe (and associated areas) and the noradrenergic locus coeruleus, as well as DA cell groups in the hypothalamus, preoptic area, thalamus, subpallium, and olfactory bulb but lack midbrain ventral tegmental (VTA)/substantia nigra (SN) DA populations found in both tetrapods and elasmobranch fishes that form the wellcharacterized ascending mesolimbic/nigrostriatal pathways involved in motivation and reward-related behaviors (for review see Carrera et al., 2012; O'Connell and Hofmann, 2011; Smeets and Gonzalez, 2000; Yamamoto and Vernier, 2011). A subpopulation of DA neurons in the diencephalic periventricular posterior tuberculum (TPp) of teleosts sends ascending projections to the ventral telencephalon and therefore was originally proposed to be homologous to VTA/SN of tetrapods (Rink and Wullimann, 2001; 2002a); (also see O'Connell and Hofmann, 2011; 2012); however, recent studies using genetic manipulations strongly suggest this group is homologous to diencephalic A11 DA neurons which are dependent on the transcription factor orthopedia (otp), and local subpallial DA neurons may function to supply DA to proposed striatal homologs (Kastenhuber et al., 2010; Lohr et al., 2009; Ryu et al., 2006; Schweitzer et al., 2012; Tay et al., 2011). Regardless of homology, the widespread projection pattern (largely descending but also ascending) of these TPp neurons position them to be important integrative neuromodulators of sensory and motor function, cognition and behavior (Ma, 2003; Schweitzer et al., 2012; Tay et al., 2011). Teleosts exhibit CA neuronal populations and innervation patterns in nuclei with proposed homologies to those found in tetrapods where they are known to modulate motivated social and reproductive behavior (Goodson and Kingsbury, 2013; O'Connell and Hofmann, 2011; Petersen et al., 2013). However, aside from DA neurons in the anterior preoptic area that are well documented to regulate the hypothalamic-pituitary-gonadal (HPG) axis in teleosts (Dufour et al., 2010; Dufour et al., 2005; Kah et al., 1987; Peter and Fryer, 1983), the function of specific CA cell groups in teleosts are largely unknown. However, recent studies in teleosts have begun to characterize $\mathrm{cFos}$ induction of $\mathrm{CA}$ nuclei to social challenge 
stimuli (O'Connell et al., 2013; Petersen et al., 2013). Furthermore, there are few examples (McLean and Fetcho, 2004b) regarding CA connectivity to physiologically and anatomically identified neural circuitry that controls behavior in teleosts.

The plainfin midshipman fish, Porichthys notatus, is a well-studied model system for understanding neural and hormonal mechanisms underlying vocal-acoustic communication in vertebrates (Bass and McKibben, 2003; Forlano and Bass, 2011), and thus is an ideal model to investigate structure- function of catecholamines in relation to well-delineated vocal and auditory circuits which may in turn provide important insights on the evolution of catecholamines in auditory-driven social behavior (Petersen et al., 2013). During the summer months in the intertidal zone off northern California and the Pacific Northwest, type I male midshipman excavate and defend nests under rocks, and court females at night by producing a long duration (>1 min) advertisement call via rapid contraction of the vocal musculature on the sides of the swimbladder (Bass and McKibben, 2003; Cohen and Winn, 1967). Females localize males by sound, spawn once and return offshore, while type I males continue to court additional females and alone care for offspring (Bass, 1996; Bass and McKibben, 2003). Type II males do not court females but rather sneak or satellite spawn in competition with type I males (Bass, 1996; Brantley and Bass, 1994).

The descending vocal motor system in midshipman has been physiologically and anatomically well-characterized and consists of forebrain nuclei in the preoptic area and anterior hypothalamus with connections to the midbrain periaqueductal gray, paratoral and midbrain isthmal nuclei, which in turn connect to the vocal pattern generator (VPG) in the hindbrain spinal-cord (Bass et al., 1994; Chagnaud et al., 2011; Goodson and Bass, 2002; Kittelberger and Bass, 2013; Kittelberger et al., 2006). The VPG consists of vocal prepacemaker neurons (VPP) that receive input from midbrain vocal centers and hindbrain auditory nuclei, and innervate vocal pacemaker neurons (VPN) and the central paired vocal motor nucleus (VMN) whose axons exit the CNS as occipital nerve roots to innervate sound-generating musculature along the lateral swim bladder (Bass and Baker, 1990; Bass et al., 1994; Chagnaud et al., 2011; Goodson and Bass, 2002). Importantly, the VPG sets the temporal pattern of natural calls and this is encoded separately by VPP for duration and VPN for frequency (Chagnaud et al., 2011; Chagnaud et al., 2012). Furthermore, the VPG of midshipman is derived from the same compartment of the CNS that patterns vocalizations in tetrapods (Bass and Baker, 1997; Bass et al., 2008).

The auditory system in midshipman has also been well characterized and like other teleosts, contains primary afferents from the saccule, the main endorgan of hearing, which synapse onto first order medullary neurons comprising the descending octaval nucleus and its subdivisions and secondary octaval populations, both of which project to the midbrain torus semicircularis, which in turn projects to several diencephalic nuclei including the anterior tuberal hypothalamus and central posterior thalamus which relays information to pallial and subpallial nuclei (Bass et al., 2000; Bass et al., 1994; Goodson and Bass, 2002; McCormick, 1999; 2011). A hindbrain octavolateral efferent nucleus (OE) receives input from the vocal motor system and projects to the inner ear endorgans and lateral line system (Bass et al., 2000; Bass et al., 1994; Chagnaud et al., 2011; Chagnaud and Bass, 2013; Weeg et al., 2005). Additionally, the auditory system in midshipman is interconnected to vocal nuclei in 
the forebrain, midbrain and hindbrain (Bass et al., 2000; 2001a; Goodson and Bass, 2002;

Kittelberger et al., 2006)

The goal of this study was to characterize CA distribution in the midshipman brain with particular emphasis on its relationship to identified circuitry that both produces and encodes social acoustic signals. We tested the hypothesis that CAergic neurons directly innervate the peripheral and central auditory system and VPG by transneuronal backfill of the saccular branch of nerve VIII and vocal occipital nerve roots, respectively, combined with immunofluorescence (-ir) for tyrosine hydroxylase (TH), the rate-limiting enzyme for CA synthesis. Data contained in the present study have, in part, been reported in abstract form (Forlano et al., 2012).

\section{MATERIALS AND METHODS}

\section{Animals}

Fish were hand collected from intertidal nests in Tomales Bay, CA or Hood Canal, WA in the summer reproductive period or captured by otter trawl off of Edmonds, WA in Puget Sound in the winter non-reproductive season (December). Fish were either shipped to the Aquatic Research and Environmental Assessment Center (AREAC) at CUNY Brooklyn College, separated by sexual morphotype and maintained in recirculating saltwater aquaria or shipped to the Marine Biological Laboratory (MBL) in Woods Hole and maintained in flow-through seawater tables. All experimental procedures performed in this study were approved by the Animal Care and Use Committee of CUNY Brooklyn College and MBL. A total number of 42 fish were used in this study which included type I males, type II males and females. Only type I males were used for vocal nerve backfill experiments (see below). Analyses regarding differences in sex and/or season are beyond the scope of the current study and will be reported elsewhere.

\section{Neuroanatomical tract-tracing}

Saccular endorgan fills-Procedures were conducted as previously reported to delineate hindbrain auditory nuclei (Bass et al., 2000; Bass et al., 1994; Sisneros et al., 2002). Type I (12.5- $15 \mathrm{~cm}$ standard length, SL) and type II $(8-9.5 \mathrm{~cm})$ males were anesthetized in a $0.025 \%$ benzocaine seawater bath and the saccule was exposed by dorsal craniotomy (see Fig. 1). Neurobiotin crystals (Vector Labs, Burlingame, CA) were applied either to the saccular nerve branch near the sensory macula $(n=5)$ or directly on the saccular macula $(\mathrm{n}=2)$ via a minutian pin. Neurobiotin was applied bilaterally on two fish and unilaterally on the others. The exposed inner ear was covered with parafilm and glued with Vetbond (3M, St. Paul, MN) for a water tight seal. Survival times ranged between 1-2 days until sacrificed by transcardial perfusion (below).

Vocal nerve backfills-Procedures were conducted as previously reported where application of neurobiotin or biocytin to a single vocal (sonic) nerve will delineate the bilateral vocal pattern generator in the hindbrain-spinal cord (Bass et al., 1996; Bass et al., 1994; Knapp et al., 1999). Type I males ( $\mathrm{n}=6)$ ranging from 11.6- $15.6 \mathrm{~cm}$ SL were used. Based on gonadosomatic index and vocal muscle appearance, 2/6 were in reproductive 
condition and 4/6 were in a non-reproductive state (see Sisneros et al., 2009). Fish were anesthetized as above and the left swimbladder muscle was exposed by a ventral incision of the body wall. The vocal nerve was then exposed by separating the medial muscle from the swimbladder wall and neurobiotin crystals were applied to the dried cut end of the nerve. The body wall was sutured shut and sealed with Vetbond. Post-surgery survival time was 6 days until sacrificed by transcardial perfusion (below).

\section{Immunohistochemistry}

Methods for fixation and immunohistochemistry have been described elsewhere (Petersen et al., 2013). Animals were deeply anesthetized in $0.025 \%$ benzocaine in seawater, transcardially perfused with ice-cold teleost ringers followed by $4 \%$ paraformaldehyde in $0.1 \mathrm{M}$ phosphate buffer (PB; $\mathrm{pH}$ 7.2). Brains and saccules were removed and postfixed for one hour, rinsed and stored in PB. Brains were cryoprotected in 30\% sucrose in PB 24-48hr at $4{ }^{\circ} \mathrm{C}$, embedded in Cryo-Gel (Instrumedics inc., $\mathrm{MO}$ ) and sectioned at $25 \mu \mathrm{m}$ (brain) or 15 $20 \mu \mathrm{m}$ (saccular epithelium) in the transverse, sagittal or horizontal plane on a Leica CM1850 cryostat. Sections were collected onto gelatin subbed microscope slides and then stored in -20 or $-80^{\circ} \mathrm{C}$.

For immunolabeling, slides were brought to room temperature (at which all subsequent steps were carried out), washed 2 X $10 \mathrm{~min}$ in $0.1 \mathrm{M}$ phosphate buffer saline (PBS) and then blocked in 0.1M PBS + 5\% normal donkey serum (NDS; Jackson Immunolabs, West grove, PA) or $5 \%$ NDS $+5 \%$ bovine serum albumin (BSA; Sigma, St. Louis, MO) + 0.3\% Triton X-100 (PBST) for one hour. Primary antibodies were diluted in PBST, applied onto tissue sections and incubated for 16 hours in a humidified chamber. The primary antibodies and dilutions were: mouse anti-TH (1:1000; Millipore/Chemicon MAB318, RRID: AB_2201528, Temecula, CA), sheep anti-TH (1:3000; Millipore/Chemicon AB1542, RRID: AB_90755) and mouse anti-hair cell HCS-1 (1:1000, RRID: AB_10804296, gift of J. Corwin). After primary antibody incubation, slides were washed 5X 10 min in PBS $+0.5 \%$ Donkey Serum (PBS-DS). For chromagen visualization (TH-ir atlas, Figure 2 only), secondary biotinylated anti-mouse antibody (Vector Labs) was diluted 1:200 in PBST and applied to sections and incubated for two hours. The slides were washed 4X $10 \mathrm{~min}$ in PBSDS. Vectastain ABC solution (Vector Labs) was diluted 1:200 in PBS-DS and then applied to the sections and incubated for one hour. The slides were washed in PB 3X $10 \mathrm{~min}$ and then incubated in $0.1 \%$ diaminobenzidine (DAB) in $0.1 \mathrm{M}$ PB with $0.3 \%$ hydrogen peroxide for two minutes to visualize the labeling. After additional washes in PB, the slides were then Nissl-stained ( $0.5 \%$ Cresyl Violet in distilled water), dehydrated and cover-slipped with eukitt (Sigma). For fluorescence visualization, slides were incubated with Alexa Fluorconjugated secondary antibodies diluted in PBST for two hours (1:200 anti-mouse Alexa Fluor 488; anti-sheep Alexa Fluor 680; Invitrogen). For tract-tracing studies, streptavidin Alexa Fluor 594 or Neutravidin Texas Red (1:1000; Invitrogen) was combined with the Alex Fluor 488 antibody incubation. Slides were then washed 4X 10 min in 0.1M PBS. In some instances an additional $1 \mathrm{X} 10 \mathrm{~min}$ wash in $0.1 \mathrm{M}$ PBS $+0.1 \%$ Triton X-100 preceded a 25 min incubation in fluorescent Nissl stain in PBS (1:100, Deep Red NeuroTrace, Invitrogen). All slides were coverslipped with Prolong Gold Antifade Reagent with DAPI nuclear counterstain (Invitrogen). 


\section{Antibody Characterization}

The mouse monoclonal anti-TH antibody (MAB318, clone LNC1) was produced against tyrosine hydroxylase purified from PC12 cells and recognizes an epitope on the outside of the regulatory $\mathrm{N}$-terminus. On Western blots it does not react with dopamine-betahydroxylase, phenylalanine hydroxylase, trytophan hydroxylase, dehydropteridine reductase, sepiapterin reductase or phenethanolamine-N-methyl transferase (manufacturer's data). Western blot analysis of rat and fish brain extracts, including midshipman, show similar expected bands of 59-63kDa (Adrio et al., 2011; Carrera et al., 2012; Gayoso et al., 2011; Goebrecht et al., 2014; manufacturer's data). This antibody stains the appropriate pattern (i.e., known CA populations of neurons and projection patterns) in all brain regions as previously documented in midshipman and other fish species (Carrera et al., 2012; Goebrecht et al., 2014; Kuscha et al., 2012; McLean and Fetcho, 2004a) and other vertebrates (e.g., Hayes et al., 2011; Nakano et al., 2009). Alternate sections from positively labeled sections incubated without primary or secondary antisera showed a complete absence of labeling.

Since the above monoclonal TH antibody could not be used readily in combination with the monoclonal hair cell marker HCS-1 (below), we used sheep polyclonal anti-TH antibody (AB1542) in the present study in order to visualize TH-ir in the saccule in combination with monoclonal anti-HCS-1. The sheep polyclonal anti-TH antibody (AB1542) was produced against native tyrosine hydroxylase from rat pheochromocytoma. This antibody recognizes a $\sim 60 \mathrm{kDa}$ band from mouse brain lysate on Western blot (manufacturer's data) and labels known catecholaminergic neuronal populations in rodent brain (e.g., Kaufling et al., 2009). Importantly, in midshipman, AB1542 shows the same pattern of labeling on adjacent sections in the saccule as the monoclonal anti-TH (MAB318, above) and a similar pattern of innervation in mammalian saccule (Drescher et al., 2010) and cochlear sensory epithelium (Darrow et al., 2006a; Niu and Canlon, 2006; see Discussion) as other polyclonal TH antibodies. Adjacent sections from positively labeled sections incubated without primary or secondary antisera showed a complete absence of labeling. Furthermore, AB1542 positively labels catecholaminergic neuronal populations in the midshipman CNS.

The mouse monoclonal HCS-1 antibody labels the soma of vertebrate hair cells (Gale et al., 2000; Warchol and Speck, 2007); the specific antigen was recently identified as otoferlin by immunoprecipitation and mass spectroscopy; the antibody labels hair cell somata in species across five vertebrate classes (Goodyear et al., 2010). In addition, this antibody has previously been documented to label the appropriate pattern, i.e., hair cell somata in the saccule of $P$. notatus (Fergus and Bass, 2013; Forlano et al., 2005; Forlano et al., 2010). Adjacent sections from positively labeled sections incubated without primary or secondary antisera showed a complete absence of labeling.

\section{Imaging and analysis}

TH Atlas-Representative sections from three DAB stained animals (2 type II males, one female) were imaged with a 10x objective on an Olympus PX41 light microscope and Olympus DP25 camera with CellSens software. Images were merged together in Adobe Photoshop CS5 (Adobe Systems). Section boundaries, landmarks, nuclei as defined by Nissl 
stain and major TH-ir fiber tracts were traced in GNU Image Manipulation Program (GIMP) using a Bamboo pen tablet (Wacom, Vancouver, WA). The final images were then compiled and labeled in Adobe Illustrator. The atlas (Fig. 2) was meant to show major TH-ir cell groups and fiber tracts in $P$. notatus. Fine caliber projections and innervation seen only at higher magnification is addressed in other parts of the study. Cell groups and fiber tracts shown here were consistent across morphs.

Fluorescence microscopy-Images were acquired on an Olympus BX61 epifluorescent microscope containing DAPI, FITC/CY2, m-Cherry-Texas Red and Cy 5.5 filter sets (Chroma, Bellows Falls, VT) with a Hamamatsu C8484-03G02 digital CCD camera, using MetaMorph imaging software (Molecular Devices, Sunnyvale, CA). Multifluorescent images were captured sequentially. To image TH-ir terminals in proximity to backfilled cells, a $60 \mathrm{X}$ or $40 \mathrm{X}$ oil immersion objective was used to capture image stacks at $0.2 \mu \mathrm{m}$ or $0.3 \mu \mathrm{m}$ steps, respectively, to encompass the cell in the z-plane. All fluorescent images were overlaid in MetaMorph; single channel z-stacks were projected into a single image before being overlaid. Images were exported to Adobe Photoshop CS5 where images were compiled, labeled, and levels adjusted to enhance contrast.

\section{Distribution and cell measurements of neurobiotin-filled TH-ir TPp neurons-}

A series of low magnification images through sections of the central diencephalon of animals with saccular endorgan fills were traced as above (see TH-ir atlas) using DAPI stain to define nuclear boundaries and the position of all TH-ir and TH-ir backfilled neurons in this area were plotted. All backfilled TPp TH-ir neurons and adjacent non-backfilled TH-ir cells containing a clear nucleus were captured in the z-plane as above but using $1 \mu \mathrm{m}$ steps with a 20X objective. The perimeter of these somata was carefully traced and measured in MetaMorph to determine the major axis of the cell diameter and soma area to enable comparisons of cell morphology and size distribution of backfilled TH-ir cells in relation to other TH-ir neurons within this brain region.

\section{RESULTS}

\section{General distribution of TH-ir cells and fibers in the midshipman CNS}

An overview of the distribution of major TH-ir cells groups and fiber tracts at fifteen levels of the midshipman brain in the transverse plane (see Fig. 1) is summarized in Figure 2. Note that these cells and fiber tracts are readily identifiable and traced at low magnification using either chromogen or fluorescence immunostaining and therefore are not meant to depict the presence of low intensity TH-ir or very fine caliber terminals and fibers. Higher magnification imaging analyses evident in subsequent figures were necessary to reveal terminals and varicosities in some areas not highlighted in Figure 2 including vocal and acoustic circuitry that comprise the focus of this study.

Forebrain-A large population of TH-ir cells are found in the olfactory bulb (OB) and local projections of these neurons cover most of the OB (Fig 2A, 3A-C). TH-ir neurons run in a rostro-caudal continuum within area ventralis $(\mathrm{V})$ of the telencephalon and are found within and just lateral to the ventral $(\mathrm{Vv})$, dorsal $(\mathrm{Vd})$, supracommissural $(\mathrm{Vs})$ and 
postcommissural (Vp) subdivisions of V (Fig 2B-D), readily seen in the sagittal (Fig. 3A, B) and horizontal (Fig. $3 \mathrm{C}$ ) planes. Fibers from these $\mathrm{TH}$-ir groups project ventromedially into Vs and central $(\mathrm{Vc}$ ) division of $\mathrm{V}$ (Fig. 2B, C, 3A, C). A conspicuous tract from V TH-ir groups projects caudally around central $(\mathrm{Dc})$ and laterally into the lateral $(\mathrm{Dl})$ and less so into posterior (Dp) zones of area dorsalis of the telencephalon (D) (Fig. 3C). The medial zone of D (Dm) is largely devoid of TH-ir fibers (Fig 2B-D, 3A, B).

The anterior parvocellular preoptic nucleus ( $\mathrm{PPa}$ ) contains numerous small $\mathrm{TH}$-ir cells positioned ventrolaterally (Fig. 2B,C, 3B), while TH-ir cells are more scattered in posterior parvocellular nucleus (PPp) of the preoptic area (POA) (Fig 2D, 3D). PPa neurons contribute to the prominent fiber bundle which demarcates the preoptico-hypophyseal tract (PHT, Fig 2D) and fibers are evident in the pituitary (Fig 2B,C). Terminals are also found in the PPp and gigantocellular division of the magnocellular preoptic nucleus (PMg, Fig. 3F). The suprachiasmatic nucleus ( $\mathrm{SCN}$ ), which lies above the horizontal commissure and just ventral to the PPp, contains small numbers of clustered TH-ir cells (Fig 2D, 3D). The ventral thalamus contains a large population of small, round TH-ir cells which extends from the level of the caudal telencephalon to just rostral to the central posterior nucleus of the thalamus (CP) (Fig. 2D, E; 3A, B; 4A, B). These cells are found in a continuum that begins in a lateral position more rostrally and merges medially adjacent to the third ventricle (Fig. 3D, E; 4A, B). TH-ir cells can be seen within the ventromedial thalamus (VM), characterized by a multilaminar cell plate most easily visible as longitudinal, parallel rows of tightly packed cells in the horizontal plane (Fig. 3E) which merges caudally into a distinct concentration of small cells along the ependyma (Fig. 4A, B), as well as within the ventrolateral thalamus (VL) which is a group of more scattered cells on the lateral border of VM (Fig. 3E; 4A) (see Braford and Northcutt, 1983). This TH-ir group characteristically has prominent, long lateral processes (Fig. 2E; 3D; 4A, B) that extend to the lateral edge of the brain where very large terminals or varicosities are often found just dorsal to the lateral division of nucleus preglomerulosus (PGl) (Fig. 4A, B). No pretectal TH-ir cell population was found in this study (PPv, Fig. 4C), however, the VM TH-ir population also sends bundles of axons into the tectum (Te) (Fig 4B). Both ventral (vT) and anterior (AT) tuberal nuclei contained few numbers of scattered, small-diameter TH-ir cells (Fig 2D-F, below). AT was heavily innervated by TH-ir fibers, especially rostral and laterally (Fig. 2F; 4B-E). Ventral (Hv) and dorsal (Hd) periventricular hypothalamus showed prominent fiber innervation at their rostral extent (Fig 2G). The caudal periventricular hypothalamus (Hc, Fig. 2H) contained tightly packed small TH-ir cells just ventral to posterior tuberal nucleus (PTN).

The periventricular posterior tuberculum includes the periventricular posterior tubercular nucleus (TPp), the paraventricular organ (PVO), and the posterior tuberal nucleus (Braford and Northcutt, 1983; Striedter, 1990). The TPp consists of the region posterior to the ventral thalamus and ventral to $\mathrm{CP}$, dorsal to the hypothalamus, but extends laterally and is not restricted to a true periventricular location (Meek and Nieuwenhuys, 1998). While a few, small, inconspicuous TH-ir cells are found in the rostral, dorsal TPp, ventral to the caudal extent of the VM population (Fig. 4B, B1), the majority of TH-ir cells in the TPp are generally large $(22 \mu \mathrm{m})$ in diameter (Fig. 4C-I; 5A) and are found in the ventral TPp along the midline, contiguous with similar type cells just lateral to the PVO which wrap 
ventromedially around the medial forebrain bundle (MFB) (Fig 2F,G; 4C-I). In transverse sections these large, pear-shaped cells (named type 2 in zebrafish by Rink and Wullimann [2001]), have prominent dorsal and lateral projections (Fig. 4C-H). However, horizontal sections through this TH-ir population shows ascending projections (Fig. 4I) while sagittal sections through this area reveal a prominent dorsal then descending fiber tract that can be traced well into the hindbrain (Fig. 3A; 5A-C). Taken together, these large TH-ir cells in ventral TPp and lateral to PVO make up approximately 400 neurons in the adult midshipman brain (Petersen et al., 2013). These cells first appear in sparse numbers just caudal to VM cells, while their greatest density is found at the level of the caudal AT and rostral $\mathrm{Hd}$, afterwhich they become more sparse and lateral in position at the level of the PTN (Fig. 4). Within the PVO proper there are a few much smaller cells (Fig. 2G, 4G), although they also have dorsal projecting fibers and do not appear to have CSF-contacting processes. The PTN lies caudal to the TPp and PVO, ventral to the MFB and consists of densely packed parvocellular TH-ir cells (Fig. 5A) which form a lateral horseshoe shape dorsomedial to $\mathrm{Hc}$ (Fig $2 \mathrm{H})$.

Midbrain-The periaqueductal gray (PAG) contains very sparse numbers ( 1-2) of large multipolar TH-ir cells found at its ventral border (Fig. 6C). Prominent TH-ir fibers are found innervating the ventral aspect of the PAG and the adjacent paratoral tegmentum (PTT) (Fig. $2 \mathrm{H}, \mathrm{I} ; 4 \mathrm{H} ; 6 \mathrm{~A}, \mathrm{~B}$ ) and these appear to originate in part from the conspicuous dorsal TH-ir projections of TPp neurons (Fig. 6A). Robust TH-ir fibers are found in the central part of the torus semicircularis (TS) and form a demarcation from the deep cell layers of the torus (TSd) (Fig. 2 F-J; 6C, D). TH-ir terminals are also found in distinct bands in superficial and deep layers of the tectum (Te), but more pronounced in the lateral than medial Te (Fig. 2F$\mathrm{J}$; 6C). Prominent TH-ir fiber bundles descending through the dorsal tegmentum (Teg, Fig. 6C) appear to originate from TPp (see Fig. 5A).

The locus coeruleus (LC) is a cluster of approximately 80 large multipolar TH-ir neurons in the isthmal region of the brain just lateral to the fourth ventricle, medial to the lateral lemniscus (1l) and dorsolateral to the medial longitudinal fasciculus (MLF) (Fig 2J,K). Rostrally, at the intersection of the caudal lateral Te and the rostral cerebellum, small clusters of TH-ir neurons are located on the dorsolateral aspect of the MLF while others are more dorsal, just lateral to the fourth ventricle (Fig. 7A). Most LC neurons have ventral and lateral oriented dendrites (Fig. 7). In the horizontal plane the LC is seen as a rostro-caudal bilateral column of $2-3$ cells and more caudally cells become sparse (1-2) and are also found more laterally (Fig. 5A; 7B-D). A few TH-ir somata of similar size and shape to other LC neurons are located caudally, in line with the majority of the LC, at the rostral border of the trigeminal motor nucleus $(\mathrm{Vm})$. These are likely a migrated part of the LC. Additionally, very few (1-2) large TH-ir cells, also similar in morphology to LC neurons, are found in the hindbrain just lateral to the midline at the level of the lateral efferent bundle tract of the octavolateralis efferent nucleus (EB) (Fig. 7C). Robust TH-ir fibers from LC neurons cross through the MLF and form a dense plexus along the midline at the level of the superior raphe nucleus (SR) (Fig. 2J; 5C; Timothy and Forlano, unpublished observations). The interpeduncular nucleus (NIn) which is rostral to and contiguous with the SR is highly innervated as well (Fig. 5C; 6D). Isthmal nuclei (as defined by Goodson and Bass, 2002) are 
heavily innervated, likely from LC (Fig. 2I, J; 6D, E; see below), and prominent TH-ir fibers also course dorsolaterally and terminate in the eminentia granularis (EG, Fig. 2K; 7A). THir fibers and terminals are present but sparse in the granule layer of the cerebellum $(\mathrm{Cg}$, Fig $2 \mathrm{~K})$.

Hindbrain-The dorsal hindbrain contains dense TH-ir fibers and terminals within octavolateral (auditory, lateral line, vestibular) processing nuclei (see below), notably the dorsal subdivisions of the descending octaval nucleus (DO) as well as the cerebellar crest (cc, Fig 2L). Other prominent TH-ir terminal fields in the hindbrain include the rostral and caudal divisions of the octavolateralis efferent nucleus (OE, Fig. 2L; 5A-D; see below) and the vagal motor nucleus (Xm, Fig 2M).

A loose continuum of TH-ir cells are found associated with the vagal area including the vagal lobe (XL) throughout its extent (Fig 2M,N; 8A, B, E-G). TH-ir cells associated with the rostral XL are found at its lateral border and rostral to the level of the caudal efferent nucleus (Fig. 2M; below) and may be comparable to interfascicular population defined by Ma (1997). More caudally, dorsolateral to Xm, elongate cells are found in clumps on either side of the ventricle with processes extending ventrolaterally as well as dorsally (Fig. 2M; $8 \mathrm{G})$. Smaller round cells are found in the periventricular region of $\mathrm{XL}$ with lateral processes (Fig. 2N), while larger mono- and bipolar elongate TH-ir cells with a tear-drop shaped soma form a dorso-ventral chain of cells dorsal to the ventricle to lateral to the dorsal vocal motor nucleus (VMN) (Fig. 8A, B-B2, E, F; 9A-C). A second caudal brainstem TH-ir cell population is in the densely packed area postrema (AP) which lies along the midline at the dorsal aspect of the hindbrain-spinal transitional zone just dorsal to the VMN (Fig 2O; 8A, B, B3-D; 9A). Higher magnification of TH-ir AP neurons reveal bi- and multipolar morphology, some of which have fine, cilia-like processes which face the midline (Fig. 8B3-D).

\section{Catecholaminergic innervation of the descending vocal motor system}

Vocal pattern generator (VPG)_As previously demonstrated, application of neurobiotin on the cut end of a single occipital nerve root backfilled vocal motor neurons, vocal pacemaker neurons (VPN) and vocal pre-pacemaker neurons (VPP) which collectively form the VPG in midshipman (Bass et al., 2008; Bass et al., 1994; Chagnaud et al., 2011). Therefore, TH-immunofluorescence combined with vocal nerve backfills enabled confirmation of TH-ir innervation throughout the VPG. Backfilled cell populations at all three nodes of the VPG were found ipsilateral and contralateral to the side of neurobiotin application, although contralateral neurons in the VPG were less intensely labeled (Fig. 9A, C; see discussion). Fibers from TH-ir neurons which flank the lateral aspect of the $4^{\text {th }}$ ventricle and VMN (Fig. 8A, B, F; 9A-C) form a robust bilateral innervation of the VMN and terminate within the nucleus (Fig. 9C). Viewed in the horizontal plane through the ventral VMN, prominent TH-ir fibers intersect and enter the lateral VMN in a perpendicular fashion along its length, while longitudinal fibers are also seen in this plane (Fig. 9D). A prominent stream of TH-ir fibers extends ventrally from AP to the level of the rostral VMN and Xm (Fig. 8A). Numerous TH-ir terminals and fiber varicosities are found encircling somata as well as on interconnected dendrites of the VMN (Fig. 9E, G). The VPN neurons 
are smaller, fusiform cells, ventrolateral to the VMN, and are often adjacent to the bundle of VMN axons that form the occipital nerve root. These cells also appear contacted by TH-ir varicose fibers (Fig. 9E, F). Finally, small, ovoid VPP neurons, rostral to the VMN, are found among a dense population of TH-ir fibers, with many putative terminals found on VPP somata (Fig. 9H).

Higher order vocal circuitry-Outside of the delineated VPG, other nuclei previously identified physiologically and neuroanatomically as part of the descending vocal motor pathway (see above) contain notably robust TH-ir innervation. In the forebrain, these areas include subdivisions of the preoptic area, PPa (Fig. 2B, C; 3B), PPp (Fig. 2D, 3D, F), and ventral hypothalamic nuclei, vT (Fig. 2D, E) and AT (Fig. 2F; 4B-D; 10E, F). All four of these nuclei include a small local population of TH-ir neurons, aside from PPa which contains a large number of TH-ir neurons. It is highly likely that most, if not all of these areas contain TH-ir fibers and terminals from other TH-ir populations. The PAG, which receives input from the above nuclei and connects directly to the VPG by innervation of VPP (Goodson and Bass, 2002; Kittelberger and Bass, 2013; Kittelberger et al., 2006), contains TH-ir terminals along its ventral border (Fig. 6B), where the dendritic field of vocal PAG neurons are located, as well as in the adjacent and connected PTT (Goodson and Bass, 2002; Kittelberger and Bass, 2013; Kittelberger et al., 2006). In the isthmus, rostral to the $\mathrm{LC}$, a massive terminal field is found in the midbrain isthmal nucleus (Is; not nucleus isthmi) and the adjacent isthmal paraventricular nucleus (IP) (Fig. 6D, E). In more caudal sections, IP is just lateral to LC and is thus a likely afferent target of LC. Comparatively fewer TH-ir varicose fibers extend into the nucleus of the lateral lemniscus (nll), while thick fiber tracts course through the paralemniscal nucleus (PL), likely originating in part from the descending TPp bundle (Fig 2I, J; 6D, E). All of the above isthmal/lemniscal nuclei are interconnected with the PAG and vocal system as well as receive input from auditory circuitry, and are therefore considered vocal-acoustic integration sites (Bass et al., 1994; Goodson and Bass, 2002; Kittelberger and Bass, 2013; Kittelberger et al., 2006).

\section{Catecholaminergic innervation of central auditory circuitry}

Hindbrain auditory-Neurobiotin application on the saccular branch of VIII, or on the sensory macula of the saccule (main endorgan of hearing), revealed transneuronal labeling of auditory hindbrain circuitry as demonstrated previously (Bass et al., 2000; Bass et al., 1994; Sisneros et al., 2002). TH-immunofluorescence combined with saccular backfills enabled confirmation of TH-ir innervation on neurons directly connected within the ascending auditory system. Examples of neurobiotin-filled neurons throughout the auditory hindbrain are seen in Figures 11 and 12. There is a conspicuous concentration of TH-ir fibers and terminals throughout the longitudinal column of the dorsal hindbrain that includes the dorsomedial $(\mathrm{dm})$ and dorsolateral ( $\mathrm{dl}$ ) divisions of the descending octaval nucleus (DO) and the lateral line recipient nucleus medialis (MED) (Fig. 5A, B; 11A-C; 12A-C). TH-ir fibers are also present but less dense within the cerebellar crest (cc), and within central tract of the posterior and anterior lateral line nerves (LL), adjacent to dl (Fig. 2L, 11A-C; 12AC). TH-ir fibers innervate the intermediate (i), and rostral intermediate (ri) division of DO and the magnocellular octaval nucleus (MG) (Fig. 11A-C). At rostral levels, TH-ir fibers are highly concentrated within the ventral medial hindbrain which includes the ventral division 
of the secondary octaval nucleus (SOv) and the ventral tegmental nucleus (VT), just medial to the trigeminal motor nucleus (Vm) (Fig. 11A-C). Analysis at higher magnification indeed shows putative TH-ir terminals on backfilled somata and dendrites of dm (Fig. 11D), SOv (Fig. 11E) and VT (Fig. 11F) neurons and on somata of ri neurons (Fig. 11G). More caudal in the ventrolateral hindbrain at the level of the VMN lies clusters of small, round, backfilled cells in the inferior olivary complex (IO; Bass et al., 2008; Sisneros et al., 2002) which also contain putative TH-ir terminals on their somata and interconnected dendrites (Fig. 11H).

Octavolateralis efferent nucleus (OE) - The OE, which sends projections to the inner ear and lateral line organs (Bass et al., 1994; Highstein and Baker, 1986; Weeg et al., 2005), is the most conspicuous area containing robust TH-ir terminals in the brain (Fig. 5A-D; 12). This nucleus lies in the hindbrain, medial to the facial motor nucleus (VIIm), just dorsal to the medial longitudinal fasciculus (MLF), below the fourth ventricle (IV). The OE is composed of rostral (OEr) and caudal (OEc) subdivisions (Bass et al., 2000) separated by the internal arcuate fiber tract (iaf) (Fig. 5A-D; 12A-D). Neurobiotin backfilled neurons in this nucleus have long, thick, bilateral dendrites that course ventrolaterally to near the edge of the brain (Bass et al., 1994). Remarkably, TH-ir fiber distribution in this region specifically tracks the OE dendritic field and forms terminals on dendrites as well as on the large round somata (Fig. 12). Both caudal and rostral OE divisions are highly innervated by TH-ir (Fig. 5A-D; 12A-D). Somata in both divisions are also lightly labeled by neurobiotin following backfill of a single vocal nerve (Fig. 12D; Bass et al., 1994). Analyses from horizontal and sagittal sections revealed two routes by which TH-ir fibers reach the OE, and both appear to originate from the TPp. The large, pear-shaped TH-ir TPp neurons send a thick tract of dorsal projections that turns to descend further into the hindbrain forming part of the prominent medial longitudinal catecholaminergic tract (mlct) which turns sharply medially onto the $\mathrm{OE}$ dendritic field (Fig. 5A-C). The mlct courses through the SOv rostral to the $\mathrm{OE}$, and appears to also branch off dorsally to innervate dm (compare Fig. 5B and 11C). A bundle of several robust TH-ir axons appear to branch off the mlct and continue laterally within the efferent bundle (EB) which serves as the conduit for the ascending $\mathrm{OE}$ efferent fibers to reach VIII (compare Fig. 5D, E with Fig. 11A where TH-ir and neurobiotin-labeled $\mathrm{OE}$ axons (ea) run together within the lateral EB just caudal to where they join VIII). At this juncture, TH-ir axons of the same caliber that branch laterally also converge medially within the descending EB (compare Fig. 5F and Fig. 11B, C) and run longitudinally along the midline, dorsal to the iaf, and clearly innervate OEr (Fig. 12A, D).

Higher auditory circuitry-Outside of the first and second order medullary populations of auditory neurons described above, major catecholaminergic innervation of higher auditory nuclei was found at all levels except the dorsal telencephalon. Following saccular backfills neurobiotin-labeled terminals were consistently found along the lateral edge of the eminentia granularis (EG), intermixed with abundant TH-ir terminals (Fig. 2K; 7A; 10G). Notably, this area of EG also contains input from the vocal hindbrain (Bass et al., 1994). Nucleus centralis in the midbrain TS is the major recipient of the ascending auditory nuclei in the medulla (Bass et al., 2000; Bass et al., 2005; McCormick, 1999) and is more robustly innervated with $\mathrm{TH}$-ir fibers and terminals compared to lateral and deeper cell layers that process lateral line stimuli (Fig. 2G-J; 6C, D; 10A, B; Bass et al., 2000; Weeg and Bass, 
2000). The TS, in turn, projects to several diencephalic nuclei including AT (see above), the central posterior thalamus (CP) and the lateral division of nucleus preglomerulosus (PGl) (Bass et al., 2000; Goodson and Bass, 2002). All three of these areas contain TH-ir varicose fibers and terminals (Fig. 10C (PGl), D (CP), E, F (AT)). Dorsal projecting TH-ir fibers from TPp neurons appear to innervate CP (arrowhead, Fig. 3A; Fig. 4C-E), while lateralprojecting TH-ir fibers from TPp and/or VM may innervate PGl (Fig. 4B, C). In a few instances transneuronal neurobiotin labeled cells from saccular backfills were seen in AT and $\mathrm{CP}$ and indeed those cells appear to have TH-ir terminal contacts (Fig. 10D inset, F). Neurobiotin-filled neurons in PPp were consistently found in animals after saccular backfills and TH-ir terminals were abundant in the PPp dendritic field just lateral to the denselypacked cell layer adjacent to the ventricle (Fig. 3F). Although PPp and AT contain their own small population of TH-ir somata (3D; 10E), backfilled cells in these areas were never THir. Parvocellular preoptic ( $\mathrm{PPa} / \mathrm{p}), \mathrm{vT}, \mathrm{AT}$ as well as Vs and Vp all have reciprocal connections with CP (Goodson and Bass, 2002). TH-ir fibers in those areas may originate, in part, from local TH-ir neurons. In addition, ascending projections from TPp may innervate various preoptic nuclei as well as the subdivisions of areas ventralis (Fig. 4I). The only efferent target of CP largely devoid of TH-ir fibers is the dorsomedial telencephalon (Dm) which lies dorsal to PPa and $\mathrm{Vd}$ at the level of the anterior commissure (Fig. 2B; 3A, B; Goodson and Bass, 2002).

\section{Catecholaminergic innervation of the inner ear and its origin in the TPp}

Because robust TH-ir fibers were seen entering VIII in single labeled tissue (Fig. 13G) and intermingled with neurobiotin fibers following saccular backfills (Fig. 13E, F), we investigated TH-ir in the saccule, the main end organ of hearing in the inner ear. Several large, thick TH-ir fibers are seen coursing through the saccular branch of VIII which bypass ganglion cells proximal to the sensory macula and finally terminate in the sensory epithelium (Fig. 13A, D). TH-ir terminals appear to contact the base of individual hair cells while fewer puncta are seen contacting the mid to apical end of hair cell somata, clearly delineated by HCS-1 antibody which labels otoferlin (Fig. 13B-D). Many robust TH-ir terminals are found within the support cell layer (Fig. 13A-C).

By combining neurobiotin backfills of the saccular branch of VIII with TH-ir in the brain, the origin of CA saccular efferents was discovered to be a small population of the numerous large, pear-shaped TH-ir neurons in the TPp (Fig. 14-16). Backfilled cells on both sides of the midline were filled regardless of which saccule was labeled with neurobiotin (Fig. 14D, E; 15C, F, G; 16H). All neurobiotin backfilled TPp cells were also TH-ir. Backfilled cells were found throughout the TPp but more prevalent in the mid-caudal TPp along the ventricular midline or within the continuum of cells that forms between the medial forebrain bundle and just lateral to the PVO (Fig. 14C, D). When found more rostrally, backfilled cells were either along the midline or ventrolateral in the sparse population of similar type (large, pear-shaped) cells just dorsal to AT (Fig. 14G; 15C; 16C, D). The most rostral backfilled cells were found lateral to the anterior PVO, just dorsal to AT. Backfilled cells were never found in the most caudal group of large cells lateral to the PTN, or in the few much smaller cells in the PTN or rostral and dorsal TPp. Figures 15 and 16 show the distribution of TH-ir neurons in the TPp in comparison to TH-ir neurons that were also backfilled following 
neurobiotin application on the saccular branch of VIII in two individual type I males. An average of 8 backfilled cells were found across animals in alternate sections ( $4 / 5$ animals had 7-11 cells while one animal had only one backfilled cell). Differences in numbers of backfilled TPp neurons may be due to variation in damage of axons within the saccular branch of VIII during neurobiotin application. Interestingly, an additional two animals in which neurobiotin was placed on the caudal end of the saccular epithelium (versus damage to VIII) resulted in excellent labeling of hindbrain ascending auditory circuitry but very few if any completely filled TPp cells. Rather, only small beads of neurobiotin could be seen in the TH-ir soma (not shown). Figure 17 shows a size distribution (area vs. major axis diameter) of backfilled neurons compared to measured non-backfilled TH-ir neurons in the same section. Backfilled cells tightly grouped in size with an average major axis diameter (mean \pm S.E.) of $21.20 \pm 0.17 \mu \mathrm{m}$ and area of $273.55 \pm 7.11 \mu \mathrm{m}^{2}$. With the techniques employed in this study, we estimate 5-10\% of the large TPp TH-ir neurons project to the saccule. Furthermore, thick TH-ir fibers are found in the anterior (Fig. 12C) and posterior lateral line nerves (not shown). Thus, similar to hindbrain cholinergic octavolateral efferent neurons (Highstein and Baker, 1986), these cells likely innervate most, if not all inner ear and lateral line endorgans.

\section{DISCUSSION}

The overall distribution of TH-ir in the midshipman CNS is largely consistent with an earlier preliminary report of general TH-ir distribution in midshipman brain using a different antibody and non-fluorescent detection (Bass et al., 2001b), and a recent report using the same antibody as the present study with non-fluorescent detection to describe TH-ir distribution patterns (Goebrecht et al., 2014). Thus, while the present study is not the first to report TH-ir in association with several known vocal and auditory centers in the midshipman CNS, we utilized double-labeling experiments which combined TH immunofluorescence with transneuronal backfill labeling of auditory circuitry and the vocal pattern generator to demonstrate putative TH-ir terminals on individual cells comprising both the peripheral and central auditory system as well as the octavolateralis efferent nucleus and vocal motor system. This methodology has allowed us to document TH-ir innervation of the auditory sensory epithelium and its origin in the brain for the first time in a non-mammalian vertebrate. In addition, by examining TH-ir in the brain at multiple planes of section, we provide a greater understanding of projection patterns originating from specific TH-ir nuclei such as TPp. Thus, the present study extends previous work in this model system and provides very strong neuroanatomical evidence for catecholamines as important neuromodulators of auditory, vocal motor circuitry and the related vocal-acoustic social behavior in midshipman fish. Differential findings or interpretations of TH-ir to what is reported by Goebrecht et al. (2014) will be addressed in specific subsections below.

Several reviews have reported the distribution of TH-ir cell populations in fishes in comparison to other vertebrates including proposed homologies (Carrera et al., 2012; Goodson and Kingsbury, 2013; O'Connell and Hofmann, 2011; Schweitzer et al., 2012; Smeets and Gonzalez, 2000; Yamamoto and Vernier, 2011) and will therefore not be a focus here. In general, the distribution of TH-ir neurons in midshipman is largely consistent with that reported in other teleosts: populations are found in the olfactory bulb, ventral 
telencephalon, preoptic area, suprachiasmatic nucleus, ventral thalamus, anterior and periventricular hypothalamus, posterior tuberculum, locus coeruleus, vagal area and area postrema. A previous description of TH-ir distribution in midshipman (Goebrecht et al., 2014) did not include labeled neurons in olfactory bulb, postcommissural nucleus of area ventralis, and anterior tuberal nucleus as found in the current study. Unlike some other species, midshipman appear to have relatively few TH-ir cells in the PPp, parvocellular PVO (see below), and unlike most other teleosts but similar to the eel, Anguilla, (Roberts et al., 1989) a pretectal group is entirely absent (Goebrecht et al., 2014). We report consistent, but very few TH-ir cells in the PAG which were not reported previously and could have been easily overlooked in other midshipman studies (Bass et al., 2001b; Goebrecht et al., 2014). TH-ir cells in this region have been reported in Astatotilapia (O'Connell et al., 2011) as well as in a similar position in zebrafish and European eel, in a region lateral to the nMLF (Kaslin and Panula, 2001; Roberts et al., 1989).

\section{TH-ir neurons of the periventricular posterior tuberculum}

The most conspicuous group of TH-ir neurons in midshipman are undoubtedly the numerous, large, pear-shaped cells of the TPp. In midshipman there are several hundred neurons of this type (Petersen et al., 2013), which far outnumber the few documented in zebrafish adults (Ma, 2003; Rink and Wullimann, 2001). These distinctive TH-ir neurons correspond to those reported as paraventricular organ-accompanying (PVOa), magnocellular hypothalamic nucleus, or nucleus of the TPp (nTPp) cells located lateral to the anterior PVO described in other teleosts (Ma, 2003; Meek, 1994; Meek and Joosten, 1993; Meek and Nieuwenhuys, 1998; Rink and Wullimann, 2001; 2002b). Using the terminology of TH-ir diencephalic neurons by Rink and Wulliman (Rink and Wullimann, 2001; 2002b), only a small group of "type 1" round, parvocellular TH-ir cells are seen in the rostral dorsal TPp in midshipman, which blends into the much larger and distinct ventral thalamic group which in zebrafish is identified as VL (Ma, 2003). The area identified as TPp by Goebrecht et al. (2014) appears as caudal VM from our analysis since TH-ir cells in that location are contiguous with VM (and VL) TH-ir cells more rostrally (see Fig. 3D,E; 4A,B). The vast majority of TPp TH-ir cells correspond to "type 2" PVOa neurons or large TPp cells described in zebrafish (Kaslin and Panula, 2001; Ma, 2003; Rink and Wullimann, 2001; 2002b; Tay et al., 2011) and those simply labeled "PVO" by Goebrecht et al. (2014) in midshipman. However, few, if any cells exhibit the "type 3" parvocellular "liquorcontacting" phenotype seen in the PVO of zebrafish (Rink and Wullimann, 2002b; Yamamoto et al., 2010; Yamamoto and Vernier, 2011). Importantly, TH-ir type 3 cells are detected by TH1 and commercially available TH antibodies, and therefore their absence in midshipman is unlikely due to these cells expressing only TH2 enzyme (Filippi et al., 2010; Yamamoto et al., 2010; Yamamoto and Vernier, 2011). If indeed type 3 cells are characteristic in defining the PVO, then the majority of TH-ir cells in the posterior tuberculum of midshipman would not be considered true PVO neurons. Instead, we propose that these large, pear-shaped cells are a continuum of the group that lie on the ventricular midline in the ventral TPp and therefore should be considered a single group not necessarily adhering to cytoarchitectural boundaries (Ma, 2003; Meek and Nieuwenhuys, 1998;

Striedter, 1990). 
A substantial amount of evidence across several species of teleosts indicates these large THir cells are dopaminergic as they are DA-ir but not dopamine beta-hydroxylase (DBH; enzyme necessary for NA synthesis)-ir (Batten et al., 1993; Ekstrom et al., 1990; Ekstrom et al., 1986; Filippi et al., 2010; Hornby and Piekut, 1988; 1990; Hornby et al., 1987; Ma, 2003; Meek and Joosten, 1993; Sas et al., 1990; Yamamoto et al., 2010; Yamamoto and Vernier, 2011). Furthermore, the equivalent diencephalic cells identified in zebrafish larvae were demonstrated to be Otp-dependent dopaminergic neurons and contribute the major descending dopaminergic projections as do otp expressing mammalian A11 cells (Kastenhuber et al., 2010; Ryu et al., 2007; Schweitzer et al., 2012; Tay et al., 2011). At least in larval zebrafish, the medial longitudinal catecholaminergic tract (mlct) is primarily derived from these descending DA projections (Schweitzer et al., 2012). These highly conserved DAergic diencephalic neurons are the first to appear during development (along with LC neurons) in all anamniotes including elasmobranchs and agnathans and are thought to be among the most ancient CA groups (see Carrera et al., 2012; Schweitzer et al., 2012; Smeets and Gonzalez, 2000 and refs within). Expression of an equivalent group of DAergic neurons in Amphioxus further supports its ancient origin (Moret et al., 2004).

As stated above, TPp neurons in adult and larval zebrafish were also discovered to send ascending projections to the proposed striatal homolog in area ventralis of the telencephalon $(\mathrm{Vd})$, although only a small percentage of rostral TPp neurons (10\% total) are known to contribute to this ascending mix of DA and NA projections (Kastenhuber et al., 2010; Rink and Wullimann, 2001; Tay et al., 2011). Ma (2003) reports that rostral TH-ir PVOa neurons project rostroventrally and laterally. Ascending projections to the ventral telencephalon from TPp TH-ir neurons can also be seen in horizontal sections through the midshipman brain, although we were unable to verify exact end targets in this study. Kaslin and Panula (2001) report TPp neurons send descending fibers and are reciprocally connected with LC neurons in adult zebrafish, consistent with descending targets of DA A11 neurons in mammals(Maeda et al., 1991). Thus, the intense TH-ir terminals seen on LC neurons in the present study (Fig 7) possibly originate from TPp as well, or may be local projections from LC (Tay et al., 2011). The heavy TH-ir terminal fields in the area of the dorsal raphe area (present study; Kaslin and Panula, 2001) are also consistent with DAergic projections from A11 neurons in mammals (Peyron et al., 1995; Smeets and Gonzalez, 2000).

The behavioral relevance for diencephalospinal projections in both zebrafish and mammals is still largely unknown (see Barraud et al., 2010; Jordan et al., 2008; Kastenhuber et al., 2010). The prominent descending projections of TH-ir neurons in the TPp further support them as A11 DA homologs. A11 is the major source of DA in the spinal cord, and in mice numbers of A11 neurons and DA innervation of the lumbar portion of the dorsal horn is sexually dimorphic. This sexual dimorphism is an androgen receptor-dependent mechanism, organized by differential exposure to androgens perinatally (Pappas et al., 2010). The function of DA in this area is thought to modulate sensory (including nociception) information and motor function (Barriere et al., 2004; Lapirot et al., 2011). Interestingly, as seen in zebrafish, single A11 neurons in mammals are known to have both descending spinal as well as ascending telencephalic projections. Although neocortical ascending targets appear to be most robust, subpallial targets such as striatal, nucleus accumbens and 
amygdala are reported as well (Takada et al., 1988a; Takada et al., 1988b; Takada et al., 1993). In canaries, both A11 and A10 (VTA) TH-ir neurons project to forebrain song control nuclei (Appeltants et al., 2000; Appeltants et al., 2002a). Thus, while the absence of VTA/SN dopaminergic groups in teleosts appears to be a derived condition (see Carrera et al., 2012), the projection pattern of TPp and its connectivity with other brain areas (e.g., hodology; see O'Connell and Hofmann, 2012) may permit analogous functions to VTA/SN of other vertebrates in addition to roles of A11 neurons.

\section{TH-ir neurons in the periventricular posterior tuberculum have widespread projections to the central and peripheral auditory system}

A recent single cell projectome study in larval zebrafish demonstrated individual TH-ir TPp neurons send strong descending projections to the hindbrain and spinal cord, ascending projections to the ventral telencephalon as well as local projections within the diencephalon. Thus, TH-ir TPp neurons are well positioned to be important regulators of sensory-motor integration (Tay et al., 2011). Similarly, our neuroanatomical findings point to TH-ir TPp neurons as modulators and integrators of auditory, motor and higher cognitive function in adult midshipman. Figure 18 summarizes TH-ir projections from TPp supported by data in the present study. These projections appear to include efferents to the ventral telencephalon, higher auditory (CP), midbrain vocal-acoustic center (PAG), hindbrain auditory nuclei (DO/ $\mathrm{SO}$ ), octavolateralis efferent nucleus (OE) and inner ear (saccule). While the direct projection of TH-ir TPp neurons to the saccule is confirmed by double-label tract tracing experiments and support earlier preliminary observations by Sisneros et al. (2002), projections to PAG (also see Goebrecht et al., 2014; Kittelberger and Bass, 2013) and CP can be seen originating from TH-ir TPp cells in the same plane of section and projections to the hindbrain auditory and $\mathrm{OE}$ are evident as branches off of the mlct tract which is derived largely from TPp. The exact target of ascending projections to the ventral telencephalon was not determined and will require further investigation. Also, like adult zebrafish (Ma, 2003), there is a strong lateral component to these projections that appears to robustly innervate PGl (Fig. 4I; not shown in Fig. 18), which receives projections from the auditory thalamus (CP; Goodson and Bass, 2002). Thus, similar to what is known for the mammalian LC system where individual neurons project to discrete nuclei within the ascending somatosensory system (Berridge and Waterhouse, 2003), individual TPp neurons may innervate multiple nuclei along the ascending auditory pathway. This arrangement is thought to provide simultaneous release of CA to coordinate information transfer along a sensory pathway (Berridge and Waterhouse, 2003). It is important to note that there is substantial TH-ir input to areas of neuroanatomical overlap between the auditory and lateral line systems, including DOdl, DOdm, MG and TS, as well as in lateral line-specific structures such as anterior and posterior branches of lateral line nerve and MED. As these lateral line specific structures are adjacent to shared auditory areas (Weeg and Bass, 2000), it is highly likely that their source of TH-ir terminals is also the TPp. Interestingly, primary afferents of the posterior lateral line nerve can indeed encode frequencies contained within midshipman vocalizations (Weeg and Bass, 2002). Whether single TPp neurons innervate both octaval sensory systems and function in a manner as above to coordinate both auditory and lateral line processing of acoustic social signals is worthy of future investigations. 


\section{TH-ir innervation of the sensory macula of the saccule and the octavolateralis} efferent nucleus-Our results demonstrate two pathways through which catecholamines could modulate the sensitivity of the peripheral auditory system in midshipman. The first pathway includes TH-ir (DA) neurons in the TPp that project directly to the base of sensory hair cells in the main endorgan of hearing, the saccule, via nerve VIII, while the second, indirect pathway, which also appears to originate in the TPp, is a massive TH-ir input on the dendrites and somata of the $\mathrm{OE}$, which in turn projects to the inner ear and lateral line organs (Bass et al., 1994; Bleckmann et al., 1991; Highstein and Baker, 1986; Highstein et al., 1992; Koppl, 2011; Tomchik and Lu, 2005; Weeg et al., 2005). To our knowledge this is the first demonstration of catecholaminergic terminals in the sensory epithelium of the inner ear of any non-mammalian vertebrate, and suggests a conserved and important anatomical and functional role for dopamine in normal audition. Whether the same neurons in the TPp that project to the inner ear also heavily innervate the $\mathrm{OE}$ requires further study. The data presented here suggest that only a few TH-ir neurons in the TPp that project to the peripheral octavolateralis system via the lateral EB also branch into the medial descending EB to terminate on OE somata, while a greater number of TPp cells that form the descending mlct innervate the $\mathrm{OE}$ dendritic field. In support of this, the small bundle of THir axons that exit the lateral EB appear to have the same morphology as those that continue to descend and innervate OE somata (compare Fig. $5 \mathrm{E}$ and F and Fig. 12D).

Although our work is the first to clearly demonstrate the target of TPp TH-ir efferents as terminals on the base of hair cells in the inner ear of a teleost, previous studies in larval and adult zebrafish showed that these diencephalic dopaminergic neurons project to the lateral line organ and toward the inner ear and VIII with unknown targets (Bricaud et al., 2001; Ma, 2003). Furthermore, dopamine receptor mRNA expression was recently found in hair cell preparations of the trout saccule (Drescher et al., 2010). Thus, there is compelling evidence that dopamine action on the inner ear may be a common feature across unrelated species of teleost fishes, and perhaps vertebrates in general. In addition, previous tract-tracing studies have identified a few diencephalic (posterior tubercular) neurons which project to lateral line nerves in goldfish (Puzdrowski, 1989; Zottoli and Van Horne, 1983), catfish (New and Singh, 1994) and larval zebrafish (Metcalfe et al., 1985), all otophysan fishes. Although those studies did not identify the neurochemical phenotype of the diencephalic efferents, it is highly likely based on their neuroanatomical location and morphology that they are dopaminergic, and support the hypothesis that TPp TH-ir neurons may innervate multiple peripheral octavolateral endorgans.

Similar to fishes, the auditory system of tetrapod vertebrates includes sensory hair cells in the inner ear that synapse onto primary afferent neurons that in turn project through the VIIIth cranial nerve to the primary processing area in the auditory hindbrain. In addition, efferent neurons from the brainstem project out toward the hair cells and modulate the signal being transmitted to the primary afferent neuron to the brain. Efferents contact auditory and vestibular hair cells directly or make synapses on afferent dendrites (Koppl, 2011; Nicolson, 2012; Ruel et al., 2007). In mammals, the medial olivocochlear (MOC) efferent system is comprised of cholinergic neurons that function to inhibit outer hair cells (cochlear amplifier), while the lateral olivocochlear (LOC) efferent system is a heterogeneous mix of 
cholinergic, dopaminergic, $\gamma$-aminobutyric acid (GABA)-ergic and other peptidergic neurons (Darrow et al., 2006b; Gaborjan et al., 1999; Lendvai et al., 2011), whose function is less well known but has been demonstrated to either elicit slow excitation or slow suppression of the nerve output from inner hair cells of the cochlea (Groff and Liberman, 2003). In the LOC, GABA colocalizes with cholinergic efferent terminals, while dopamine comprises a small but separate population (5-35\%) of efferents (Darrow et al., 2006b). The majority of DA terminals lack clear synaptic specializations (Lendvai et al., 2011). Perfusion of dopamine on the cochlea decreases sound-evoked activity and inhibits compound action potentials of afferent dendrites (Ruel et al., 2001) and acoustic overstimulation leads to depletion of TH-ir in the cochlea (Niu and Canlon, 2002), although interestingly, low level (non-toxic) sound conditioning upregulates DAergic terminals in the cochlea and reduces subsequent damage by trauma (Niu et al., 2004). Many studies, mostly in rodents, have investigated mechanisms of action of dopamine signaling on the inner ear, but its functional significance remains unclear. Largely, these investigations have suggested a role of dopamine in protection from acoustic trauma damage, as dopamine appears to suppress the excitotoxic effects of acoustic overstimulation (see Lendvai et al., 2011), although a role in sound localization was also suggested (Darrow et al., 2006a).

Like other vertebrates, octavolateral efferent $(\mathrm{OE})$ neurons in teleosts are also cholinergic (Brantley and Bass, 1988; Clemente et al., 2004; Danielson et al., 1988; Roberts et al., 1994), and project onto saccular hair cells where they have been shown to have an inhibitory role on saccular afferent activity in goldfish (Sugihara, 2001). However, in the toadfish (Opansus tau) activation of the octavolateralis efferent neurons can reduce the gain (or sensitivity) of the evoked receptor potentials of hair cells but also increase the spontaneous discharge rate of the inner ear afferents connected to the peripheral vestibular system (Boyle et al., 2009). Similarly, recent findings suggest cholinergic OE neurons co-express GABA in the toadfish Opsanus (Edds-Walton et al., 2010), a close relative of midshipman. The intensely robust $\mathrm{TH}$-ir innervation pattern of midshipman $\mathrm{OE}$ has not been reported in other teleosts and therefore may either reflect a specialization of vocal teleosts, or this brain area has not been examined closely in most other species. However, varicose DA-ir fibers as well as both $\mathrm{D} 1 \mathrm{~A} / \mathrm{B}$ and $\mathrm{D} 2 \mathrm{~A} / \mathrm{B}$ receptors have been localized to OE in the European eel (Kapsimali et al., 2000; Pasqualini et al., 2009; Roberts et al., 1989), which supports dopaminergic innervation of this area, and interestingly, there is evidence for sound production in eels (Lagardere and Ernande, 2004; Rountree et al., 2002). Importantly, midshipman OE neurons receive direct input from the VPP, are active during vocalization in midshipman males and are proposed to maintain sensitivity to external acoustic stimuli during vocal behavior (Chagnaud et al., 2011; Weeg et al., 2005). In addition, OE neurons were recently found to generate a vocal corollary discharge that encodes duration, thus providing feedback which may prevent self-generated auditory afferent overstimulation (reafference suppression; see Chagnaud and Bass, 2013) or perhaps protect from acoustic trauma during courtship calls that are measured at $130 \mathrm{~dB}$ and can be produced continuously for $>1 \mathrm{hr}$ (Bass and McKibben, 2003). Thus, modulation of input from the auditory periphery by dense $\mathrm{CA}$ terminals on cholinergic $\mathrm{OE}$ neurons likely provides an additional layer of control on the octavolateral efferent system and may serve an important component of adaptive seasonal plasticity of peripheral auditory tuning in midshipman (Sisneros, 2009; 
Sisneros et al., 2004; Rohmann and Bass, 2011; Rohmann et al., 2013), or increase signal above ambient noise (e.g., Tomchik and $\mathrm{Lu}, 2006$ ) in females who are actively localizing concurrently calling males by sound. However, although $\mathrm{OE}$ neurons are responsive to external sound, the pathway which connects OE to primary auditory information has not been identified (Highstein and Baker, 1986; Tomchik and Lu, 2006). One possibility is that OE receives external auditory input via PAG (see below; Kittelberger and Bass, 2013). Modulation of hindbrain auditory efferents by catecholamines was previously shown in rats where norepinephrine had largely excitatory but also inhibitory effects on certain neurons in the MOC (Wang and Robertson, 1997). Interestingly, a recent study in larval zebrafish indicates that A11-like DAergic TPp neurons also express glutamate as a neurotransmitter (Filippi et al., in press). Therefore, these neurons may excite OE neurons which in turn may further inhibit neurotransmission of hair cells of the inner ear.

TH-ir innervation of central auditory circuitry—Like Goebrecht et al. (2014), we provide strong anatomical evidence for CAergic modulation of audition in midshipman as robust TH-ir innervation is found in nuclei throughout all levels of the central auditory system, with the exception of Dm (Goodson and Bass, 2002). Importantly, we demonstrate here that putative terminals on dendrites and somata of neurons in auditory nuclei that are anatomically connected (some via multiple synapses) to afferents from the saccule. For example, DOdm, DOri and SOv receive input from primary auditory afferents and project to auditory-specific nucleus centralis division (nc) of TS (Bass et al., 2000; 2001a). In addition, DOri is a major vocal-acoustic integrative site in the medulla (Bass et al., 1994; Bass et al., 2000). TSnc in turn, projects to Is, nll, Te, PGl, AT and CP (Bass et al., 2000) all of which show strong TH-ir innervation. This is similar to findings by Goebrecht et al. (2014) except they report minimal TH-ir fibers in PGl. Interestingly, TSnc sends ascending projections which appear to terminate adjacent to $\mathrm{Vp}$ and $\mathrm{Vv}$ (Bass et al., 2000) where clusters of locally projecting TH-ir neurons are located (current study; Tay et al., 2011).

Notably, TSnc is heavily innervated by TH-ir varicosities and terminals and there is some evidence that this may be more robust in type I males than females (Goebrecht et al., 2014). This robust pattern of TH-ir in TS appears to be consistent across teleosts and is likely a mixture of DA and NAergic input, as there are reports of DBH, TH, and DA-ir fibers and terminals in this area across a variety of species (e.g., Adrio et al., 2002; Batten et al., 1993; Corio et al., 1991; Ekstrom et al., 1990; Ekstrom et al., 1986; Hornby and Piekut, 1990; Kaslin and Panula, 2001; Ma, 1994; O'Connell et al., 2011; Roberts et al., 1989; Sas et al., 1990; Vetillard et al., 2002). Furthermore, the amphibian TS, mammalian inferior colliculus (IC, TS homolog; Bass et al., 2005) and dorsal lateral mesencephalic nucleus in birds (MLd, IC homolog; Karten, 1967) all receive substantial CAergic input (Appeltants et al., 2001; Endepols et al., 2000; Kitahama et al., 1996; Klepper and Herbert, 1991; Mello et al., 1998; Tong et al., 2005), which suggests a conserved pattern and modulatory role of CAs on central auditory processing across vertebrates. The primary source of NAergic fibers is likely the LC (Ma, 1994) as is the case in mammals (Hormigo et al., 2012; Klepper and Herbert, 1991) and birds (Kitt and Brauth, 1986a) since projection patterns of NAergic neurons are highly conserved (Smeets and Gonzalez, 2000; Tay et al., 2011). Furthermore, small clusters of retrogradely filled cells are found in the isthmus just dorsomedial to the 
lateral lemniscus after neurobiotin injection into the TSnc in midshipman (Bass et al., 2000). These cells appear to approximate the morphology and location of ventrolateral TH-ir neurons of the LC. The source of DAergic fibers to TS may include VM, which is known to send efferents to TS in catfish (Striedter, 1991) and false kelpfish Sebasticus (Ito et al., 1986). Importantly, the TS in midshipman is known to physiologically encode concurrent male vocalizations (Bodnar and Bass, 1997; 1999; 2001), which is a significant computational problem in the intertidal nesting area (Bass and McKibben, 2003). Thus, DAergic and/or NAergic input may function to alter temporal encoding and frequency discrimination in a complex naturalistic sound field (see Hurley et al., 2004). Recently, Gittelman et al. (2013) demonstrated both excitatory and inhibitory DA modulation of auditory responses in IC of mice and there is evidence for NE- induced suppression of IC neuronal response in the bat (Hurley et al., 2004). Less is known about behavioral implications of CA action in the auditory midbrain although manipulating DA receptor activation in IC of rats disrupts acoustic startle-mediated prepulse inhibition (Satake et al., 2012).

Studies in other teleosts have also reported TH-ir, DBH-ir and/or DA-ir in other ascending auditory nuclei including hindbrain octaval sensory nuclei (Ekström et al., 1990; Ekstrom et al., 1986; Hornby and Piekut, 1990; Hornby et al., 1987; Kaslin and Panula, 2001; Ma, 2003; Roberts et al., 1989), CP (Adrio et al., 2002; Batten et al., 1993; Corio et al., 1991; Ekstrom et al., 1990; Ekstrom et al., 1986; Hornby and Piekut, 1990; Hornby et al., 1987; Kaslin and Panula, 2001; Sas et al., 1990), AT (Adrio et al., 2002; Anadon et al., 2002; Batten et al., 1993; Ekstrom et al., 1990; Hornby et al., 1987; Kaslin and Panula, 2001; Meek et al., 1993; O'Connell et al., 2011; Sas et al., 1990) and PGl (Batten et al., 1993; Corio et al., 1991; Ekstrom et al., 1986; Kaslin and Panula, 2001; O'Connell et al., 2011; Sas et al., 1990). A few studies in teleosts have demonstrated DAergic and/or NAergic receptor distribution in auditory nuclei which supports TH-ir innervation of those areas and the auditory system as a $C A$ target for sensory modulation. In European eel, $\mathrm{D}_{1 \mathrm{~B}}$ and $\mathrm{D}_{2 \mathrm{~A} / \mathrm{B}}$ mRNA expression is localized in TS and $\mathrm{D}_{1 \mathrm{~A} 2}$ and $\mathrm{D}_{2 \mathrm{~A} / \mathrm{B}} \mathrm{mRNA}$ in MG, close to VIII exit (Kapsimali et al., 2000; Pasqualini et al., 2009). Vacher et al., (2003) showed $\mathrm{D}_{2}$ mRNA in TS (centralis and lateralis) in trout, and O'Connell et al. (2011) reports $\mathrm{D}_{1 \mathrm{~A}}$ and $\mathrm{D}_{2}$ in TS, $\mathrm{CP}$ and $\mathrm{AT}$ of the cichlid A. burtoni. Using both autoradiography and immunohistochemistry techniques, Ampatzis and Dermon (2010) showed $\beta_{2}$ adrenergic receptor (AR) in CP, TS, PGl, MG and medial octaval nucleus (MON) in adult zebrafish which largely overlaps the distribution of $\mathrm{a}_{2 \mathrm{~A}} \mathrm{AR}$-ir in the same areas (Ampatzis et al., 2008). Similar distributions of ARs are found in a marine species, the red porgy, although hindbrain nuclei are not reported (Zikopoulos and Dermon, 2005).

Although homologies of auditory nuclei between fishes and tetrapods is less clear outside of the midbrain TS, CAergic innervation is consistently found in auditory nuclei in hindbrain and thalamus in mammals, birds and frogs (e.g., Appeltants et al., 2001; Bottjer, 1993; Gonzalez and Smeets, 1991; Kitahama et al., 1996; Kitt and Brauth, 1986a; b; Klepper and Herbert, 1991; Matragrano et al., 2011; Mello et al., 1998; Woods and Azeredo, 1999). Thus, CAergic innervation at multiple levels of ascending auditory circuitry appears to be a common feature across vertebrates. Interestingly, Kossl and Vater (1989) found NE 
enhances temporal auditory contrasts in cochlear nucleus of the mustached bat and may be relevant for sound localization and recognition of temporal patterns, both of which are essential behavioral and computational tasks midshipman and other toadfish employ for reproductive behavior and may also occur in the auditory hindbrain (Fay, 2005). The auditory thalamus in fishes, $\mathrm{CP}$, is thought to process more complex, wideband spectral features compared to TS (Lu and Fay, 1995), and indeed shows a robust cFos-ir response when male midshipman are exposed to calls of other males (Petersen et al., 2013). Indeed, CA modulation of frequency tuning and sensory gating has been demonstrated in the auditory thalamus in mammals and birds (Edeline et al., 2011; Schall et al., 1999). Based on its connectivity to TSnc, as well as AT and vT, CP is a strong candidate site for auditoryvocal integration (Goodson and Bass, 2002) and modulation by catecholamines. Similarly, studies in songbirds have shown effects of norepinephrine on auditory processing in forebrain nuclei associated with learned song production (Cardin and Schmidt, 2004).

\section{TH-ir neurons in TPp and LC show cFos induction in response to social acoustic signals in midshipman}

Recently, we demonstrated that TH-ir neurons in the TPp show a significant cFos-ir response when type I males are exposed to mate calls of other males (Petersen et al., 2013). Therefore these neurons appear responsive to social acoustic signals over ambient noise. Furthermore, there was a significant positive correlation between numbers of cFos-ir in both $\mathrm{CP}$ and AT (higher auditory processing nuclei) and percent colocalization of cFos in TH-ir TPp neurons (Petersen et al., 2013). This functional connectivity supports anatomical projections of TPp TH-ir fibers into these auditory nuclei. Previous neuroanatomical tracttracing studies have revealed connectivity of the ascending auditory pathway with TPp via PAG, a major node in the vocal motor pathway in midshipman, which has bidirectional connections with TS (Goodson and Bass, 2002; Kittelberger and Bass, 2013). Thus, TPp neurons have indirect access to auditory information. Since some of those same neurons may not only project to the saccule and hindbrain auditory nuclei, but also send ascending projections to the ventral telencephalon (i.e., Vd, Vv; see Rink and Wullimann, 2001, 2002; Tay et al., 2011), these dopaminergic neurons in the TPp are in a perfect position to affect primary auditory processing and higher brain function involved in behavioral decision making to salient auditory cues (Fig. 18; Goodson and Kingsbury, 2013; O'Connell and Hofmann, 2011; 2012; Petersen et al., 2013). Interestingly, 8\% of TPp TH-ir cells in male midshipman were colabeled with cFos-ir after mate call playback (Petersen et al., 2013) which approximates the number of TH-ir neurons that project to the saccule (current study).

Like TH-ir neurons in the TPp, LC neurons also show robust cFos-ir response to conspecific vocalizations in male midshipman. In addition, there were significant positive correlations between numbers of cFos-ir at all levels of the auditory system we investigated (DOri, TSnc, $\mathrm{CP}$ and AT) and percent colocalization of cFos in TH-ir LC neurons (Petersen et al., 2013) which may reflect LC connectivity to those areas (see Hoke et al., 2005). The LC may receive direct and/or indirect auditory input as both the TS and PAG send projections to the corresponding isthmal region in midshipman (Bass et al., 2000; Kittelberger and Bass, 2013), although whether contacts are made on LC neurons would require confirmation by double-label experiments. 
Our previous study is consistent with social acoustic induction of immediate early genes (IEGs) in CA neurons in songbirds (e.g., Bharati and Goodson, 2006; Lynch et al., 2012; Maney et al., 2003; Nordeen et al., 2009) and supports a conserved role for catecholamines in vocal-acoustic behavior, notably attention and appropriate responses to acoustic social signals (Maney, 2013). An intact LC NAergic system is necessary for song-induced IEG expression in the auditory forebrain (Velho et al., 2012) as well as normal behavioral response to conspecific song (e.g., Appeltants et al., 2002b; Lynch and Ball, 2008; Pawlisch et al., 2011). Neurophysiological studies in rodent models have shown direct stimulation of LC paired with sound can directly affect frequency tuning in the thalamus and cortex (Edeline et al., 2011) and NE release from LC mediates GABA transmission in auditory cortex (Salgado et al., 2012). In zebra finch, midbrain DA neurons are connected to and activated by auditory information from a forebrain song learning nucleus in the basal ganglia (Gale and Perkel, 2010). Lesioning of DA neurons in the posterior tuberculum (PT) by 6hydroxydopamine disrupts phonotaxis behavior in frogs (Endepols et al., 2004). As proposed for tungara frogs (Hoke and Pitts, 2012; Hoke et al., 2007), hormone-sensitive DA neurons in posterior tuberculum of midshipman females (see Forlano et al., 2005; Forlano et al., 2001; Forlano et al., 2010) may function to mediate phonotaxis to male mate calls via activation of forebrain centers comparable to basal ganglia (Vd, Vc; O'Connell and Hofmann, 2011; 2012; Wullimann and Mueller, 2004; Wullimann and Rink, 2002).

\section{TH-ir in vocal motor and vocal-acoustic integration centers}

Robust TH-ir innervation is found in nuclei throughout all levels (forebrain: PPa, PPp, vT, AT; midbrain: PAG, PTT, Is, IP, PL; hindbrain-spinal VPG) of the descending vocal motor circuitry (Bass et al., 1994; Chagnaud et al., 2011; Goodson and Bass, 2002; Kittelberger and Bass, 2013; Kittelberger et al., 2006) which supports catecholamines as important neuromodulators of vocal behavior in midshipman. Our findings are generally consistent with the description of TH-ir fiber innervation of vocal circuitry by Goebrecht et al. (2014) although we are now able to definitively show connectivity to backfilled neurons at all three levels of the vocal pattern generator (see below) and have documented additional sparse populations of TH-ir neurons within AT and PAG. To date, other teleost species with defined vocal circuitry have not been investigated. Like the PAG discussed above, the other vocally-active sites contain reciprocal connections to the auditory midbrain (TSnc) and thalamus (CP) and are therefore considered vocal-acoustic integration sites (Goodson and Bass, 2002). Aside from PPa which contains a large population of TH-ir neurons, PPp, vT, AT and PAG all have a small number of TH-ir cells within their respective nuclear boundaries. However, it is unclear how much innervation, if any, is provided by these "local" TH-ir neurons. It is likely that each nucleus may contain a mix of DA- and NAergic terminals from several TH-ir populations (e.g., Tay et al., 2011). Nuclei in the ventral telencephalon, namely, $\mathrm{Vs}$ and $\mathrm{Vv}$, contain their own population of local-projecting TH-ir cells and have reciprocal connections to forebrain vocal-acoustic sites (Goodson and Bass, 2002). The PPp is known to be interconnected to several vocal-acoustic integration sites including AT, vT, PAG and PL; furthermore, PPa/p, vT and AT all have reciprocal connections with $\mathrm{CP}$ and are thus designated the forebrain vocal-acoustic complex (Goodson and Bass, 2002). Whether TH-ir cells in AT/vT and PPp project to CP is unknown. It is noteworthy that $\mathrm{Vs}, \mathrm{Vv}, \mathrm{PPa} / \mathrm{p}, \mathrm{AT}, \mathrm{vT}$ and $\mathrm{PAG}$ are all major nodes in the vertebrate social 
behavior network and are substrates for modulation by DA (Goodson, 2005; Goodson and Kingsbury, 2013; O'Connell and Hofmann, 2011; 2012).

As mentioned above, previous tract tracing experiments demonstrated reciprocal projections between TPp and PAG (Goodson and Bass, 2002; Kittelberger and Bass, 2013). Although neurochemical characterization of specific projections was not conducted in those studies, they support our findings that TH-ir neurons in TPp project to and provide DAergic input to PAG. Furthermore, PAG sends projections to ri, SOv and VT and OE in the auditory hindbrain (see above) which supports these nuclei as auditory-vocal integration sites (Kittelberger and Bass, 2013). Importantly, the PAG has a conserved role in vocal motor control across vertebrates (see Goodson and Bass, 2002; Goodson and Kingsbury, 2013; Kittelberger and Bass 2013 and references within) and is innervated by CAergic fibers (Appeltants et al., 2001; Dujardin and Jurgens, 2005; Herbert and Saper, 1992; Mello et al., 1998). Preliminary neurophysiological studies in midshipman suggest an inhibitory role of DA on vocal output via the PAG (Kittelberger et al., 2011), which is consistent with inhibitory effects of systemic DA pharmacology on calling behavior in frogs (Creighton et al., 2013) and mice (Scardochio and Clarke, 2013) but see Brudzynski et al. (2012) for differential effect of DA agonist dosage. A variety of studies in songbirds have demonstrated a strong positive relationship between sexually motivated song and activation of mesolimbic circuits, largely focusing on DA neurons in the VTA (Goodson et al., 2009; Hara et al., 2007; Leblois and Perkel, 2012; Lynch et al., 2008; Maney and Ball, 2003; Sasaki et al., 2006; Yanagihara and Hessler, 2006); (for review see Ball and Balthazart, 2010; Riters, 2012). While both VTA (A10) and central gray A11 DA neurons innervate forebrain song circuitry in canaries, including higher vocal center (HVC) and premotor robust nucleus of the arcopallium (RA) (Appeltants et al., 2000; Appeltants et al., 2002a), it appears that A11 neurons project into the nucleus intercollicularis (ICo; Appeltants, et al., 2001), the vocally-active mammalian PAG homolog (Goodson and Kingsbury, 2013). Importantly, expression of immediate early gene products in A11 TH-ir neurons are strongly coupled to social vocalizations in male zebra finches and across other Estrildid species (Lynch et al., 2008; Goodson et al., 2009). Whether A11 equivalent DA neurons in TPp (Kastenhuber et al., 2010; Tay et al., 2011) which project to PAG in midshipman show an ancestral, conserved function in song production in a social context is an interesting hypothesis for further investigations.

Vocally- active isthmal nuclei contain dense TH-ir terminals. The LC is a good candidate for projecting to and providing NAergic modulation of these areas, which along with PAG/PTT, make up the midbrain vocal-acoustic complex in midshipman (Goodson and Bass, 2002). In particular, LC sits in close proximity to the caudal IP and hindbrain paraventricular (HP) cell groups (Bass et al., 1994; Goodson and Bass, 2002; Kittelberger and Bass, 2013). In addition, neurobiotin injections into PAG indicate projections from this area as well (Kittelberger and Bass, 2013). In general, projections from LC are thought to be highly conserved and provide the majority of NAergic fibers in the midbrain and forebrain (Ma, 1994; Tay et al., 2011). In songbirds, LC projects widely to forebrain song circuitry (Appeltants et al., 2001; 2002a; Castelino et al., 2007), but less is known of its direct projections to less derived vocal areas (Castelino and Schmidt, 2010). The dorso medial nucleus of ICo (PAG homolog) has the highest density of dopamine beta hydroxylase 
(DBH)-ir fibers compared to other song control regions (Mello et al., 1998). Thus, although DBH-ir has not been investigated in midshipman, one would predict a mixture of DAergic and NAergic fibers in PAG as well.

Importantly, backfilled neurons throughout the VPG circuitry (VPP, VPN and VMN; Bass et al., 2008; Chagnaud et al., 2011) contain dense putative TH-ir terminals and thus the VPG itself appears to be a major target for CA modulation of vocal output. In contrast to the prominent VMN, the VPN and VPP consist of sparse numbers of neurons within the reticular formation that are not easily discernable with Nissl stain alone. This is likely why TH-ir innervation of VPN was not obvious in the study by Goebrecht et al. (2014). Results from the present study support distinct TH-ir fiber populations entering VMN which spans the caudal hindbrain-spinal cord boundary (Bass et al., 2008): those entering laterally appear to originate from the vagal/AP populations which lie dorsal and lateral to VMN, while those coursing longitudinally are likely diencephalospinal from TPp as predicted from their proposed A11 homology (Fig. 18); TPp TH-ir projections into the spinal cord have been clearly demonstrated in zebrafish (Kastenhuber et al., 2010; McLean and Fetcho, 2004a; b; Tay et al., 2011). Using the same methodology in the present study, Bass et al. (1994) and Knapp et al. (1999) show a few backfilled cells dorsal lateral to the VMN in similar position to some vagal TH-ir cells shown here. Although we did not find TH-ir cells that were backfilled from the vocal nerve in our study, it may be due to using largely non-reproductive type I males (regressed vocal musculature and testes) which may account for decreased transneuronal transport due to a regression of vocal musculature and presumed inactivity of the vocal system in general. While it is unconfirmed whether those previously reported backfilled cells are indeed TH-ir, our study shows TH-ir neurons in that position indeed appear to send strong projections into the mid-lateral aspect of the VMN.

The TH-ir neurons proximal to VMN likely correspond, in part, to the highly conserved A1 and A2 CA groups found in all vertebrates (Kaslin and Panula, 2001; Smeets and Gonzalez, 2000). Studies in teleosts have shown these nuclei contain a mix of DA, NA and adrenalineproducing neurons (Batten et al., 1993; Ma, 1997; Roberts et al., 1989; Sas et al., 1990). There is evidence in adult zebrafish that paraventricular vagal neurons are DAergic while some extraventricular neurons are NAergic (Ma, 1997). In mammals, A2 neurons reside within the dorsal vagal complex, which includes AP, are known to have multiple connections to higher brain areas and diverse physiological functions associated with attention, arousal, motivation and learning, etc. (Rinaman, 2011, for review). As seen in mammals, Tay et al. (2011) demonstrated these medullary CA neurons in larval zebrafish to have strong local projections in addition to far-reaching projections into the ventral telencephalon, hypothalamus and posterior tuberculum. Importantly, these caudal TH-ir groups (vagal and AP) are proximal to and likely provide local innervation of Xm and inferior reticular formation (Ri) in amphibians (Gonzalez and Smeets, 1991), the tracheosyringeal division of hypoglossal motor nucleus in birds (Appeltants et al., 2001; Bottjer, 1993; Mello et al., 1998) and nucleus ambiguus in mammals (Rinaman, 2011) all comparable vocal areas to midshipman VPG nuclei (Bass et al., 2008). Thus, CA modulation of vocal motor patterning may also be a general vertebrate feature. 


\section{Conclusions}

Here we provide strong neuroanatomical evidence for CA modulation at multiple levels of auditory, vocal motor and vocal-acoustic integration sites in midshipman and propose this is a conserved feature across vocal vertebrates. While these data do not unambiguously demonstrate direct synaptic contact of TH-ir fibers on anatomically identified neurons, we do provide evidence that catecholamines could be released in very close proximity to labeled neurons in these circuits. Catecholamines in particular are well documented to be released volumetrically at non-classical synapses in a paracrine fashion (Cragg et al., 2001; Descarries et al., 2008; Pickel et al., 1996). Whether or not putative TH-ir terminals are coincident with classical synaptic specializations will need to be confirmed by future studies using electron microscopy.

Ultimately, catecholamines may function to modulate auditory neural responsiveness in coordination with appropriate motor output within the context of motivated seasonal reproductive behaviors. This may include both male vocalizations in the context of courtship and competition for mates (Petersen et al., 2013) and the female's directed decision (i.e., phonotaxis) to localize a potential mate's nest. Our data provide support for catecholamines as important modulators of vocal-acoustic circuitry and as a conserved characteristic across vertebrates which use acoustic communication in social contexts.

\section{Supplementary Material}

Refer to Web version on PubMed Central for supplementary material.

\section{Acknowledgments}

Support or grant information: This work was supported by NIH SC2DA034996 to PMF, PSC-CUNY Award 65650-00 43 jointly funded by The Professional Staff Congress and The City University of New York to PMF, Leonard and Claire Tow Travel Award to PMF and Brooklyn College and CUNY Research Foundation. This study was conducted in part at the Marine Biological Laboratory, Woods Hole, MA and was partially supported by MBL Faculty Research Fellowships to PMF and JAS.

We thank Rob Dickie, AREAC, the Bodega Marine Laboratory and the Marine Biological Laboratory for logistical support, Miky Timothy, Chris Petersen, Robert Mohr and Ashwin Bhandiwad for help with animal collections and Lilja Nielsen and Camillia Monestime for histological assistance. We also thank Steve Zottoli and Alberto Pereda for helpful discussions.

\section{Neuroanatomical Abbreviations}

ac

AP

AT

C

CA

cc

Cg anterior commissure

area postrema

anterior tuberal nucleus

cerebellum

cerebral aqueduct

cerebellar crest

granular layer of the corpus of the cerebellum 


\begin{tabular}{|c|c|}
\hline $\mathbf{C m}$ & molecular layer of the corpus of the cerebellum \\
\hline $\mathbf{C P}$ & central posterior nucleus of the thalamus \\
\hline CPc & compact division of the central posterior nucleus \\
\hline CPd & diffuse division of the central posterior nucleus \\
\hline d & dendrites of octavolateralis efferent nucleus \\
\hline D & area dorsalis of the telencephalon \\
\hline Dc & central zone of D \\
\hline Df & diffuse nucleus of the hypothalamus \\
\hline DI & lateral zone of $\mathrm{D}$ \\
\hline Dm & medial zone of D \\
\hline Dm-p & posterior zone of Dm \\
\hline DOdl/dl & dorsolateral division of descending octaval nucleus \\
\hline DOdm/dm & dorsomedial division of descending octaval nucleus \\
\hline DOi/i & intermediate division of descending octaval nucleus \\
\hline DOri/ri & rostral intermediate division of descending octaval nucleus \\
\hline Dp & posterior zone of $\mathrm{D}$ \\
\hline DPo & dorsal posterior nucleus of the thalamus \\
\hline ea & efferent axons of octavolateralis efferent nucleus \\
\hline EB & efferent bundle tract of octavolateralis efferent nucleus \\
\hline EG & eminentia granularis \\
\hline G & nucleus glomerulosus \\
\hline Ha & habenula \\
\hline $\mathbf{H C}$ & hair cell layer \\
\hline Hc & central periventricular hypothalamus \\
\hline Hd & dorsal periventricular hypothalamus \\
\hline HoC & horizontal commissure \\
\hline $\mathbf{H v}$ & ventral periventricular hypothalamus \\
\hline iaf & internal arcuate fiber tract \\
\hline III & third ventricle \\
\hline IL & inferior lobe of the hypothalamus \\
\hline IN & intermediate nucleus of the hypothalamus \\
\hline IP & isthmal paraventricular nucleus \\
\hline
\end{tabular}

J Comp Neurol. Author manuscript; available in PMC 2015 September 01. 


\begin{tabular}{|c|c|}
\hline Is & midbrain isthmal nucleus (not nucleus isthmi) \\
\hline IV & fourth ventricle \\
\hline $\mathbf{L H}$ & lateral hypothalamus \\
\hline $\mathbf{L C}$ & locus coeruleus \\
\hline $\mathbf{L} \mathbf{L}$ & central tract of the lateral line nerves \\
\hline 11 & lateral lemniscus \\
\hline MED & cell plate of medial octavolateralis nucleus \\
\hline MFB & medial forebrain bundle \\
\hline MG & magnocellular octaval nucleus \\
\hline mlct & medial longitudinal catecholaminergic tract \\
\hline MLF & medial longitudinal fasiculus \\
\hline nIII & oculomotor nucleus \\
\hline nll & nucleus of the lateral lemniscus \\
\hline NIn & nucleus interpeduncularis \\
\hline $\mathbf{O B}$ & olfactory bulb \\
\hline oc & occipital nerves \\
\hline $\mathbf{O E}$ & octavolateralis efferent nucleus \\
\hline OEc & caudal division of $\mathrm{OE}$ \\
\hline OEd-c & caudal division of OE dendritic field \\
\hline OEd-r & rostral division of OE dendritic field \\
\hline OEr & rostral division of $\mathrm{OE}$ \\
\hline $\mathbf{O N}$ & optic nerve \\
\hline OT & optic tract \\
\hline PAG & periaqueductal gray \\
\hline Pe & periventricular cell layer of the torus semicircularis \\
\hline PGI & lateral division of nucleus preglomerulosus \\
\hline PGm & medial division of nucleus preglomerulosus \\
\hline PHT & preoptico-hypophysial tract \\
\hline Pit & pituitary \\
\hline PL & paralemniscal midbrain tegmentum \\
\hline PM & magnocellular preoptic nucleus \\
\hline PMg & gigantocellular division of PM \\
\hline
\end{tabular}




\begin{tabular}{|c|c|}
\hline PoC & posterior commissure \\
\hline $\mathbf{P P a}$ & anterior parvocellular preoptic nucleus \\
\hline $\mathbf{P P p}$ & posterior parvocellular preoptic nucleus \\
\hline $\mathbf{P P v}$ & nucleus pretectalis periventricularis pars ventralis \\
\hline PTN & posterior tuberal nucleus \\
\hline PTT & paratoral tegmentum \\
\hline PVO & paraventricular organ \\
\hline $\mathbf{R F}$ & reticular formation \\
\hline SC & support cell layer \\
\hline SCN & suprachiasmatic nucleus \\
\hline SD & saccus dorsalis \\
\hline SE & sensory epithelium of the saccule \\
\hline SOv & ventral division of secondary octaval nucleus \\
\hline SR & superior raphe \\
\hline SU & supramedullary neurons \\
\hline SV & saccus vasculosus \\
\hline $\mathbf{T}$ & telencephalon \\
\hline Teg & tegmentum \\
\hline Te & midbrain tectum \\
\hline TL & torus longitudinalis \\
\hline $\mathbf{T P p}$ & periventricular nucleus of the posterior tuberculum \\
\hline TS & torus semicircularis \\
\hline TSd & deep layer of torus semicircularis \\
\hline $\mathbf{v}$ & ventricle \\
\hline $\mathbf{V}$ & area ventralis of the telencephalon \\
\hline Vc & central nucleus of $\mathrm{V}$ \\
\hline Vd & dorsal nucleus of $\mathrm{V}$ \\
\hline Vde & descending tract of the trigeminal nerve \\
\hline Vg & granular layer of the valvula \\
\hline VIII & eighth nerve \\
\hline VL & ventrolateral nucleus of the thalamus \\
\hline Vm & trigeminal motor nucleus \\
\hline
\end{tabular}

J Comp Neurol. Author manuscript; available in PMC 2015 September 01. 


$\begin{array}{ll}\text { VM } & \text { ventromedial nucleus of the thalamus } \\ \text { VMN } & \text { vocal motor nucleus } \\ \text { Vp } & \text { postcommissural nucleus of V } \\ \text { VPN } & \text { vocal pacemaker nucleus } \\ \text { VPP } & \text { vocal prepacemaker nucleus } \\ \text { Vs } & \text { supracommissural nucleus of V } \\ \text { vT } & \text { ventral tuberal hypothalamus } \\ \text { VT } & \text { ventral tegmental nucleus } \\ \text { Vv } & \text { ventral nucleus of V } \\ \text { XL } & \text { vagal lobe } \\ \text { Xm } & \text { vagal motor nucleus }\end{array}$

\section{LITERATURE CITED}

Adrio F, Anadon R, Rodriguez-Moldes I. Distribution of tyrosine hydroxylase (TH) and dopamine beta-hydroxylase $(\mathrm{DBH})$ immunoreactivity in the central nervous system of two chondrostean fishes (Acipenser baeri and Huso huso). J Comp Neurol. 2002; 448(3):280-297. [PubMed: 12115709]

Adrio F, Rodriguez-Moldes I, Anadon R. Distribution of glycine immunoreactivity in the brain of the Siberian sturgeon (Acipenser baeri): comparison with gamma-aminobutyric acid. J Comp Neurol. 2011; 519(6):1115-1142. [PubMed: 21344405]

Ampatzis K, Dermon CR. Regional distribution and cellular localization of beta2-adrenoceptors in the adult zebrafish brain (Danio rerio). J Comp Neurol. 2010; 518(9):1418-1441. [PubMed: 20187137]

Ampatzis K, Kentouri M, Dermon CR. Neuronal and glial localization of alpha(2A)-adrenoceptors in the adult zebrafish (Danio rerio) brain. J Comp Neurol. 2008; 508(1):72-93. [PubMed: 18300261]

Anadon R, Rodriguez-Moldes I, Gonzalez A. Tyrosine hydroxylase immunoreactive neurons in the forebrain of the trout: Organization, cellular features and innervation. Brain Res Bull. 2002; 57(34):389-392. [PubMed: 11922995]

Appeltants D, Absil P, Balthazart J, Ball GF. Identification of the origin of catecholaminergic inputs to $\mathrm{HVc}$ in canaries by retrograde tract tracing combined with tyrosine hydroxylase immunocytochemistry. J Chem Neuroanat. 2000; 18(3):117-133. [PubMed: 10720795]

Appeltants D, Ball GF, Balthazart J. The distribution of tyrosine hydroxylase in the canary brain: demonstration of a specific and sexually dimorphic catecholaminergic innervation of the telencephalic song control nulcei. Cell Tissue Res. 2001; 304(2):237-259. [PubMed: 11396718]

Appeltants D, Ball GF, Balthazart J. The origin of catecholaminergic inputs to the song control nucleus RA in canaries. Neuroreport. 2002a; 13(5):649-653. [PubMed: 11973464]

Appeltants D, Del Negro C, Balthazart J. Noradrenergic control of auditory information processing in female canaries. Behav Brain Res. 2002b; 133(2):221-235. [PubMed: 12110456]

Ball GF, Balthazart J. Seasonal and hormonal modulation of neurotransmitter systems in the song control circuit. J Chem Neuroanat. 2010; 39(2):82-95. [PubMed: 19712741]

Barraud Q, Obeid I, Aubert I, Barriere G, Contamin H, McGuire S, Ravenscroft P, Porras G, Tison F, Bezard E, Ghorayeb I. Neuroanatomical study of the A11 diencephalospinal pathway in the nonhuman primate. PLoS One. 2010; 5(10):e13306. [PubMed: 20967255]

Barriere G, Mellen N, Cazalets JR. Neuromodulation of the locomotor network by dopamine in the isolated spinal cord of newborn rat. Eur J Neurosci. 2004; 19(5):1325-1335. [PubMed: 15016090]

Bass AH. Shaping brain sexuality. American Scientist. 1996; 84(4):352-363. 
Bass AH, Baker R. Sexual dimorphisms in the vocal control system of a teleost fish: morphology of physiologically identified neurons. J Neurobiol. 1990; 21(8):1155-1168. [PubMed: 2273398]

Bass AH, Baker R. Phenotypic specification of hindbrain rhombomeres and the origins of rhythmic circuits in vertebrates. Brain Behav Evol. 1997; 50:3-16. [PubMed: 9217990]

Bass AH, Bodnar DA, Marchaterre MA. Midbrain acoustic circuitry in a vocalizing fish. J Comp Neurol. 2000; 419(4):505-531. [PubMed: 10742718]

Bass AH, Bodnar DA, Marchaterre MA. Acoustic nuclei in the medulla and midbrain of the vocalizing gulf toadfish (Opsanus beta). Brain Behav and Evol. 2001a; 57(2):63-79.

Bass AH, Gilland EH, Baker R. Evolutionary origins for social vocalization in a vertebrate hindbrainspinal compartment. Science. 2008; 321(5887):417-421. [PubMed: 18635807]

Bass AH, Horvath BJ, Brothers EB. Nonsequential developmental trajectories lead to dimorphic vocal circuitry for males with alternative reproductive tactics. J Neurobiol. 1996; 30(4):493-504. [PubMed: 8844513]

Bass AH, Marchaterre MA, Baker H. Catecholaminergic innervation of central auditory sytem in a vocal teleost. Society for Neuroscience Abstracts 88.15. 2001b

Bass AH, Marchaterre MA, Baker R. Vocal-acoustic pathways in a teleost fish. J Neurosci. 1994; 14(7):4025-4039. [PubMed: 8027760]

Bass AH, McKibben JR. Neural mechanisms and behaviors for acoustic communication in teleost fish. Prog Neurobiol. 2003; 69(1):1-26. [PubMed: 12637170]

Bass, AH.; Rose, GJ.; Pritz, MB. Auditory midbrain of fish, amphibians and reptiles: models systems for understanding auditory function. In: Winer, JA.; Schreiner, CE., editors. The Inferior Colliculus. New York: Springer; 2005. p. 459-492.

Batten TF, Berry PA, Maqbool A, Moons L, Vandesande F. Immunolocalization of catecholamine enzymes, serotonin, dopamine and L-dopa in the brain of Dicentrarchus labrax (Teleostei). Brain Res Bull. 1993; 31(3-4):233-252. [PubMed: 8098256]

Berridge CW. Noradrenergic modulation of arousal. Brain Res Rev. 2008; 58(1):1-17. [PubMed: 18199483]

Berridge CW, Waterhouse BD. The locus coeruleus-noradrenergic system: modulation of behavioral state and state-dependent cognitive processes. Brain Res Brain Res Rev. 2003; 42(1):33-84. [PubMed: 12668290]

Bharati IS, Goodson JL. Fos responses of dopamine neurons to sociosexual stimuli in male zebra finches. Neuroscience. 2006; 143(3):661-670. [PubMed: 17027163]

Bleckmann H, Niemann U, Fritzsch B. Peripheral and central aspects of the acoustic and lateral line system of a bottom dwelling catfish, Ancistrus sp. J Comp Neurol. 1991; 314(3):452-466. [PubMed: 1726106]

Bodnar DA, Bass AH. Temporal coding of concurrent acoustic signals in auditory midbrain. J Neurosci. 1997; 17(19):7553-7564. [PubMed: 9295400]

Bodnar DA, Bass AH. Midbrain combinatorial code for temporal and spectral information in concurrent acoustic signals. J Neurophys. 1999; 81(2):552-563.

Bodnar DA, Bass AH. Coding of concurrent vocal signals by the auditory midbrain: effects of duration. J Comp Physiol A- Sens Neur Behav Physiol. 2001; 187(5):381-391.

Bottjer SW. The distribution of tyrosine hydroxylase immunoreactivity in the brains of male and female zebra finches. J Neurobiol. 1993; 24(1):51-69. [PubMed: 8093477]

Boyle R, Rabbitt RD, Highstein SM. Efferent control of hair cell and afferent responses in the semicircular canals. Journal of neurophysiology. 2009; 102(3):1513-1525. [PubMed: 19571186]

Braford, MR., Jr; Northcutt, RG. Organization of the diencephalon and pretectum of the ray-finned fishes. In: Davis, RE.; Northcutt, RG., editors. Fish neurobiology. Ann Arbor: University of Michigan Press; 1983. p. 117-164.

Brantley RK, Bass AH. Cholinergic neurons in the brain of a teleost fish (Porichthys notatus) located with a monoclonal antibody to choline acetyltransferase. J Comp Neurol. 1988; 275(1):87-105. [PubMed: 3170792] 
Brantley RK, Bass AH. Alternative male spawning tactics and acoustic-signals in the plainfin midshipman fish Porichthys notatus Girard (Teleostei, Batrachoididae). Ethology. 1994; 96(3): 213-232.

Bricaud O, Chaar V, Dambly-Chaudiere C, Ghysen A. Early efferent innervation of the zebrafish lateral line. J Comp Neurol. 2001; 434(3):253-261. [PubMed: 11331527]

Brudzynski SM, Komadoski M, St Pierre J. Quinpirole-induced $50 \mathrm{kHz}$ ultrasonic vocalization in the rat: role of D2 and D3 dopamine receptors. Behav Brain Res. 2012; 226(2):511-518. [PubMed: 22015714]

Cardin JA, Schmidt MF. Noradrenergic inputs mediate state dependence of auditory responses in the avian song system. J Neurosci. 2004; 24(35):7745-7753. [PubMed: 15342742]

Carrera I, Anadon R, Rodriguez-Moldes I. Development of tyrosine hydroxylase-immunoreactive cell populations and fiber pathways in the brain of the dogfish Scyliorhinus canicula: new perspectives on the evolution of the vertebrate catecholaminergic system. J Comp Neurol. 2012; 520(16):35743603. [PubMed: 22473828]

Castelino CB, Diekamp B, Ball GF. Noradrenergic projections to the song control nucleus area X of the medial striatum in male zebra finches (Taeniopygia guttata). J Comp Neurol. 2007; 502(4): 544-562. [PubMed: 17394158]

Castelino CB, Schmidt MF. What birdsong can teach us about the central noradrenergic system. J Chem Neuroanat. 2010; 39(2):96-111. [PubMed: 19686836]

Chagnaud BP, Baker R, Bass AH. Vocalization frequency and duration are coded in separate hindbrain nuclei. Nat Commun. 2011; 2:346. [PubMed: 21673667]

Chagnaud BP, Bass AH. Vocal corollary discharge communicates call duration to vertebrate auditory system. J Neurosci. 2013; 33(48):18775-18780. [PubMed: 24285884]

Chagnaud BP, Zee MC, Baker R, Bass AH. Innovations in motoneuron synchrony drive rapid temporal modulations in vertebrate acoustic signaling. Journal of neurophysiology. 2012; 107(12): 3528-3542. [PubMed: 22423004]

Clemente D, Porteros A, Weruaga E, Alonso JR, Arenzana FJ, Aijon J, Arevalo R. Cholinergic elements in the zebrafish central nervous system: Histochemical and immunohistochemical analysis. J Comp Neurol. 2004; 474(1):75-107. [PubMed: 15156580]

Cohen MJ, Winn HE. Electrophysiological observations on hearing and sound production in the fish, Porichthys notatus. J Exp Zool. 1967; 165:355-370. [PubMed: 6076901]

Corio M, Peute J, Steinbusch HW. Distribution of serotonin- and dopamine-immunoreactivity in the brain of the teleost Clarias gariepinus. J Chem Neuroanat. 1991; 4(2):79-95. [PubMed: 2059346]

Cragg SJ, Nicholson C, Kume-Kick J, Tao L, Rice ME. Dopamine-mediated volume transmission in midbrain is regulated by distinct extracellular geometry and uptake. Journal of neurophysiology. 2001; 85(4):1761-1771. [PubMed: 11287497]

Creighton A, Satterfield D, Chu J. Effects of dopamine agonists on calling behavior in the green tree frog, Hyla cinerea. Physiol Behav. 2013; 116-117:54-59.

Danielson PD, Zottoli SJ, Corrodi JG, Rhodes KJ, Mufson EJ. Localization of choline acetyltransferase to somata of posterior lateral line efferents in the goldfish. Brain Res. 1988; 448(1):158-161. [PubMed: 2455582]

Darrow KN, Maison SF, Liberman MC. Cochlear efferent feedback balances interaural sensitivity. Nat Neurosci. 2006a; 9(12):1474-1476. [PubMed: 17115038]

Darrow KN, Simons EJ, Dodds L, Liberman MC. Dopaminergic innervation of the mouse inner ear: evidence for a separate cytochemical group of cochlear efferent fibers. J Comp Neurol. 2006b; 498(3):403-414. [PubMed: 16871528]

Descarries L, Berube-Carriere N, Riad M, Bo GD, Mendez JA, Trudeau LE. Glutamate in dopamine neurons: synaptic versus diffuse transmission. Brain Res Rev. 2008; 58(2):290-302. [PubMed: 18042492]

Drescher MJ, Cho WJ, Folbe AJ, Selvakumar D, Kewson DT, Abu-Hamdan MD, Oh CK, Ramakrishnan NA, Hatfield JS, Khan KM, Anne S, Harpool EC, Drescher DG. An adenylyl cyclase signaling pathway predicts direct dopaminergic input to vestibular hair cells. Neuroscience. 2010; 171(4):1054-1074. [PubMed: 20883745] 
Dufour S, Sebert ME, Weltzien FA, Rousseau K, Pasqualini C. Neuroendocrine control by dopamine of teleost reproduction. Journal of fish biology. 2010; 76(1):129-160. [PubMed: 20738703]

Dufour S, Weltzien FA, Sebert ME, Le Belle N, Vidal B, Vernier P, Pasqualini C. Dopaminergic inhibition of reproduction in teleost fishes: ecophysiological and evolutionary implications. Ann N Y Acad Sci. 2005; 1040:9-21. [PubMed: 15891002]

Dujardin E, Jurgens U. Afferents of vocalization-controlling periaqueductal regions in the squirrel monkey. Brain Res. 2005; 1034(1-2):114-131. [PubMed: 15713263]

Edds-Walton PL, Holstein GR, Fay RR. Gamma-aminobutyric acid is a neurotransmitter in the auditory pathway of oyster toadfish, Opsanus tau. Hearing research. 2010; 262(1-2):45-55. [PubMed: 20097279]

Edeline JM, Manunta Y, Hennevin E. Induction of selective plasticity in the frequency tuning of auditory cortex and auditory thalamus neurons by locus coeruleus stimulation. Hearing research. 2011; 274(1-2):75-84. [PubMed: 20709165]

Ekstrom P, Honkanen T, Steinbusch HW. Distribution of dopamine-immunoreactive neuronal perikarya and fibres in the brain of a teleost, Gasterosteus aculeatus L. comparison with tyrosine hydroxylase- and dopamine-beta-hydroxylase-immunoreactive neurons. J Chem Neuroanat. 1990; 3(4):233-260. [PubMed: 1975745]

Ekstrom P, Reschke M, Steinbusch H, van Veen T. Distribution of noradrenaline in the brain of the teleost Gasterosteus aculeatus L.: an immunohistochemical analysis. J Comp Neurol. 1986; 254(3):297-313. [PubMed: 3540043]

Endepols H, Schul J, Gerhardt HC, Walkowiak W. 6-hydroxydopamine lesions in anuran amphibians: a new model system for Parkinson's disease? J Neurobiol. 2004; 60(4):395-410. [PubMed: 15307145]

Endepols H, Walkowiak W, Luksch H. Chemoarchitecture of the anuran auditory midbrain. Brain Res Brain Res Rev. 2000; 33(2-3):179-198. [PubMed: 11011065]

Fay, RR. Sound source localization by fishes. In: Popper, AN.; Fay, RR., editors. Sound Source Localization. New York: Springer; 2005. p. 36-66.

Fergus DJ, Bass AH. Localization and divergent profiles of estrogen receptors and aromatase in the vocal and auditory networks of a fish with alternative mating tactics. J Comp Neurol. 2013; 521(12):2850-2869. [PubMed: 23460422]

Filippi A, Mahler J, Schweitzer J, Driever W. Expression of the paralogous tyrosine hydroxylase encoding genes th1 and th2 reveals the full complement of dopaminergic and noradrenergic neurons in zebrafish larval and juvenile brain. J Comp Neurol. 2010; 518(4):423-438. [PubMed: 20017209]

Filippi A, Mueller T, Driever W. Vglut2 and gad expression reveal distinct patterns of dual GABAergic versus glutamatergic cotransmitter phenotypes of dopaminergic and noradrenergic neurons in the zebrafish brain. J Comp Neurol. in press.

Fine ML, Perini MA. Sound production evoked by electrical stimulation of the forebrain in the oyster toadfish. J Comp Physiol [A]. 1994; 174(2):173-185.

Forlano PM, Bass AH. Neural and hormonal mechanisms of reproductive-related arousal in fishes. Horm Behav. 2011; 59(5):616-629. [PubMed: 20950618]

Forlano PM, Deitcher DL, Bass AH. Distribution of estrogen receptor alpha mRNA in the brain and inner ear of a vocal fish with comparisons to sites of aromatase expression. J Comp Neurol. 2005; 483(1):91-113. [PubMed: 15672394]

Forlano PM, Deitcher DL, Myers DA, Bass AH. Anatomical distribution and cellular basis for high levels of aromatase activity in the brain of teleost fish: aromatase enzyme and mRNA expression identify glia as source. J Neurosci. 2001; 21(22):8943-8955. [PubMed: 11698605]

Forlano PM, Krzyminska ZM, Nielsen L, Sisneros JA. Catecholaminergic connectivity to central and peripheral auditory and vocal motor pathways in a teleost fish. Society for Neuroscience Abstracts 296.10. 2012

Forlano PM, Marchaterre M, Deitcher DL, Bass AH. Distribution of androgen receptor mRNA expression in vocal, auditory, and neuroendocrine circuits in a teleost fish. J Comp Neurol. 2010; 518(4):493-512. [PubMed: 20020540] 
Gaborjan A, Lendvai B, Vizi ES. Neurochemical evidence of dopamine release by lateral olivocochlear efferents and its presynaptic modulation in guinea-pig cochlea. Neuroscience. 1999; 90(1):131-138. [PubMed: 10188940]

Gale JE, Meyers JR, Corwin JT. Solitary hair cells are distributed throughout the extramacular epithelium in the bullfrog's saccule. Journal of the Association for Research in Otolaryngology: JARO. 2000; 1(2):172-182. [PubMed: 11545144]

Gale SD, Perkel DJ. A basal ganglia pathway drives selective auditory responses in songbird dopaminergic neurons via disinhibition. J Neurosci. 2010; 30(3):1027-1037. [PubMed: 20089911]

Gayoso JA, Castro A, Anadon R, Manso MJ. Differential bulbar and extrabulbar projections of diverse olfactory receptor neuron populations in the adult zebrafish (Danio rerio). J Comp Neurol. 2011; 519(2):247-276. [PubMed: 21165974]

Gittelman JX, Perkel DJ, Portfors CV. Dopamine modulates auditory responses in the inferior colliculus in a heterogeneous manner. Journal of the Association for Research in Otolaryngology: JARO. 2013; 14(5):719-729. [PubMed: 23835945]

Goebrecht GKE, Kowtoniuk RA, Kelly BG, Kittelberger JM. Sexually-dimorphic expression of tyrosine hydroxylase immunoreactivity in the brain of a vocal teleost fish (Porichthys notatus). J Chem Neuroanat. 2014 in press.

Gonzalez A, Smeets WJ. Comparative analysis of dopamine and tyrosine hydroxylase immunoreactivities in the brain of two amphibians, the anuran Rana ridibunda and the urodele Pleurodeles waltlii. J Comp Neurol. 1991; 303(3):457-477. [PubMed: 1672535]

Goodson JL. The vertebrate social behavior network: evolutionary themes and variations. Horm Behav. 2005; 48(1):11-22. [PubMed: 15885690]

Goodson JL, Bass AH. Vocal-acoustic circuitry and descending vocal pathways in teleost fish: Convergence with terrestrial vertebrates reveals conserved traits. J Comp Neurol. 2002; 448(3): 298-322. [PubMed: 12115710]

Goodson JL, Kabelik D, Kelly AM, Rinaldi J, Klatt JD. Midbrain dopamine neurons reflect affiliation phenotypes in finches and are tightly coupled to courtship. Proc Natl Acad Sci U S A. 2009; 106(21):8737-8742. [PubMed: 19439662]

Goodson JL, Kingsbury MA. What's in a name? Considerations of homologies and nomenclature for vertebrate social behavior networks. Horm Behav. 2013; 64(1):103-112. [PubMed: 23722238]

Goodyear RJ, Legan PK, Christiansen JR, Xia B, Korchagina J, Gale JE, Warchol ME, Corwin JT, Richardson GP. Identification of the hair cell soma-1 antigen, HCS-1, as otoferlin. Journal of the Association for Research in Otolaryngology: JARO. 2010; 11(4):573-586. [PubMed: 20809368]

Groff JA, Liberman MC. Modulation of cochlear afferent response by the lateral olivocochlear system: activation via electrical stimulation of the inferior colliculus. Journal of neurophysiology. 2003; 90(5):3178-3200. [PubMed: 14615429]

Hara E, Kubikova L, Hessler NA, Jarvis ED. Role of the midbrain dopaminergic system in modulation of vocal brain activation by social context. Eur J Neurosci. 2007; 25(11):3406-3416. [PubMed: 17553009]

Hayes L, Zhang Z, Albert P, Zervas M, Ahn S. Timing of Sonic hedgehog and Gli1 expression segregates midbrain dopamine neurons. J Comp Neurol. 2011; 519(15):3001-3018. [PubMed: 21713771]

Herbert H, Saper CB. Organization of medullary adrenergic and noradrenergic projections to the periaqueductal gray matter in the rat. J Comp Neurol. 1992; 315(1):34-52. [PubMed: 1371780]

Highstein SM, Baker R. Organization of the efferent vestibular nuclei and nerves of the toadfish, Opsanus tau. J Comp Neurol. 1986; 243(3):309-325. [PubMed: 2869067]

Highstein SM, Kitch R, Carey J, Baker R. Anatomical organization of the brainstem octavolateralis area of the oyster toadfish, Opsanus tau. J Comp Neurol. 1992; 319(4):501-518. [PubMed: 1619042]

Hoke KL, Pitts NL. Modulation of sensory-motor integration as a general mechanism for context dependence of behavior. General and comparative endocrinology. 2012; 176(3):465-471. [PubMed: 22405704]

Hoke KL, Ryan MJ, Wilczynski W. Social cues shift functional connectivity in the hypothalamus. Proc Natl Acad Sci U S A. 2005; 102(30):10712-10717. [PubMed: 16020531] 
Hoke KL, Ryan MJ, Wilczynski W. Integration of sensory and motor processing underlying social behaviour in tungara frogs. Proc Biol Sci. 2007; 274(1610):641-649. [PubMed: 17254988]

Hormigo S, de Horta JA Junior, Gomez-Nieto R, Lopez DE. The selective neurotoxin DSP-4 impairs the noradrenergic projections from the locus coeruleus to the inferior colliculus in rats. Front Neural Circuits. 2012; 6:41. [PubMed: 22754504]

Hornby PJ, Piekut DT. Immunoreactive dopamine beta-hydroxylase in neuronal groups in the goldfish brain. Brain Behav Evol. 1988; 32(4):252-256. [PubMed: 3069181]

Hornby PJ, Piekut DT. Distribution of catecholamine-synthesizing enzymes in goldfish brains: presumptive dopamine and norepinephrine neuronal organization. Brain Behav Evol. 1990; 35(1): 49-64. [PubMed: 1971189]

Hornby PJ, Piekut DT, Demski LS. Localization of immunoreactive tyrosine hydroxylase in the goldfish brain. J Comp Neurol. 1987; 261(1):1-14. [PubMed: 2887592]

Hurley LM, Devilbiss DM, Waterhouse BD. A matter of focus: monoaminergic modulation of stimulus coding in mammalian sensory networks. Curr Opin Neurobiol. 2004; 14(4):488-495. [PubMed: 15321070]

Ito H, Murakami T, Fukuoka T, Kishida R. Thalamic fiber connections in a teleost (Sebastiscus marmoratus): visual somatosensory, octavolateral, and cerebellar relay region to the telencephalon. J Comp Neurol. 1986; 250(2):215-227. [PubMed: 3745513]

Jordan LM, Liu J, Hedlund PB, Akay T, Pearson KG. Descending command systems for the initiation of locomotion in mammals. Brain Res Rev. 2008; 57(1):183-191. [PubMed: 17928060]

Joshua M, Adler A, Bergman H. The dynamics of dopamine in control of motor behavior. Curr Opin Neurobiol. 2009; 19(6):615-620. [PubMed: 19896833]

Kah O, Dulka JG, Dubourg P, Thibault J, Peter RE. Neuroanatomical substrate for the inhibition of gonadotrophin secretion in goldfish: existence of a dopaminergic preoptico-hypophyseal pathway. Neuroendocrinology. 1987; 45(6):451-458. [PubMed: 2886934]

Kapsimali M, Vidal B, Gonzalez A, Dufour S, Vernier P. Distribution of the mRNA encoding the four dopamine $\mathrm{D}(1)$ receptor subtypes in the brain of the european eel (Anguilla anguilla): comparative approach to the function of $\mathrm{D}(1)$ receptors in vertebrates. J Comp Neurol. 2000; 419(3):320-343. [PubMed: 10723008]

Karten HJ. The organization of the ascending auditory pathway in the pigeon (Columba livia). I. Diencephalic projections of the inferior colliculus (nucleus mesencephali lateralis, pars dorsalis). Brain Res. 1967; 6(3):409-427. [PubMed: 6076249]

Kaslin J, Panula P. Comparative anatomy of the histaminergic and other aminergic systems in zebrafish (Danio rerio). J Comp Neurol. 2001; 440(4):342-377. [PubMed: 11745628]

Kastenhuber E, Kratochwil CF, Ryu S, Schweitzer J, Driever W. Genetic dissection of dopaminergic and noradrenergic contributions to catecholaminergic tracts in early larval zebrafish. J Comp Neurol. 2010; 518(4):439-458. [PubMed: 20017210]

Kaufling J, Veinante P, Pawlowski SA, Freund-Mercier MJ, Barrot M. Afferents to the GABAergic tail of the ventral tegmental area in the rat. J Comp Neurol. 2009; 513(6):597-621. [PubMed: 19235223]

Kitahama K, Sakamoto N, Jouvet A, Nagatsu I, Pearson J. Dopamine-beta-hydroxylase and tyrosine hydroxylase immunoreactive neurons in the human brainstem. J Chem Neuroanat. 1996; 10(2): 137-146. [PubMed: 8783042]

Kitt CA, Brauth SE. Telencephalic projections from midbrain and isthmal cell groups in the pigeon. I. Locus coeruleus and subcoeruleus. J Comp Neurol. 1986a; 247(1):69-91. [PubMed: 2423564]

Kitt CA, Brauth SE. Telencephalic projections from midbrain and isthmal cell groups in the pigeon. II. The nigral complex. J Comp Neurol. 1986b; 247(1):92-110. [PubMed: 2423565]

Kittelberger JM, Bass AH. Vocal-motor and auditory connectivity of the midbrain periaqueductal gray in a teleost fish. J Comp Neurol. 2013; 521(4):791-812. [PubMed: 22826153]

Kittelberger JM, Heisler EK, Allen AK. Dopamine injections to the midbrain periaqueductal gray rapidly and reversibly inhibit vocal production in a teleost fish. Soc Neurosci Abstr 413.11. 2011

Kittelberger M, Land BR, Bass AH. Midbrain periaqueductal gray and vocal pattering in a teleost fish. Journal of neurophysiology. 2006; 96:71-85. [PubMed: 16598068] 
Klepper A, Herbert H. Distribution and origin of noradrenergic and serotonergic fibers in the cochlear nucleus and inferior colliculus of the rat. Brain Res. 1991; 557(1-2):190-201. [PubMed: 1747753]

Knapp R, Marchaterre MA, Bass AH. Early development of the motor and premotor circuitry of a sexually dimorphic vocal pathway in a teleost fish. J Neurobiol. 1999; 38(4):475-490. [PubMed: 10084683]

Koppl, C. Evolution of the octavolateralis efferent system. In: Ryugo, DK.; Fay, RR.; Popper, AN., editors. Auditory and Vestibular Efferents. New York: Springer; 2011. p. 217-259.

Kossl M, Vater M. Noradrenaline enhances temporal auditory contrast and neuronal timing precision in the cochlear nucleus of the mustached bat. J Neurosci. 1989; 9(12):4169-4178. [PubMed: 2574231]

Kuscha V, Barreiro-Iglesias A, Becker CG, Becker T. Plasticity of tyrosine hydroxylase and serotonergic systems in the regenerating spinal cord of adult zebrafish. J Comp Neurol. 2012; 520(5):933-951. [PubMed: 21830219]

Lagardere JP, Ernande B. Sounds recorded in salt marshes and attributed to the European eel. C R Biol. 2004; 327(4):353-359. [PubMed: 15212367]

Lapirot O, Melin C, Modolo A, Nicolas C, Messaoudi Y, Monconduit L, Artola A, Luccarini P, Dallel $\mathrm{R}$. Tonic and phasic descending dopaminergic controls of nociceptive transmission in the medullary dorsal horn. Pain. 2011; 152(8):1821-1831. [PubMed: 21514054]

Leblois A, Perkel DJ. Striatal dopamine modulates song spectral but not temporal features through D1 receptors. Eur J Neurosci. 2012; 35(11):1771-1781. [PubMed: 22594943]

Lendvai B, Halmos GB, Polony G, Kapocsi J, Horvath T, Aller M, Sylvester Vizi E, Zelles T. Chemical neuroprotection in the cochlea: the modulation of dopamine release from lateral olivocochlear efferents. Neurochem Int. 2011; 59(2):150-158. [PubMed: 21672572]

Lohr H, Ryu S, Driever W. Zebrafish diencephalic A11-related dopaminergic neurons share a conserved transcriptional network with neuroendocrine cell lineages. Development. 2009; 136(6):1007-1017. [PubMed: 19234064]

Lu Z, Fay RR. Acoustic response properties of single neurons in the central posterior nucleus of the thalamus of the goldfish, Carassius auratus. J Comp Physiol A. 1995; 176(6):747-760. [PubMed: 7776269]

Lynch KS, Ball GF. Noradrenergic deficits alter processing of communication signals in female songbirds. Brain Behav Evol. 2008; 72(3):207-214. [PubMed: 18815444]

Lynch KS, Diekamp B, Ball GF. Catecholaminergic cell groups and vocal communication in male songbirds. Physiol Behav. 2008; 93(4-5):870-876. [PubMed: 18191965]

Lynch KS, Diekamp B, Ball GF. Colocalization of immediate early genes in catecholamine cells after song exposure in female zebra finches (Taeniopygia guttata). Brain Behav Evol. 2012; 79(4): 252-260. [PubMed: 22572406]

Ma PM. Catecholaminergic systems in the zebrafish. II. Projection pathways and pattern of termination of the locus coeruleus. J Comp Neurol. 1994; 344(2):256-269. [PubMed: 8077460]

Ma PM. Catecholaminergic systems in the zebrafish. III. Organization and projection pattern of medullary dopaminergic and noradrenergic neurons. J Comp Neurol. 1997; 381(4):411-427. [PubMed: 9136799]

Ma PM. Catecholaminergic systems in the zebrafish. IV. Organization and projection pattern of dopaminergic neurons in the diencephalon. J Comp Neurol. 2003; 460(1):13-37. [PubMed: 12687694]

Maeda T, Kojima Y, Arai R, Fujimiya M, Kimura H, Kitahama K, Geffard M. Monoaminergic interaction in the central nervous system: a morphological analysis in the locus coeruleus of the rat. Comparative biochemistry and physiology C, Comparative pharmacology and toxicology. 1991; 98(1):193-202.

Maney DL. The incentive salience of courtship vocalizations: hormone-mediated 'wanting' in the auditory system. Hearing research. 2013; 305:19-30. [PubMed: 23665125]

Maney DL, Ball GF. Fos-like immunoreactivity in catecholaminergic brain nuclei after territorial behavior in free-living song sparrows. J Neurobiol. 2003; 56(2):163-170. [PubMed: 12838581] 
Maney DL, MacDougall-Shackleton EA, MacDougall-Shackleton SA, Ball GF, Hahn TP. Immediate early gene response to hearing song correlates with receptive behavior and depends on dialect in a female songbird. J Comp Physiol A Neuroethol Sens Neural Behav Physiol. 2003; 189(9):667_ 674. [PubMed: 12879354]

Matragrano LL, Sanford SE, Salvante KG, Sockman KW, Maney DL. Estradiol-dependent catecholaminergic innervation of auditory areas in a seasonally breeding songbird. Eur J Neurosci. 2011; 34(3):416-425. [PubMed: 21714815]

McCormick, CA. Anatomy of the central auditory pathways of fish and amphibians. In: Popper, A.; Fay, RR., editors. Comparative hearing: fish and amphibians. New York: Springer; 1999. p. 155-217.

McCormick, CA. Auditory/lateral line CNS: Anatomy. In: Farrell, AP., editor. Encyclopedia of Fish Physiology: From Genome to Environment. San Diego: Academic Press; 2011.

McLean DL, Fetcho JR. Ontogeny and innervation patterns of dopaminergic, noradrenergic, and serotonergic neurons in larval zebrafish. J Comp Neurol. 2004a; 480(1):38-56. [PubMed: 15515022]

McLean DL, Fetcho JR. Relationship of tyrosine hydroxylase and serotonin immunoreactivity to sensorimotor circuitry in larval zebrafish. J Comp Neurol. 2004b; 480(1):57-71. [PubMed: 15514919]

Meek, J. Catecholamines in the brains of Osteichthyes. In: Smeets, W.; Reiner, A., editors. Phylogeny and development of catecholamine systems in the CNS of vertebrates. Cambridge University Press; 1994. p. 49-76.

Meek J, Joosten HW. Tyrosine hydroxylase-immunoreactive cell groups in the brain of the teleost fish Gnathonemus petersii. J Chem Neuroanat. 1993; 6(6):431-446. [PubMed: 7908204]

Meek J, Joosten HW, Hafmans TG. Distribution of noradrenaline-immunoreactivity in the brain of the mormyrid teleost Gnathonemus petersii. J Comp Neurol. 1993; 328(1):145-160. [PubMed: 8429126]

Meek, J.; Nieuwenhuys, R. Holosteans and teleosts. In: Nieuwenhuys, R.; Donkelaar, HJ.; Hans, J.; Nicholson, C., editors. The central nervous system of vertebrates. Berlin: Springer-Verlag; 1998.

Mello CV, Pinaud R, Ribeiro S. Noradrenergic system of the zebra finch brain: immunocytochemical study of dopamine-beta-hydroxylase. J Comp Neurol. 1998; 400(2):207-228. [PubMed: 9766400]

Metcalfe WK, Kimmel CB, Schabtach E. Anatomy of the posterior lateral line system in young larvae of the zebrafish. J Comp Neurol. 1985; 233(3):377-389. [PubMed: 3980776]

Moret F, Guilland JC, Coudouel S, Rochette L, Vernier P. Distribution of tyrosine hydroxylase, dopamine, and serotonin in the central nervous system of amphioxus (Branchiostoma lanceolatum): implications for the evolution of catecholamine systems in vertebrates. J Comp Neurol. 2004; 468(1):135-150. [PubMed: 14648696]

Nakano M, Goris RC, Atobe Y, Kadota T, Funakoshi K. Mediolateral and rostrocaudal topographic organization of the sympathetic preganglionic cell pool in the spinal cord of Xenopus laevis. J Comp Neurol. 2009; 513(3):292-314. [PubMed: 19148922]

New JG, Singh S. Central topography of anterior lateral line nerve projections in the channel catfish, Ictalurus punctatus. Brain Behav Evol. 1994; 43(1):34-50. [PubMed: 8306190]

Nicolson, T. The hair cell synapse. In: Trussell, LO.; Popper, AN.; Fay, RR., editors. Synaptic Mechanisms in the Auditory System. New York: Springer; 2012. p. 43-60.

Niu X, Bogdanovic N, Canlon B. The distribution and the modulation of tyrosine hydroxylase immunoreactivity in the lateral olivocochlear system of the guinea-pig. Neuroscience. 2004; 125(3):725-733. [PubMed: 15099686]

Niu X, Canlon B. Activation of tyrosine hydroxylase in the lateral efferent terminals by sound conditioning. Hearing research. 2002; 174(1-2):124-132. [PubMed: 12433403]

Niu X, Canlon B. The signal transduction pathway for the dopamine D1 receptor in the guinea-pig cochlea. Neuroscience. 2006; 137(3):981-990. [PubMed: 16330149]

Nordeen EJ, Holtzman DA, Nordeen KW. Increased Fos expression among midbrain dopaminergic cell groups during birdsong tutoring. Eur J Neurosci. 2009; 30(4):662-670. [PubMed: 19686474] 
O’Connell LA, Fontenot MR, Hofmann HA. Characterization of the dopaminergic system in the brain of an African cichlid fish, Astatotilapia burtoni. J Comp Neurol. 2011; 519(1):75-92. [PubMed: 21120929]

O'Connell LA, Hofmann HA. The vertebrate mesolimbic reward system and social behavior network: a comparative synthesis. J Comp Neurol. 2011; 519(18):3599-3639. [PubMed: 21800319]

O'Connell LA, Hofmann HA. Evolution of a vertebrate social decision-making network. Science. 2012; 336(6085):1154-1157. [PubMed: 22654056]

O'Connell LA, Rigney MM, Dykstra DW, Hofmann HA. Neuroendocrine mechanisms underlying sensory integration of social signals. Journal of neuroendocrinology. 2013; 25(7):644-654. [PubMed: 23631684]

Pappas SS, Tiernan CT, Behrouz B, Jordan CL, Breedlove SM, Goudreau JL, Lookingland KJ. Neonatal androgen-dependent sex differences in lumbar spinal cord dopamine concentrations and the number of A11 diencephalospinal dopamine neurons. J Comp Neurol. 2010; 518(13):24232436. [PubMed: 20503420]

Pasqualini C, Weltzien FA, Vidal B, Baloche S, Rouget C, Gilles N, Servent D, Vernier P, Dufour S. Two distinct dopamine D2 receptor genes in the European eel: molecular characterization, tissuespecific transcription, and regulation by sex steroids. Endocrinology. 2009; 150(3):1377-1392. [PubMed: 18974275]

Pawlisch BA, Stevenson SA, Riters LV. alpha(1)-Noradrenegic receptor antagonism disrupts female songbird responses to male song. Neurosci Lett. 2011; 496(1):20-24. [PubMed: 21463661]

Peter, RE.; Fryer, JN. Endocrine functions of the hypothalamus of actinopterygians. In: Davis, RE.; Northcutt, RG., editors. Fish Neurobiology. Ann Arbor: University of Michigan Press; 1983. p. 165-201.

Petersen CL, Timothy M, Kim DS, Bhandiwad AA, Mohr RA, Sisneros JA, Forlano PM. Exposure to advertisement calls of reproductive competitors activates vocal-acoustic and catecholaminergic neurons in the plainfin midshipman fish, Porichthys notatus. PLoS One. 2013; 8(8):e70474. [PubMed: 23936438]

Peyron C, Luppi PH, Kitahama K, Fort P, Hermann DM, Jouvet M. Origin of the dopaminergic innervation of the rat dorsal raphe nucleus. Neuroreport. 1995; 6(18):2527-2531. [PubMed: 8741755]

Pickel VM, Nirenberg MJ, Milner TA. Ultrastructural view of central catecholaminergic transmission: immunocytochemical localization of synthesizing enzymes, transporters and receptors. J Neurocytol. 1996; 25(12):843-856. [PubMed: 9023729]

Puzdrowski RL. Peripheral distribution and central projections of the lateral-line nerves in goldfish, Carassius auratus. Brain Behav Evol. 1989; 34(2):110-131. [PubMed: 2819411]

Remage-Healey L, Bass AH. Rapid, hierarchical modulation of vocal patterning by steroid hormones. J Neurosci. 2004; 24(26):5892-5900. [PubMed: 15229236]

Rinaman L. Hindbrain noradrenergic A2 neurons: diverse roles in autonomic, endocrine, cognitive, and behavioral functions. Am J Physiol Regul Integr Comp Physiol. 2011; 300(2):R222-235. [PubMed: 20962208]

Rink E, Wullimann MF. The teleostean (zebrafish) dopaminergic system ascending to the subpallium (striatum) is located in the basal diencephalon (posterior tuberculum). Brain Res. 2001; 889(1-2): 316-330. [PubMed: 11166725]

Rink E, Wullimann MF. Connections of the ventral telencephalon and tyrosine hydroxylase distribution in the zebrafish brain (Danio rerio) lead to identification of an ascending dopaminergic system in a teleost. Brain Res Bull. 2002a; 57(3-4):385-387. [PubMed: 11922994]

Rink E, Wullimann MF. Development of the catecholaminergic system in the early zebrafish brain: an immunohistochemical study. Brain Res Dev Brain Res. 2002b; 137(1):89-100.

Riters LV. The role of motivation and reward neural systems in vocal communication in songbirds. Front Neuroendocrinol. 2012; 33(2):194-209. [PubMed: 22569510]

Roberts BL, Maslam S, Los I, Van der Jagt B. Coexistence of calcitonin gene-related peptide and choline acetyltransferase in eel efferent neurons. Hearing research. 1994; 74(1-2):231-237. [PubMed: 8040093] 
Roberts BL, Meredith GE, Maslam S. Immunocytochemical analysis of the dopamine system in the brain and spinal cord of the European eel, Anguilla anguilla. Anat Embryol (Berl). 1989; 180(4): 401-412. [PubMed: 2802190]

Rohmann KN, Bass AH. Seasonal plasticity of auditory hair cell frequency sensitivity correlates with plasma steroid levels in a vocal fish. J Exp Biol. 2011; 214:1931-1942. [PubMed: 21562181]

Rohmann KN, Fergus DJ, Bass AH. Plasticity in ion channel expression underlies variation in hearing during reproductive cycles. Curr Biol. 2013; (8):678-683. [PubMed: 23562266]

Rountree RA, Perkins PJ, Kenney RD, Hinga KR. Sounds of Western North Atlantic Fishes: Data rescue. Bioacoustics. 2002; 12:242-244.

Ruel J, Nouvian R, Gervais d'Aldin C, Pujol R, Eybalin M, Puel JL. Dopamine inhibition of auditory nerve activity in the adult mammalian cochlea. Eur J Neurosci. 2001; 14(6):977-986. [PubMed: 11595036]

Ruel J, Wang J, Rebillard G, Eybalin M, Lloyd R, Pujol R, Puel JL. Physiology, pharmacology and plasticity at the inner hair cell synaptic complex. Hearing research. 2007; 227(1-2):19-27. [PubMed: 17079104]

Ryu S, Holzschuh J, Mahler J, Driever W. Genetic analysis of dopaminergic system development in zebrafish. J Neural Transm Suppl. 2006; (70):61-66. [PubMed: 17017510]

Ryu S, Mahler J, Acampora D, Holzschuh J, Erhardt S, Omodei D, Simeone A, Driever W. Orthopedia homeodomain protein is essential for diencephalic dopaminergic neuron development. Curr Biol. 2007; 17(10):873-880. [PubMed: 17481897]

Salamone JD, Correa M. The mysterious motivational functions of mesolimbic dopamine. Neuron. 2012; 76(3):470-485. [PubMed: 23141060]

Salgado H, Garcia-Oscos F, Martinolich L, Hall S, Restom R, Tseng KY, Atzori M. Pre- and postsynaptic effects of norepinephrine on gamma-aminobutyric acid-mediated synaptic transmission in layer 2/3 of the rat auditory cortex. Synapse. 2012; 66(1):20-28. [PubMed: 21905124]

Sas E, Maler L, Tinner B. Catecholaminergic systems in the brain of a gymnotiform teleost fish: an immunohistochemical study. J Comp Neurol. 1990; 292(1):127-162. [PubMed: 1968915]

Sasaki A, Sotnikova TD, Gainetdinov RR, Jarvis ED. Social context-dependent singing-regulated dopamine. J Neurosci. 2006; 26(35):9010-9014. [PubMed: 16943558]

Satake S, Yamada K, Melo LL, Barbosa Silva R. Effects of microinjections of apomorphine and haloperidol into the inferior colliculus on prepulse inhibition of the acoustic startle reflex in rat. Neurosci Lett. 2012; 509(1):60-63. [PubMed: 22230886]

Scardochio T, Clarke PB. Inhibition of 50-kHz ultrasonic vocalizations by dopamine receptor subtypeselective agonists and antagonists in adult rats. Psychopharmacology (Berl). 2013; 226(3):589600. [PubMed: 23192317]

Schall U, Keysers C, Kast B. Pharmacology of sensory gating in the ascending auditory system of the pigeon (Columba livia). Psychopharmacol (Berl). 1999; 145(3):273-282.

Schweitzer J, Lohr H, Filippi A, Driever W. Dopaminergic and noradrenergic circuit development in zebrafish. Dev Neurobiol. 2012; 72(3):256-268. [PubMed: 21567980]

Sisneros JA. Seasonal plasticity of auditory saccular sensitivity in the vocal plainfin midshipman fish, Porichthys notatus. J Neurophysiol. 2009; 102(2):1121-1131. [PubMed: 19553489]

Sisneros JA, Alderks PW, Leon K, Sniffen B. Morphometric changes associated with the reproductive cycle and behaviour of the intertidal-nesting, male plainfin midshipman Porichthys notatus. Journal of fish biology. 2009; 74(1):18-36. [PubMed: 20735522]

Sisneros JA, Forlano PM, Deitcher DL, Bass AH. Steroid-dependent auditory plasticity leads to adaptive coupling of sender and receiver. Science. 2004; 305(5682):404-407. [PubMed: 15256672]

Sisneros JA, Marchaterre MA, Bass AH. Otolithic endorgan projections of the inner ear in a vocal fish. Bioacoustics. 2002; 12:137-139.

Smeets WJ, Gonzalez A. Catecholamine systems in the brain of vertebrates: new perspectives through a comparative approach. Brain Res Brain Res Rev. 2000; 33(2-3):308-379. [PubMed: 11011071] 
Striedter GF. The diencephalon of the channel catfish, Ictalurus punctatus. I. Nuclear organization. Brain Behav Evol. 1990; 36(6):329-354. [PubMed: 2073573]

Striedter GF. Auditory, electrosensory, and mechanosensory lateral line pathways through the forebrain in channel catfishes. J Comp Neurol. 1991; 312(2):311-331. [PubMed: 1748736]

Sugihara I. Efferent innervation in the goldfish saccule examined by acetylcholinesterase histochemistry. Hearing research. 2001; 153(1-2):91-99. [PubMed: 11223299]

Takada M, Li ZK, Hattori T. Single thalamic dopaminergic neurons project to both the neocortex and spinal cord. Brain Res. 1988a; 455(2):346-352. [PubMed: 2900059]

Takada M, Nishihama MS, Nishihama CC, Hattori T. Two separate neuronal populations of the rat subthalamic nucleus project to the basal ganglia and pedunculopontine tegmental region. Brain Res. 1988b; 442(1):72-80. [PubMed: 3359258]

Takada M, Sugimoto T, Hattori T. Tyrosine hydroxylase immunoreactivity in cerebellar Purkinje cells of the rat. Neurosci Lett. 1993; 150(1):61-64. [PubMed: 8097025]

Tay TL, Ronneberger O, Ryu S, Nitschke R, Driever W. Comprehensive catecholaminergic projectome analysis reveals single-neuron integration of zebrafish ascending and descending dopaminergic systems. Nat Commun. 2011; 2:171. [PubMed: 21266970]

Tomchik SM, Lu Z. Octavolateral projections and organization in the medulla of a teleost fish, the sleeper goby (Dormitator latifrons). J Comp Neurol. 2005; 481(1):96-117. [PubMed: 15558734]

Tomchik SM, Lu ZM. Modulation of auditory signal-to-noise ratios by efferent stimulation. Journal of neurophysiology. 2006; 95(6):3562-3570. [PubMed: 16554519]

Tong L, Altschuler RA, Holt AG. Tyrosine hydroxylase in rat auditory midbrain: distribution and changes following deafness. Hearing research. 2005; 206(1-2):28-41. [PubMed: 16080996]

Vacher C, Pellegrini E, Anglade I, Ferriere F, Saligaut C, Kah O. Distribution of dopamine D-2 receptor mRNAs in the brain and the pituitary of female rainbow trout: An in situ hybridization study. Journal of Comparative Neurology. 2003; 458(1):32-45. [PubMed: 12577321]

Velho TA, Lu K, Ribeiro S, Pinaud R, Vicario D, Mello CV. Noradrenergic control of gene expression and long-term neuronal adaptation evoked by learned vocalizations in songbirds. PLoS One. 2012; 7(5):e36276. [PubMed: 22574146]

Vetillard A, Benanni S, Saligaut C, Jego P, Bailhache T. Localization of tyrosine hydroxylase and its messenger RNA in the brain of rainbow trout by immunocytochemistry and in situ hybridization. Journal of Comparative Neurology. 2002; 449(4):374-389. [PubMed: 12115673]

Wang X, Robertson D. Two types of actions of norepinephrine on identified auditory efferent neurons in rat brain stem slices. Journal of neurophysiology. 1997; 78(4):1800-1810. [PubMed: 9325349]

Warchol ME, Speck JD. Expression of GATA3 and tenascin in the avian vestibular maculae: normative patterns and changes during sensory regeneration. J Comp Neurol. 2007; 500(4):646657. [PubMed: 17154269]

Weeg MS, Bass AH. Central lateral line pathways in a vocalizing fish. Journal of Comparative Neurology. 2000; 418(1):41-64. [PubMed: 10701755]

Weeg MS, Bass AH. Frequency response properties of lateral line superficial neuromasts in a vocal fish, with evidence for acoustic sensitivity. Journal of neurophysiology. 2002; 88(3):1252-1262. [PubMed: 12205146]

Weeg MS, Land BR, Bass AH. Vocal pathways modulate efferent neurons to the inner ear and lateral line. J Neurosci. 2005; 25(25):5967-5974. [PubMed: 15976085]

Woods CI, Azeredo WJ. Noradrenergic and serotonergic projections to the superior olive: potential for modulation of olivocochlear neurons. Brain Res. 1999; 836(1-2):9-18. [PubMed: 10415400]

Wullimann MF, Mueller T. Teleostean and mammalian forebrains contrasted: Evidence from genes to behavior. J Comp Neurol. 2004; 475(2):143-162. [PubMed: 15211457]

Wullimann MF, Rink E. The teleostean forebrain: a comparative and developmental view based on early proliferation, Pax6 activity and catecholaminergic organization. Brain Res Bull. 2002; 57(3-4):363-370. [PubMed: 11922990]

Yamamoto K, Ruuskanen JO, Wullimann MF, Vernier P. Differential expression of dopaminergic cell markers in the adult zebrafish forebrain. J Comp Neurol. 2010; 519(3):576-598. [PubMed: 21192085] 
Yamamoto K, Vernier P. The evolution of dopamine systems in chordates. Front Neuroanat. 2011; 5:21. [PubMed: 21483723]

Yanagihara S, Hessler NA. Modulation of singing-related activity in the songbird ventral tegmental area by social context. Eur J Neurosci. 2006; 24(12):3619-3627. [PubMed: 17229110]

Zikopoulos B, Dermon CR. Comparative anatomy of alpha(2) and beta adrenoceptors in the adult and developing brain of the marine teleost the red porgy (Pagrus pagrus, Sparidae): $[(3) \mathrm{H}]$ clonidine and $[(3) \mathrm{H}]$ dihydroalprenolol quantitative autoradiography and receptor subtypes immunohistochemistry. J Comp Neurol. 2005; 489(2):217-240. [PubMed: 15984005]

Zottoli SJ, Van Horne C. Posterior lateral line afferent and efferent pathways within the central nervous system of the goldfish with special reference to the Mauthner cell. J Comp Neurol. 1983; 219(1):100-111. [PubMed: 6619328] 


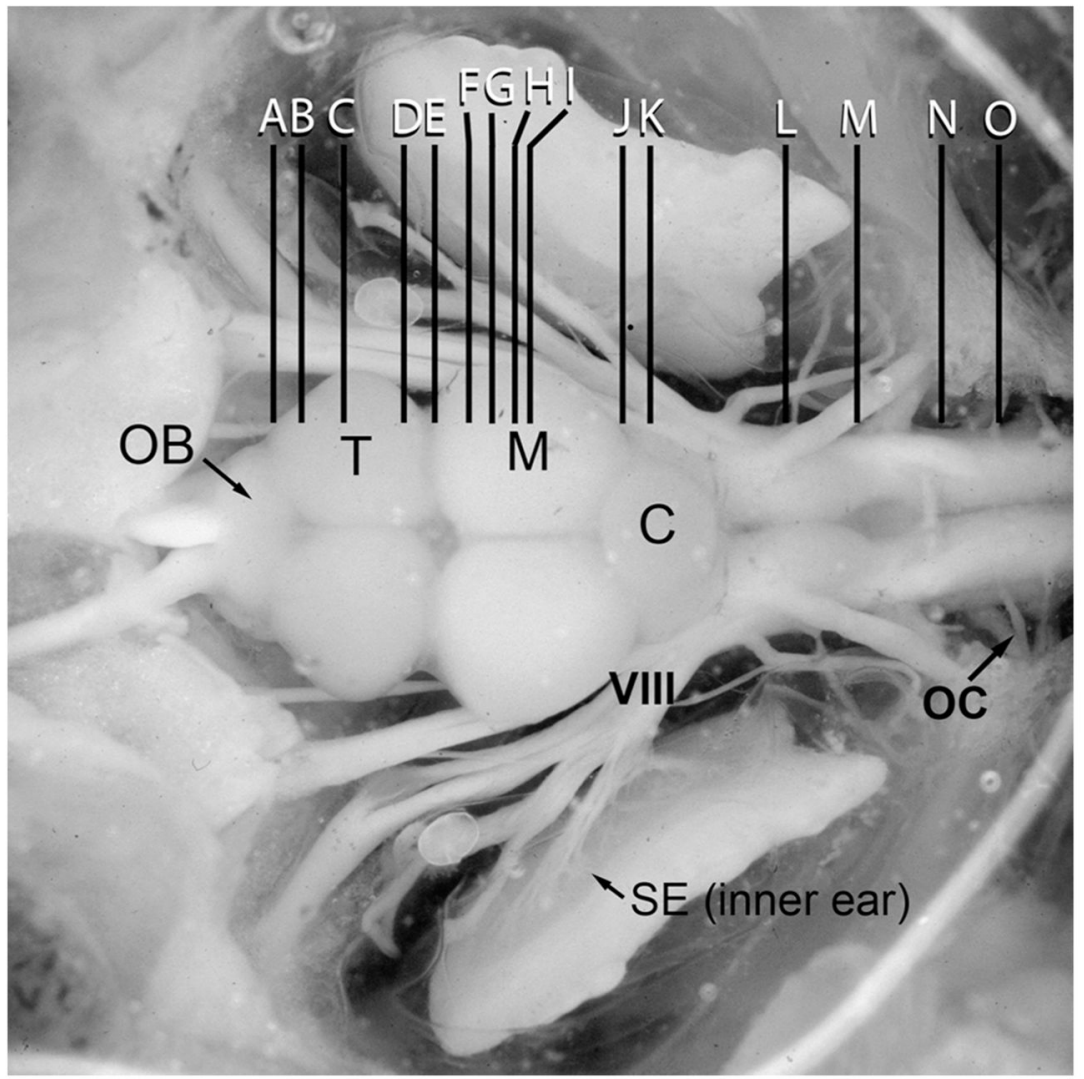

Figure 1.

Dorsal view of exposed brain and inner ear of a midshipman indicating levels (rostralcaudal) of transverse sections for the brain atlas of tyrosine hydroxylase immunoreactivity shown in figure 2. Abbreviations: C, cerebellum; M, midbrain; OB, olfactory bulb; OC, occipital nerve roots; T, telencephalon; SE, saccular epithelium of the inner ear; VIII, eighth nerve. Scale bar $=1.5 \mathrm{~mm}$. Modified from Forlano et al., 2010 . 


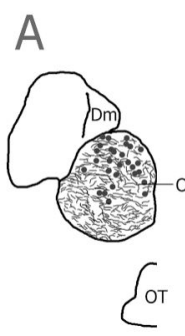

B
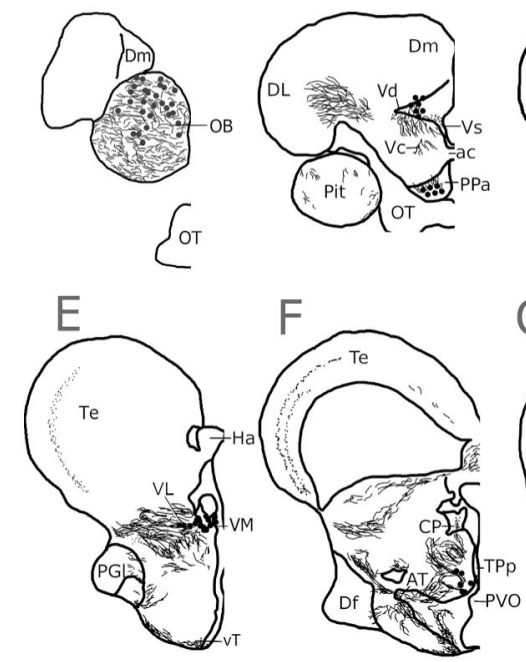

$\mathrm{F}$

I

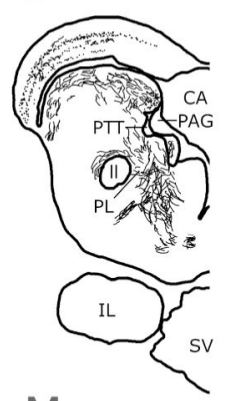

M
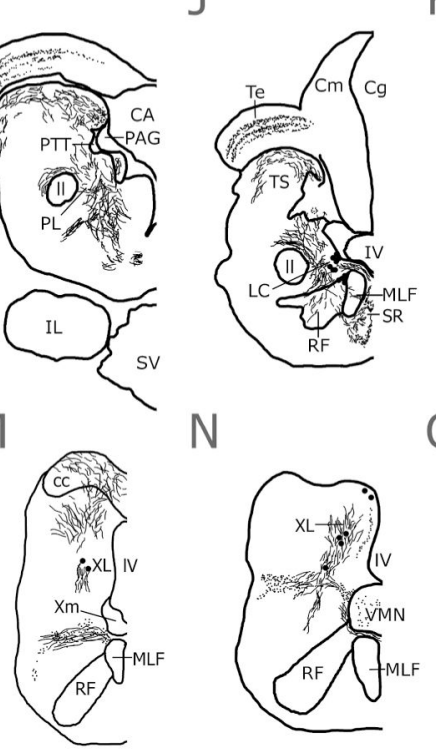

$\mathrm{C}$
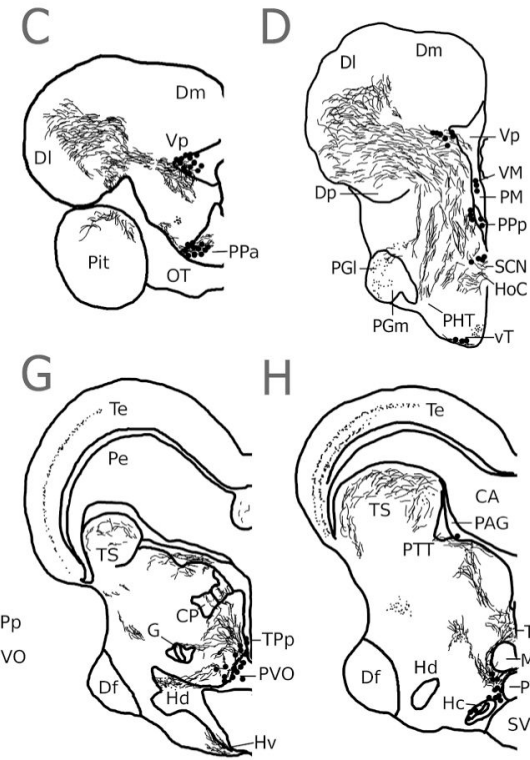

K

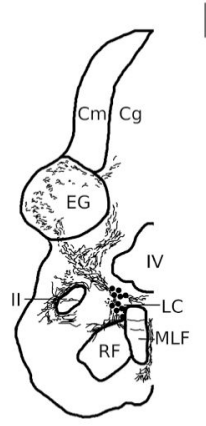

0
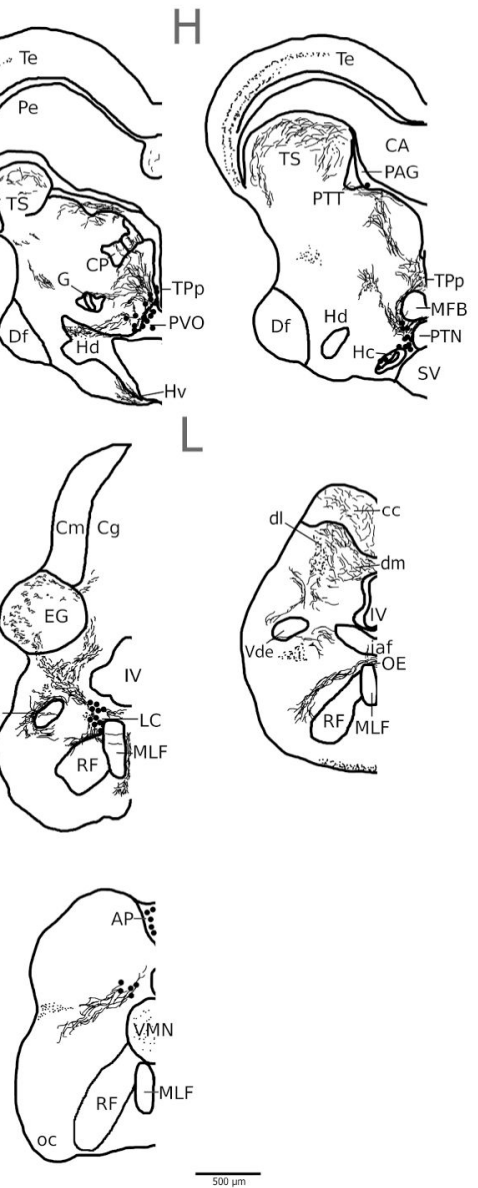

Figure 2.

A representative series of line drawings illustrating rostro-caudal distribution of major tyrosine hydroxylase immunoreactive (TH-ir) cell populations (large dots), fibers (lines) and terminals (small dots) in the midshipman brain. 

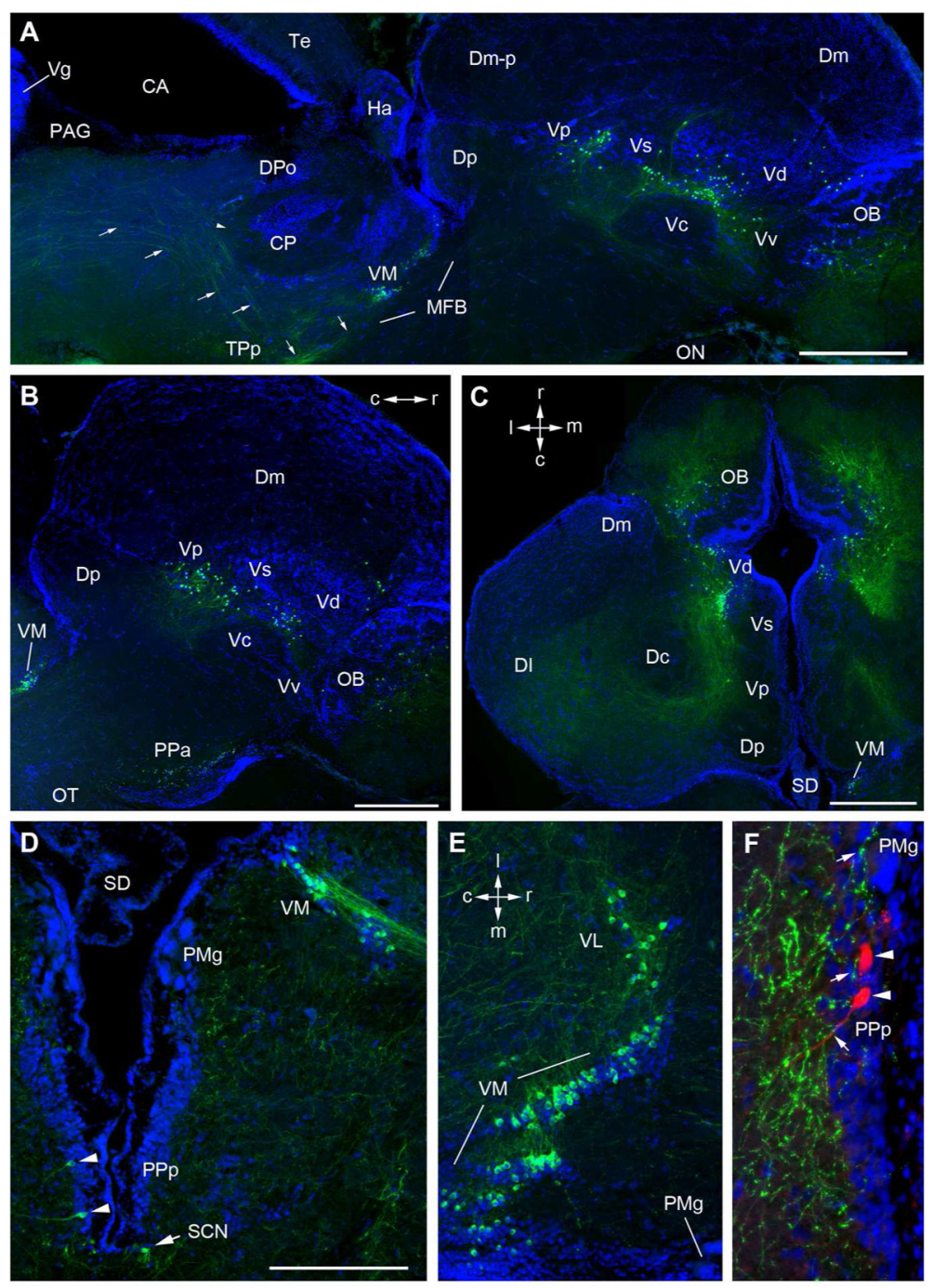

Figure 3.

TH-ir cell groups (green) in the telencephalon and rostral diencephalon; blue is DAPI nuclear stain. A: Composite parasagittal section (rostral is to the right) through the forebrain showing a chain of TH-ir cell populations starting in the olfactory bulb (OB) and continuing through dorsal (Vd), ventral (Vv), supracommissural (Vs) and postcommissural (Vp) nuclei of area ventralis of the telencephalon. In the diencephalon a tight cluster of small TH-ir cells is seen in the ventral medial thalamus (VM) just beneath the rostral central posterior nucleus (CP). Prominent ascending and dorsal- descending fiber tracts (arrows) emanate from the periventicular posterior tuberculum (TPp). A single arrowhead indicates a branch of the descending tract entering the auditory CP. B: A parasagittal section more lateral compared to A showing TH-ir somata in the anterior parvocellular preoptic area $(\mathrm{PPa})$ and $\mathrm{Vp}$. $\mathbf{C}$ : A horizontal section through the ventral telencephalon showing $\mathrm{TH}$-ir cells spanning $\mathrm{OB}, \mathrm{Vd}$ and Vs. Local fibers cover much of the OB and fibers from Vd, Vs and Vp wrap caudally around the central nucleus of area dorsalis (Dc) and fan out laterally toward the lateral division of area dorsalis (D1). D: Cross section through the caudal preoptic area showing $\mathrm{TH}$-ir cells in the posterior parvocellular preoptic area (PPp) and the adjacent 
suprachiasmatic nucleus (SCN). Also seen are TH-ir cells in the ventral medial (VM) and lateral (VL) thalamus with lateral projections. E: Horizontal section through the ventral thalamus. Rostrally, small, round TH-ir somata begin lateral to the midline in VL and VM and form a continuous chain caudally within the cell-dense plate characteristic of VM and merge with the midline proximal to the third ventricle. The rostral part of this section shows the TH-ir cells at a level parallel to PMg as seen in D. F: Neurobiotin-labeled neurons in the PPp (red, arrowheads) following a saccular nerve backfill. TH-ir terminals and varicosities are found in the PMg and in close contact to backfilled PPp cells. Scale Bars in A-C = $500 \mu \mathrm{m} ; \mathrm{D}=200 \mu \mathrm{m}$; same bar in $\mathrm{D}=200 \mu \mathrm{m}$ in $\mathrm{E}$ and $100 \mu \mathrm{m}$ in F. 

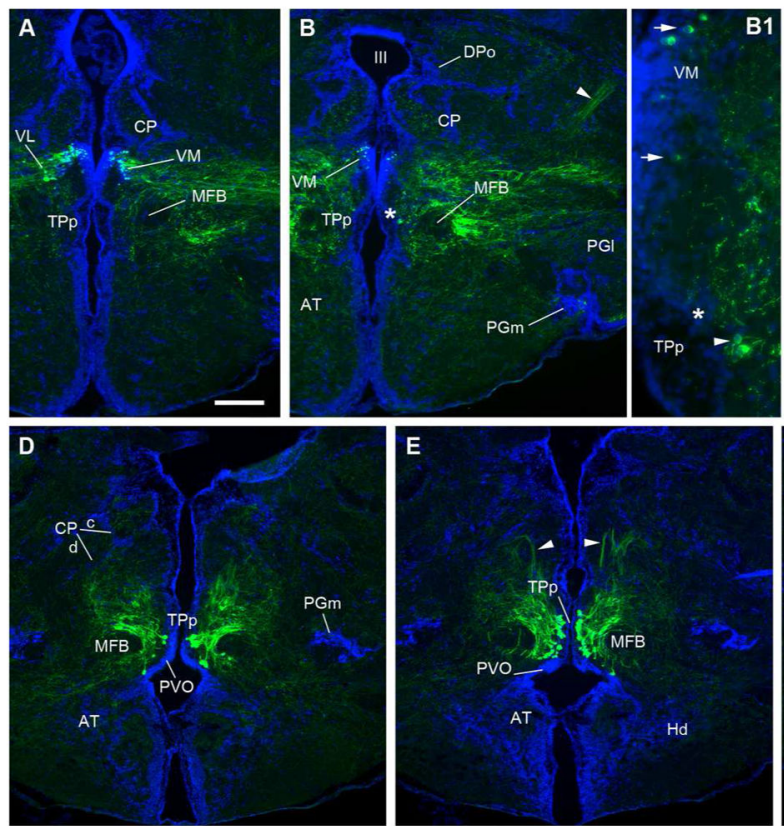

G
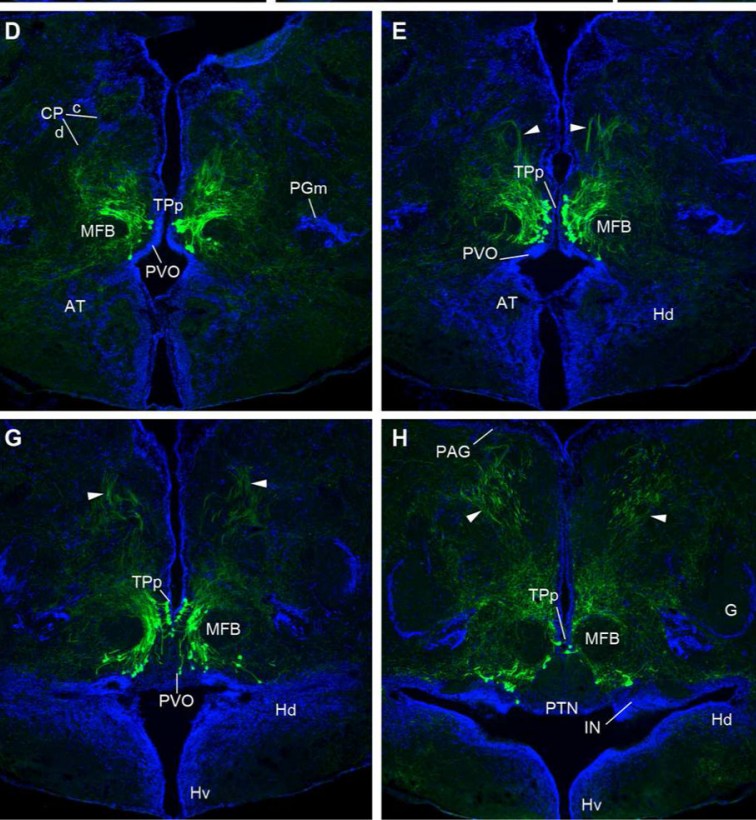
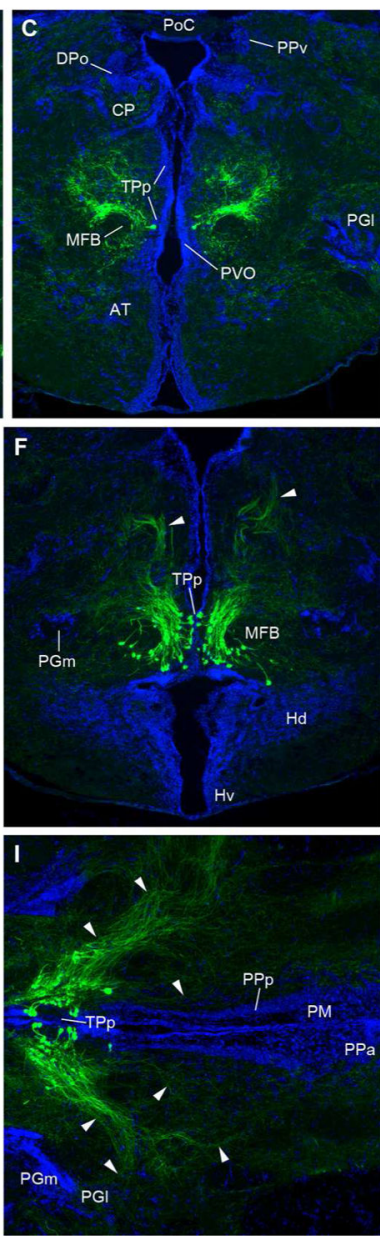

Figure 4.

Rostro-caudal distribution of TH-ir neurons (green) in the periventricular posterior tuberculum (TPp). Blue is DAPI nuclear stain. A: Few, if any TH-ir cells are found in the rostral TPp, ventral to a prominent population of small TH-ir cells with lateral projections in the ventral medial (VM) and lateral (VL) thalamus which follow a dense cell plate extending ventrolateral from the midline. B: Caudal extent of TH-ir VM cells along the midline. A bundle of TH-ir fibers (arrowhead) which innervates the tectum (not shown) appears to originate from VM/VL. A few small round TH-ir cells $\left(^{*}\right)$ are seen in the TPp at this level. B1: Higher magnification of distinct TH-ir cell groups in VM (arrows) and TPp (arrowhead). C: Large, pear-shaped TH-ir cells appear in the ventral TPp just lateral to paraventricular organ (PVO) which lines the third ventricle. Note abundance of TH-ir fibers and terminals in the anterior tuberal nucleus (AT), lateral division of nucleus preglomerulosus ( $\mathrm{PGl}$ ) and the central posterior nucleus $(\mathrm{CP})$, all part of the ascending auditory pathway. D: Pear-shaped cells send TH-ir projections both laterally around the medial forebrain bundle (MFB) and dorsally, some reaching the compact (c) and diffuse (d) division of CP. E-G: Majority of large TH-ir neurons are found just lateral to the midline and wrap around the MFB in a continuum ventrolaterally, dorsal to the caudal AT and the rostral level of the dorsal periventricular hypothalamus (Hd). Some cells (seen in F and G) are in a true periventricular position (TPp) just dorsal to the PVO. Arrowheads indicate thick 
dorsal projections that turn to descend through the brainstem (see Fig. 5). A few small TH-ir cells (seen in G) are found scattered in the PVO proper with dorsal projections. H: At the level of the rostral posterior tuberal nucleus (PTN), a few large TH-ir cells are ventrolateral to the MFB and dorsal to the intermediate hypothalamic nucleus (IN). Dorsal TH-ir projections innervate the periaqueductal gray (PAG) (also see Fig. 6). I: A horizontal section (rostral to the right) shows prominent ascending fibers (arrowheads) from large TH-ir cells in the TPp. The ascending tract appears to branch laterally to innervate PGl as well as continue rostrally seen at the level of the preoptic area (PPp, PM, PPa). Scale bar $=250 \mu \mathrm{m}$

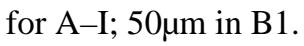



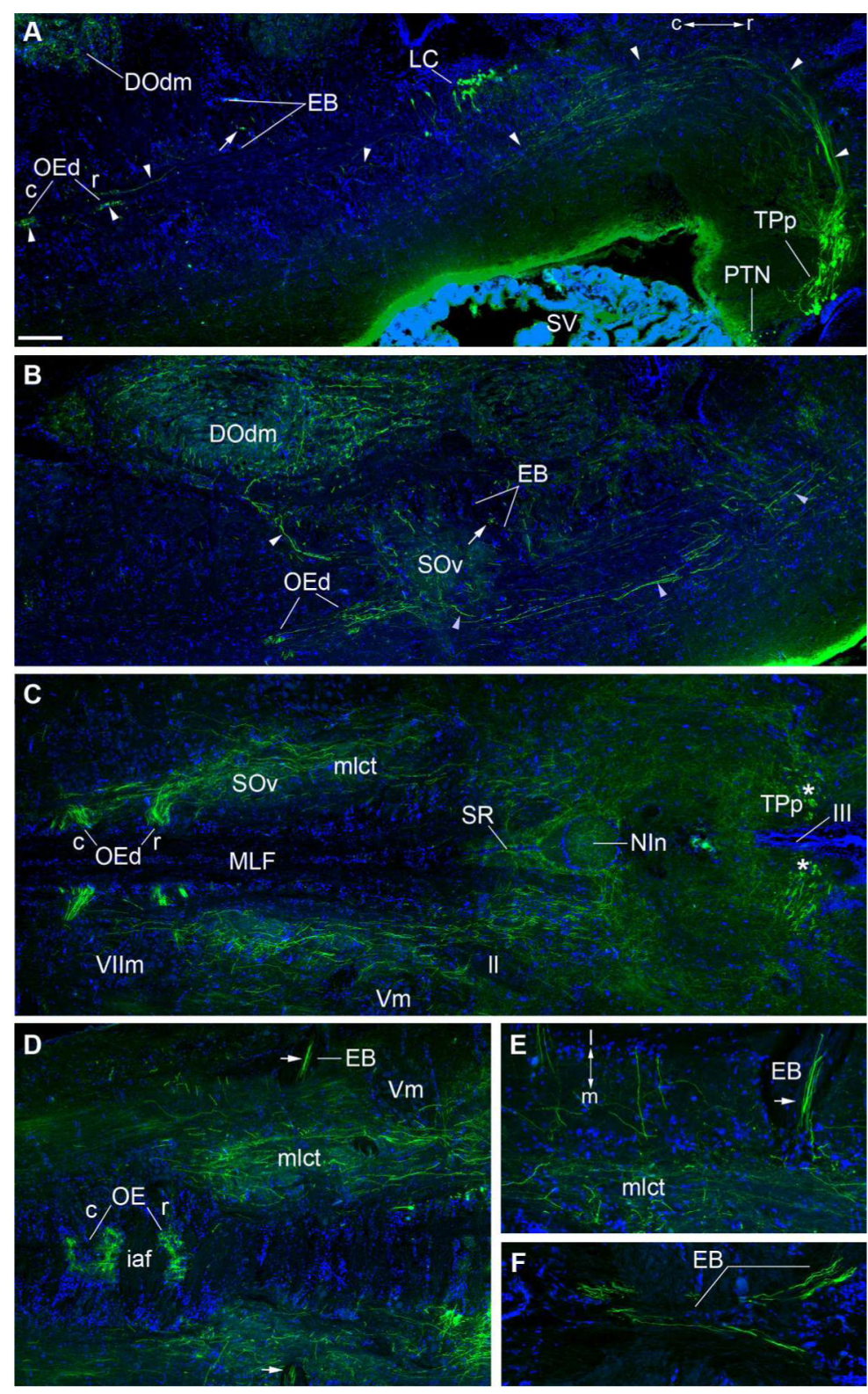

Figure 5.

Descending TH-ir projections (green) from the periventricular posterior tuberculum (TPp).

Blue is DAPI nuclear stain. Rostral (r) is to the right in all images. A: Composite parasagittal section showing large TPp TH-ir neurons which sit rostral to smaller TH-ir cells in the posterior tuberal nucleus (PTN) and send a thick tract of dorsal projections (arrowheads) that turns to descend and passes ventral to the locus coeruleus (LC) further into the hindbrain. Prominent terminations are seen within the rostral (r) and caudal (c) dendritic field (d) of the octavolateralis efferent nucleus (OE). B: Composite parasagittal section lateral to A showing descending TH-ir fiber tracts which innervate ventral secondary octaval (SOv) and the dorsal medial descending octaval nuclei (DOdm). Arrows in A and B indicate cross-sections through TH-ir axons within the efferent bundle (EB). C: Composite horizontal section showing $\mathrm{TH}$-ir tracts from the caudal diencephalon to the level of the $\mathrm{OE}$ 
in the hindbrain. Asterisks (*) indicate cross-sections through thick dorsal TH-ir projections from the TPp on either side of the third ventricle (III). The medial longitudinal catecholaminergic tract (mlct) is evident in this plane of section where a large subset of fibers turn sharply medial into the rostral and caudal OEd. TH-ir fibers also heavily innervate nucleus interpeduncularis (NIn) and superior raphe (SR). D: Horizontal section dorsal to $\mathrm{C}$ showing robust $\mathrm{TH}$-ir innervation of the medially located somata of the OE. Arrow indicates bundle of TH-ir axons within the lateral portion of the EB that will eventually merge with cranial nerve VIII. E: A bundle of several robust TH-ir axons appear to branch off the mlct and continue laterally as seen in D (horizontal plane). F: A more dorsal horizontal section to E shows TH-ir axons (of the same caliber as in E) converge medially within the descending EB tract. The EB serves as the conduit for the OE efferent fibers to reach VIII. Compare with transverse sections through the medulla in Figs. 11 and 12. Scale bar $=250 \mu \mathrm{m}$ in A-D, $50 \mu \mathrm{m}$ in E and F. 

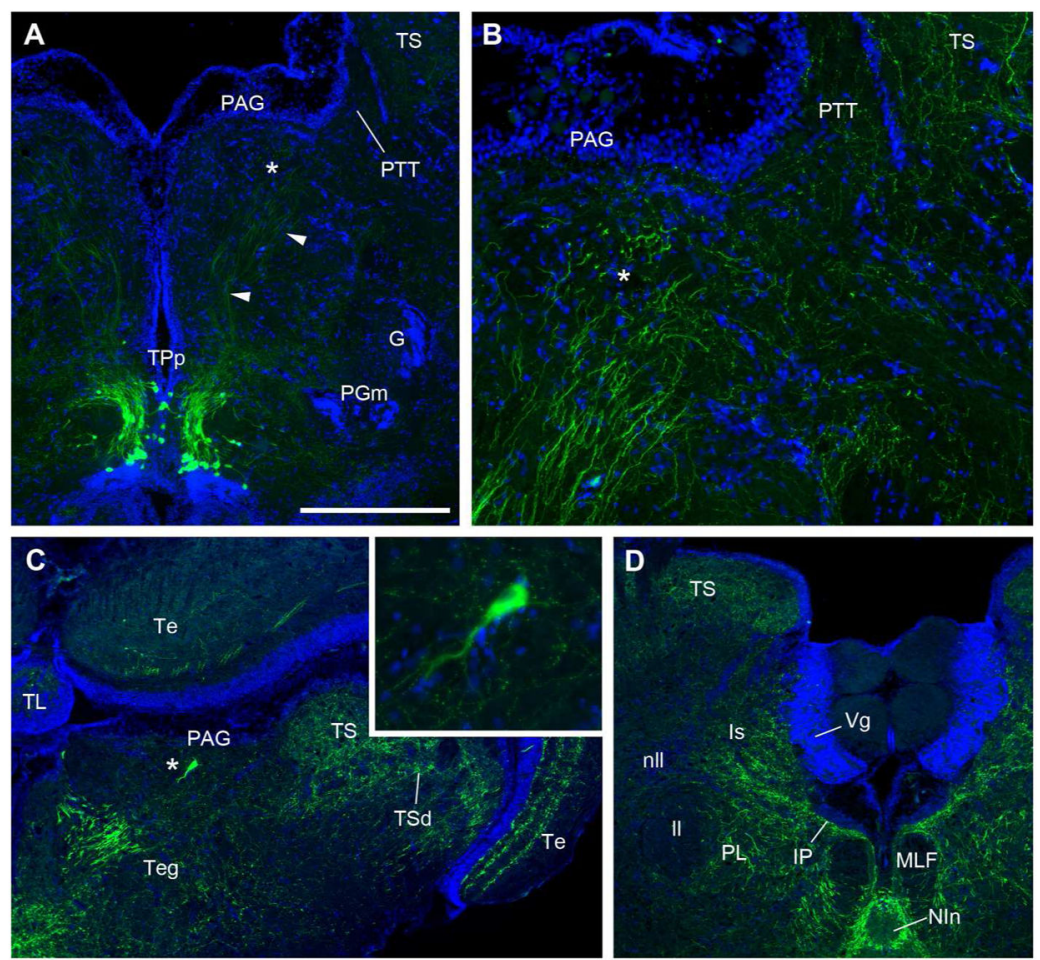

E

nII

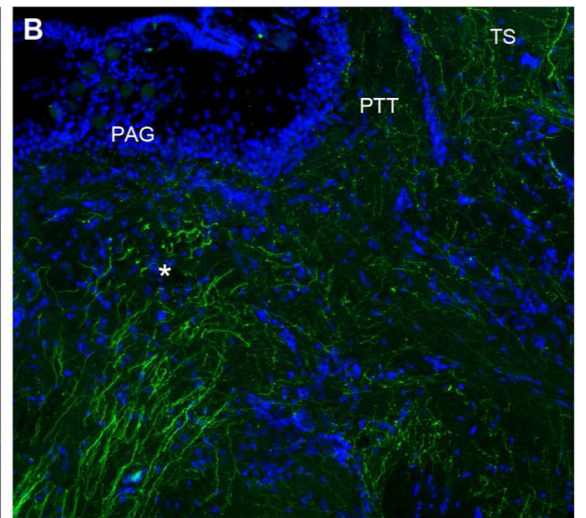

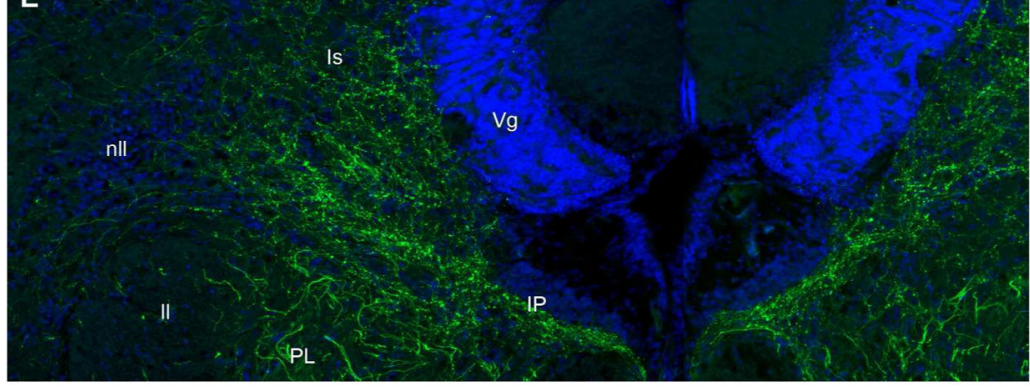

Figure 6.

TH-ir (green) in transverse section through the vocal midbrain and isthmus; blue is DAPI nuclear stain. A, B: Thick TH-ir dorsal projections from posterior periventricular tuberculum (TPp) are seen entering the ventral aspect of the periaqueductal gray (PAG) and the paratoral tegmentum (PTT). Asterisk in A denotes same location at higher magnification in B. C: Low magnification section through the midbrain. Midline is to the left. A lone multipolar TH-ir cell (*) found at the ventral aspect of the PAG. Inset in $\mathrm{C}$ is higher magnification of this cell. TH-ir cells in the PAG are very few in number. Robust TH-ir fibers are found in the central part of the auditory torus semicircularis (TS) and form a demarcation from the deep cell layers of the torus (TSd). TH-ir terminals are also found in distinct bands in superficial and deep layers of the tectum (Te). Prominent fibers descending through the tegmentum (Teg) likely originate from TPp. D,E: Abundant TH-ir terminals and varicosities are found within the isthmal (Is) and isthmal paraventricular (IP) nuclei as well as the paralemniscal midbrain tegmentum (PL). TH-ir fibers extend into but are less abundant in the nucleus of the lateral lemniscus (nll). E is a higher magnification of D. Scale bar $=500 \mu \mathrm{m}$ in $\mathrm{A}, \mathrm{C}, \mathrm{D}, 200 \mu \mathrm{m} \mathrm{B}$ and $\mathrm{E}$, and $50 \mu \mathrm{m}$ in C inset. 

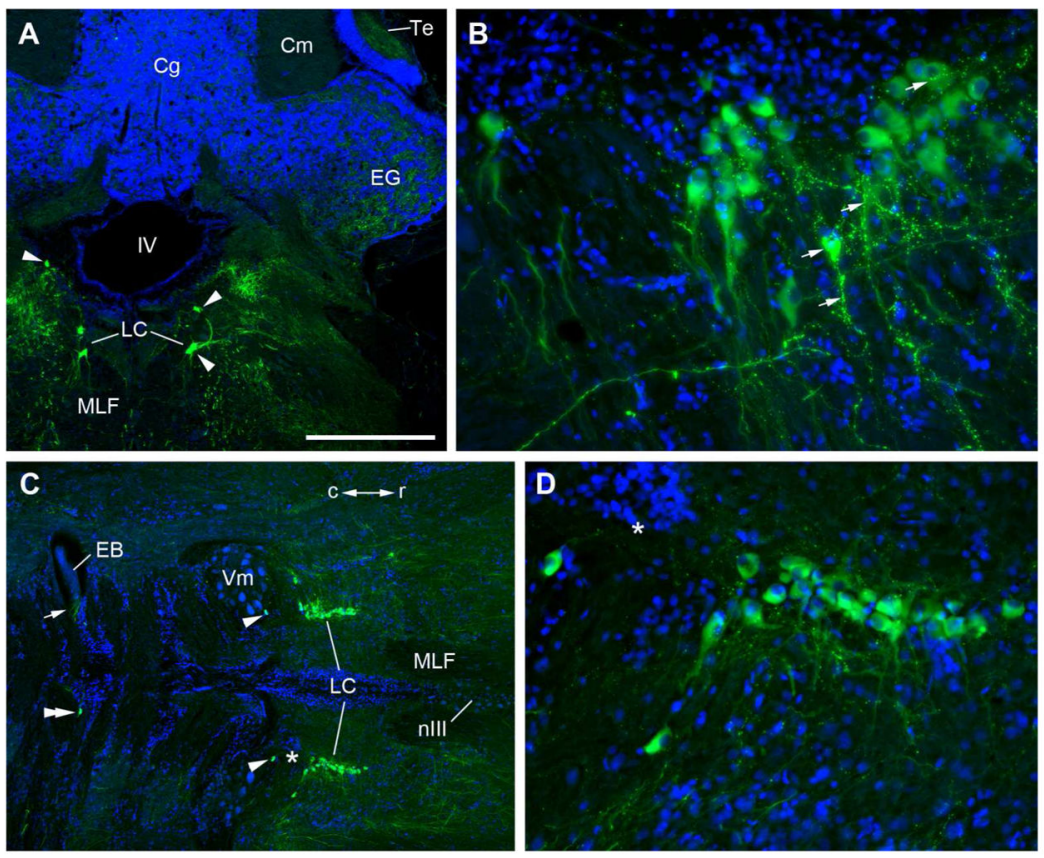

Figure 7.

Cytoarchitecture of the locus coeruleus (LC). TH-ir (green), blue is DAPI nuclear stain. A: Transverse section through the rostral LC shows small clusters of large multipolar TH-ir neurons (arrowheads) located on the dorsolateral aspect of the medial longitudinal fasciculus (MLF) while others are more dorsal, just lateral to the fourth ventricle (IV). Robust TH-ir fibers and terminals are found in the lateral eminentia granularis (EG) and paraventricular area. B: Parasagittal section through the LC; rostral is to the right. Note prevalence of ventral-oriented dendrites and highly intense $\mathrm{TH}$-ir varicosities and terminals (arrows) on lighter-labeled LC somata and dendrites. C: Horizontal section through LC and caudal hindbrain. LC in this plane is seen as a rostro-caudal (r/c) bilateral column of 2-3 cells with lateral dendrites and projections. Some caudal LC cells are found more laterally and few somata of similar size and shape are located at the rostral border of the trigeminal motor nucleus (Vm) (arrowheads). A lone TH-ir cell (double arrowhead) in the hindbrain just lateral to the midline is seen at the level of the efferent bundle (EB, see Figs. 5, 11). TH-ir cells in this location are very few in number. Arrow points to bundle of TH-ir axons in EB. Asterisk in $\mathrm{C}$ denotes same location at higher magnification in D. Scale bar $=500 \mu \mathrm{m}$ in A and $\mathrm{C}, 100 \mu \mathrm{m}$ in B and D. 

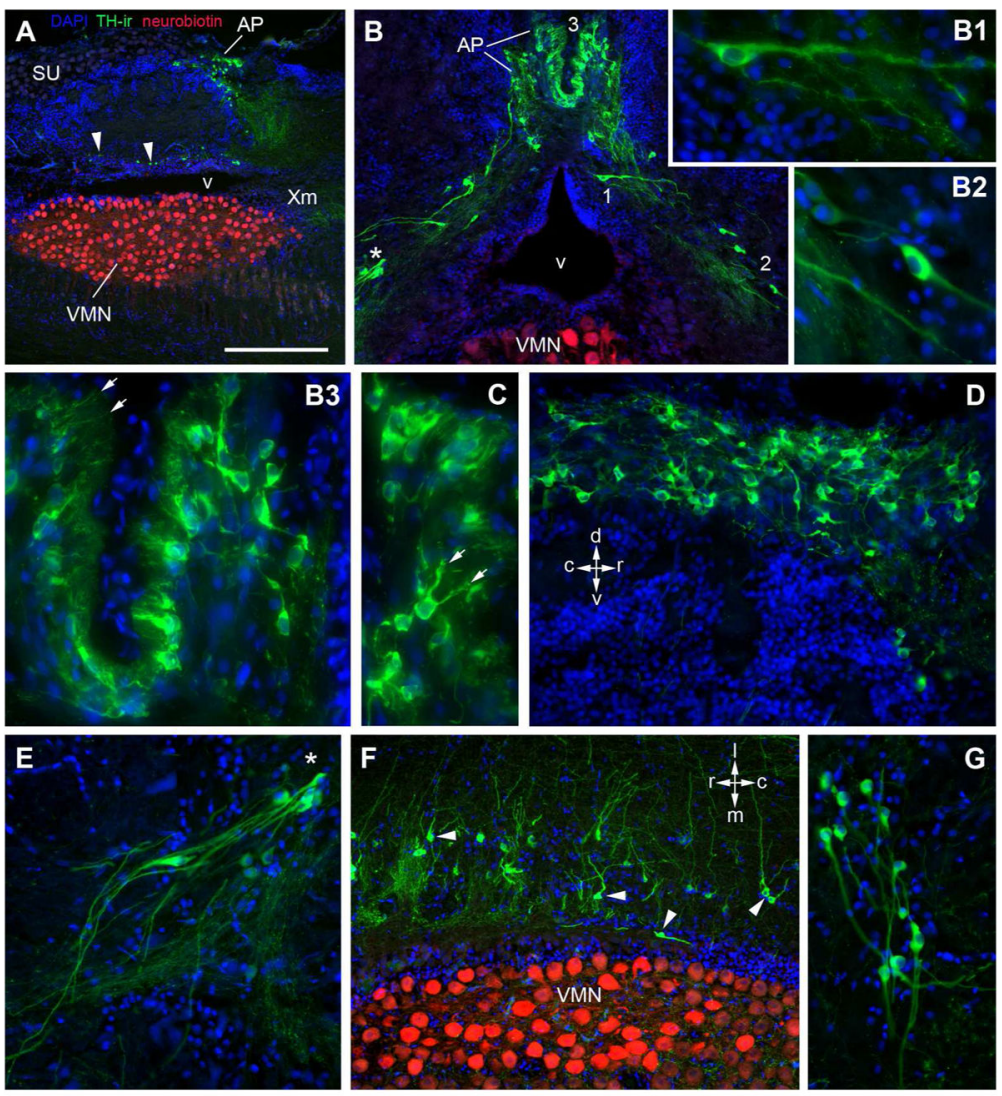

Figure 8.

TH-ir cells in the caudal hindbrain. A: Sagittal section through the hindbrain-spinal cord containing the vocal motor nucleus (VMN, red) labeled by bulk neurobiotin backfill of a single vocal nerve. Rostral is to the right. TH-ir neurons of the vagal cell group are found just dorsal to the ventricle (arrowheads) as well as tightly clustered within the area postrema (AP). A prominent stream of TH-ir fibers extends ventrally from AP to the level of the rostral VMN and vagal motor nucleus (Xm). B: Transverse section through the AP showing a continuum of TH-ir cells surrounding the dorsolateral aspect of the VMN. B1,2: Higher magnification of individual cells in B demonstrating teardrop-shaped soma morphology. B3: Higher magnification of TH-ir AP neurons from B showing fine, cilia-like processes (arrows) which face the midline. C: Another example of AP neuron with double processes with fine cilia-type endings. D: Sagittal section through the AP showing column of bi- and multipolar TH-ir AP neurons along the midline of the dorsal aspect of the hindbrain. $\mathbf{E}$ : Higher magnification of $(*)$ in B showing small clusters of teardrop-shaped TH-ir cells just dorsolateral to the VMN. These cells appear to have thick ventrolateral dendrites and smaller caliber ventromedial and ventrolateral projecting fibers. F: Horizontal section showing population of TH-ir neurons (arrowheads) just lateral to the rostral-caudal extent of the dorsal VMN. G: Transverse section rostral to the VMN showing a loose cluster of TH-ir cells with long thick dendrites in the XL. Scale bar $=500 \mu \mathrm{m}$ in A $200 \mu \mathrm{m}$ in B and F, $100 \mu \mathrm{m}$ $\mathrm{D}, \mathrm{E}$ and $\mathrm{G}$, and $50 \mu \mathrm{m}$ in $\mathrm{B} 1-3$ and $\mathrm{C}$. 

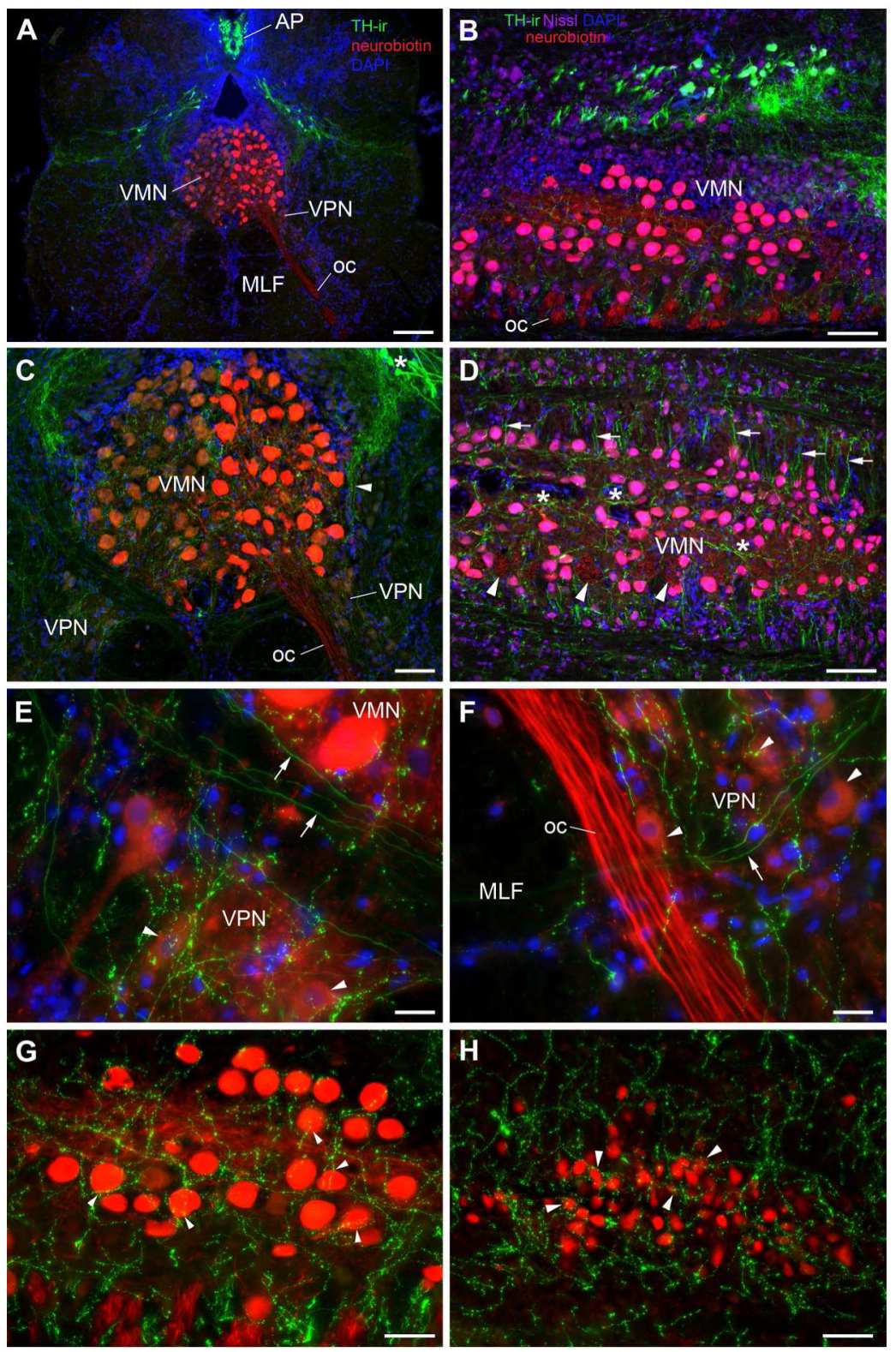

Figure 9.

Extensive TH-ir innervation throughout the vocal pattern generator (VPG). The VPG consists of vocal prepacemaker neurons (VPP), vocal pacemaker neurons (VPN) and the vocal motor nucleus (VMN) which innervates vocal musculature on the swim bladder. All three components were delineated by bulk neurobiotin backfill (red) of a single vocal nerve. A: Transverse section through the VMN-VPN showing relative dorsal and dorsolateral position of TH-ir neurons of the area postrema (AP) and vagal group, respectively. Also note neurobiotin-labeled occipital nerve (oc) which will exit the base of the brain. B: Parasagittal section showing vagal group TH-ir neurons running in a column parallel to the lateral zone of VMN. TH-ir fibers from this group are seen projecting ventrally and rostrally (to the right). Neurobiotin- backfilled VMN neurons overlaying Nissl stain appear pink. C: Higher magnification of image in A showing proximity of TH-ir neurons (*) just lateral to 
the dorsal zone of VMN and large TH-ir fiber bundles entering the lateral VMN (arrowhead) and terminating within the nucleus. D: Horizontal section through the ventral VMN. Prominent TH-ir fibers (arrows) intersect and enter the lateral VMN in a perpendicular fashion along its length. Also note longitudinal fibers $(*)$ coursing centrally through VMN. Arrowheads indicate cross-sections through bundles of axons that exit the ventrolateral base of the VMN to form the oc. Color legend in B applies to D. E,F: Examples of TH-ir terminals and varicosities within neurobiotin-filled VPN (arrowheads). Arrows designate smooth TH-ir axon fibers that follow the ventral aspect of the VMN. G: Higher magnification of the lower left half of B demonstrating an abundance of TH-ir terminals and varicosities on somata and dendrites in the VMN. H: Prominent TH-ir beaded fibers within and around the VPP in a sagittal plane. Note the relative size difference of VPP neurons to

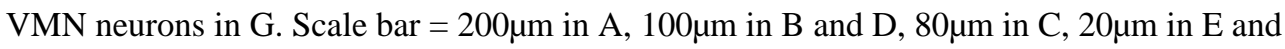

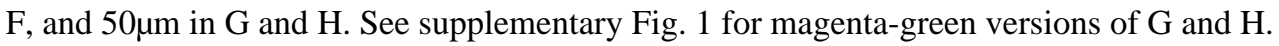



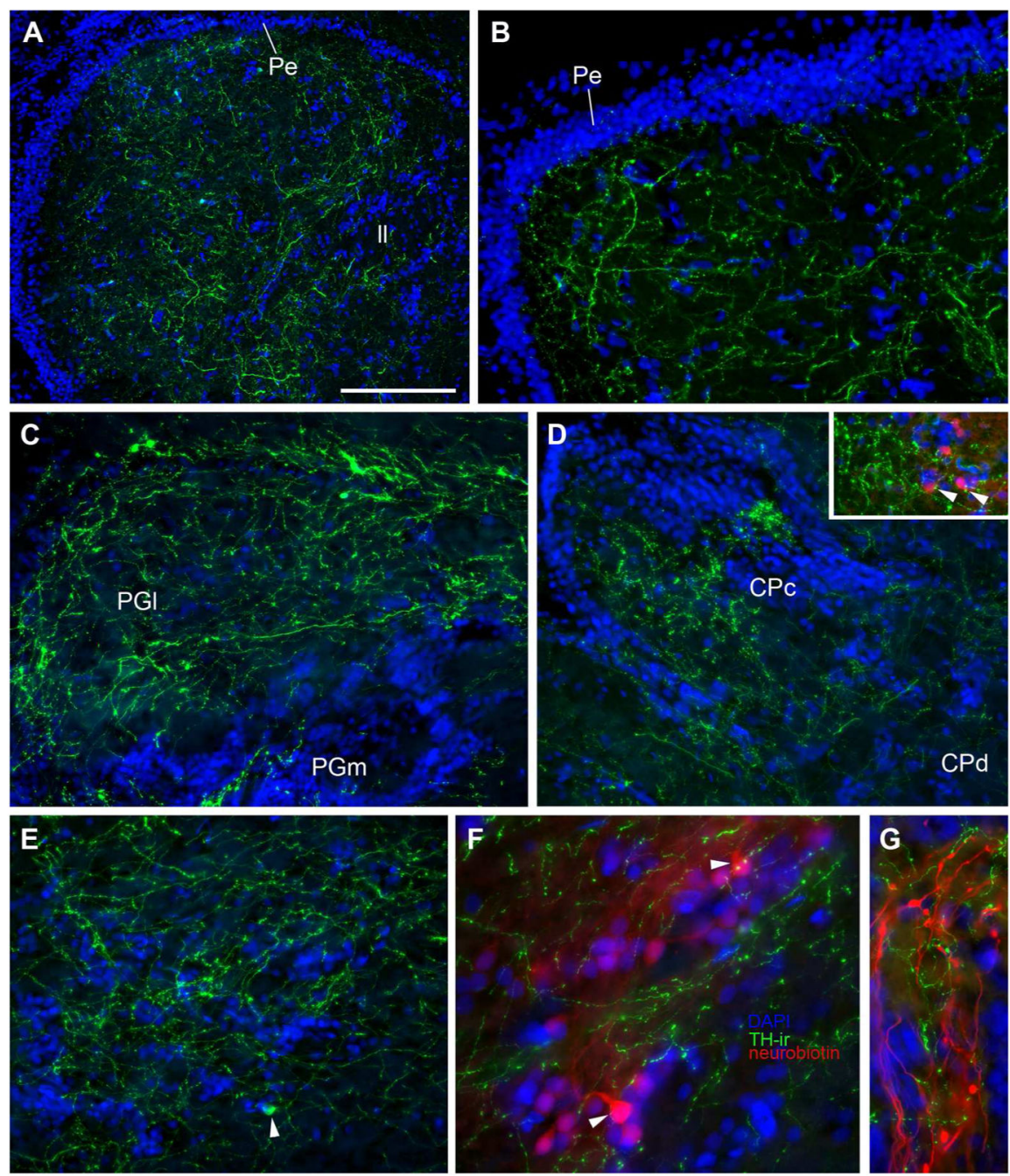

Figure 10.

TH-ir in higher order auditory nuclei; blue is DAPI nuclear stain. A,B: TH-ir fibers and terminals are abundant in the midbrain torus semicircularis (TS). A: Horizontal section through TS. Rostral is to the left, medial is top of the image. B: Transverse section through auditory area centralis of TS. Compact band of nuclei is the periventricular cell layer (Pe) of TS. C: TH-ir projections and varicosities in the lateral (PGl) and medial (PGm) division of nucleus preglomerulosus. Image taken from same section shown in 4C. D: TH-ir terminals in the compact $(\mathrm{CPc})$ and diffuse (CPd) divisions of the central posterior nucleus (auditory thalamus). Inset shows $\mathrm{TH}-\mathrm{ir}$ terminals on neurobiotin-filled cells (red) in $\mathrm{CPc}$ following a bilateral backfill of the saccular branch of VIII. E: A single TH-ir cell (arrowhead) together with dense TH-ir terminals in the hypothalamic anterior tuberal nucleus (AT). Image taken from same section shown in 4C. F: TH-ir terminals on neurobiotin-filled cells (red, arrowheads) in AT following a bilateral backfill of the saccular branch of VIII. AT is also part of the descending vocal motor circuitry and contains reciprocal connections with CP. G: TH-ir terminals are found intermixed with neurobiotin-filled afferents (red) from a 
saccular backfill in the eminentia granularis. Scale bar in $=200 \mu \mathrm{m}$ in A, $100 \mu \mathrm{m}$ in B-E, $50 \mu \mathrm{m}$ in $\mathrm{F}$ and $\mathrm{G}$. 

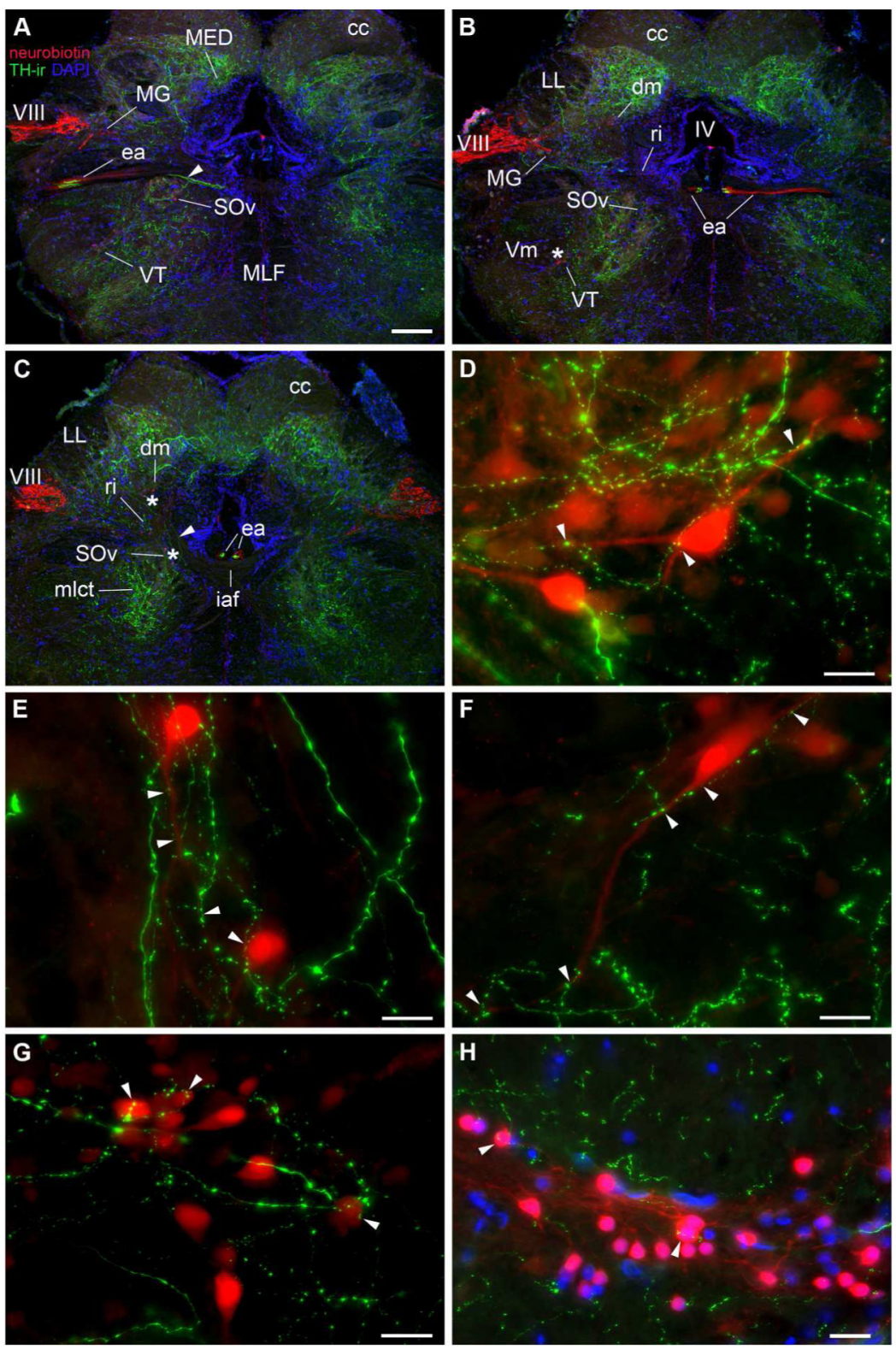

Figure 11.

TH-ir innervation of transneuronal-labeled hindbrain auditory nuclei following a bilateral application of neurobiotin on the saccular epithelium. A-C: Low magnification rostralcaudal series of transverse sections showing location of neurobiotin-filled cells in the auditory system and prominent TH-ir terminal fields in the dorsal and ventral hindbrain. Note both TH-ir and neurobiotin-labeled (red) octavolateralis efferent axons (ea) within the lateral efferent bundle just caudal to where they join VIII. Arrowhead in A indicates TH-ir axon bundle entering the lateral efferent tract just dorsal to the ventral secondary octaval nucleus (SOv). TH-ir axons are seen descending within the efferent tract (B) as it turns to run longitudinally along the midline $(\mathbf{C})$ dorsal to internal arcuate fiber tract (iaf) rostral to the octavolateralis efferent nucleus (OE, see Fig 12D). Arrowhead in C shows TH-ir fibers projecting dorsally into the rostral intermediate (ri) and dorsal medial (dm) subdivisions of 
the descending octaval nucleus (compare with Fig. 5B). D,E: High magnification of areas indicated by (*) in $\mathrm{C}$ showing TH-ir terminals and varicosities on somata and dendrites (arrowheads) of dm and SOv neurons in D and E, respectively. F: High magnification of area indicated by $(*)$ in B showing TH-ir varicosities on dendrites of a ventral tegmental (VT) neuron which lies just medial to the trigeminal motor nucleus (Vm). G, H: TH-ir terminals and varicosities on filled cells in ri and inferior olive (IO), respectively. Images in $\mathrm{G}$ and $\mathrm{H}$ were selected from sections outside of $\mathrm{A}-\mathrm{C}$. IO lies along the ventrolateral border of the caudal hindbrain. Scale bar $=200 \mu \mathrm{m}$ in $\mathrm{A}-\mathrm{C}, 16 \mu \mathrm{m}$ in $\mathrm{D}-\mathrm{G}$, and $20 \mu \mathrm{m}$ in $\mathrm{H}$. See supplementary Fig. 2 for magenta-green versions of D-G. 

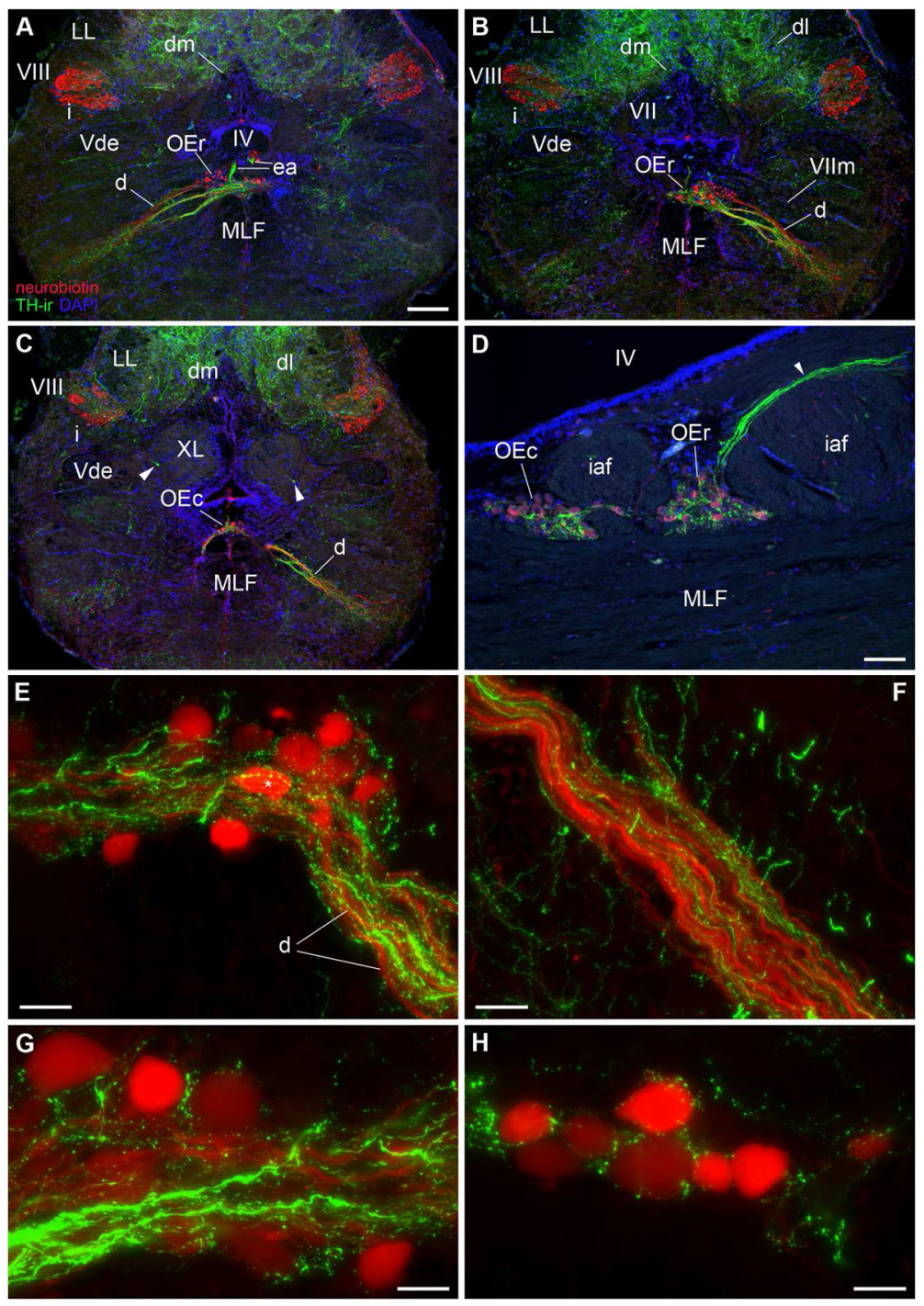

Figure 12.

Massive TH-ir innervation on somata and dendrites of the octavolateralis efferent nucleus (OE). A-C: Low magnification series of transverse sections that show backfilled neurons of the rostral (OEr) and caudal (OEc) subdivisions of the $\mathrm{OE}$ after bilateral application of neurobiotin on the saccular epithelium. OE neurons lie on the midline between the medial longitudinal fasciculus (MLF) and the fourth ventricle (IV). OE dendrites (d) extend ventrolaterally toward the edge of the brain and prominent $\mathrm{TH}$-ir fiber tracts run along the length of the OE dendrites. The medial efferent axon tract can be seen in A as a caudal continuation from Fig. 11C which connects to the $\mathrm{OE}$ somata (also see D). Arrowheads in C indicate single TH-ir cells associated with the rostral vagal lobe (XL). D: In the sagittal plane a bundle of intensely labeled TH-ir axons can be seen entering the OE via the efferent tract (arrowhead). E-H: High magnification images of robust TH-ir terminals and varicosities on and around OE somata and dendrites. TH-ir in this area appears highly localized to $\mathrm{OE}$ and its dendritic field. Scale bar $=200 \mu \mathrm{m}$ in $\mathrm{A}-\mathrm{C}, 80 \mu \mathrm{m}$ in $\mathrm{D}, 25 \mu \mathrm{m}$ in E and $16 \mu \mathrm{m}$ in F-H. See supplementary Fig. 3 for magenta-green versions of E-H. 

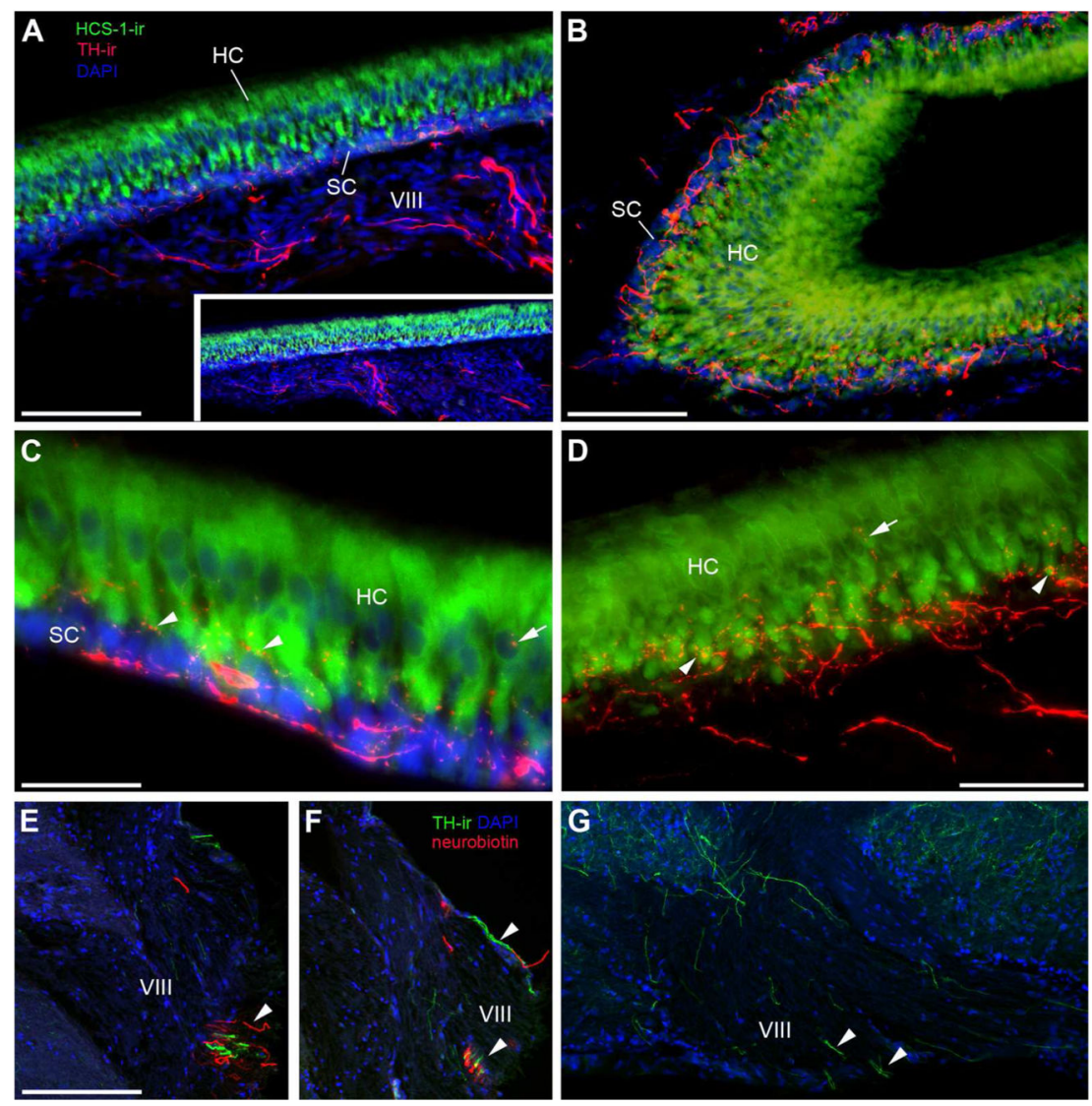

\section{Figure 13.}

TH-ir innervation of the saccule, the main endorgan of hearing. A: Section through the saccular epithelium (SE) including the attached branch of the eighth nerve (VIII). The hair cell layer (HC) is delineated using the hair cell specific antibody (HCS-1, green) which labels HC somata and can be distinguished from the basal support cells (SC) labeled by DAPI (blue) alone. Thick and smooth TH-ir fibers (red) course through VIII prior to terminating largely at the base of the HC layer. Inset is lower magnification of same section. B: Horizontal section showing larger varicose $\mathrm{TH}$-ir fibers in the $\mathrm{SC}$ and finer terminals in the HC layer of the SE. C,D: High magnification images showing thick TH-ir varicose fibers along the SC layer, fine-caliber terminals (arrowheads) at the base of the $\mathrm{HC}$ and less frequently terminals on the central portion of individual hair cells proximal to the nucleus (arrows). E,F: Transverse section through the lateral hindbrain where VIII converges with the CNS. Arrowheads indicate intermingled TH-ir fibers with neurobiotin-labeled fibers from a saccular backfill. G: Horizontal section through the hindbrain; medial is top lateral is bottom of image. Arrowheads show small bundles of TH-ir axons exiting the brain via VIII.

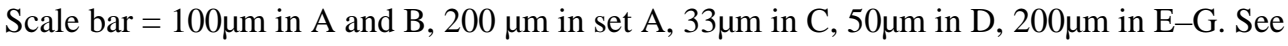
supplementary Fig. 4 for magenta-green version of D. 

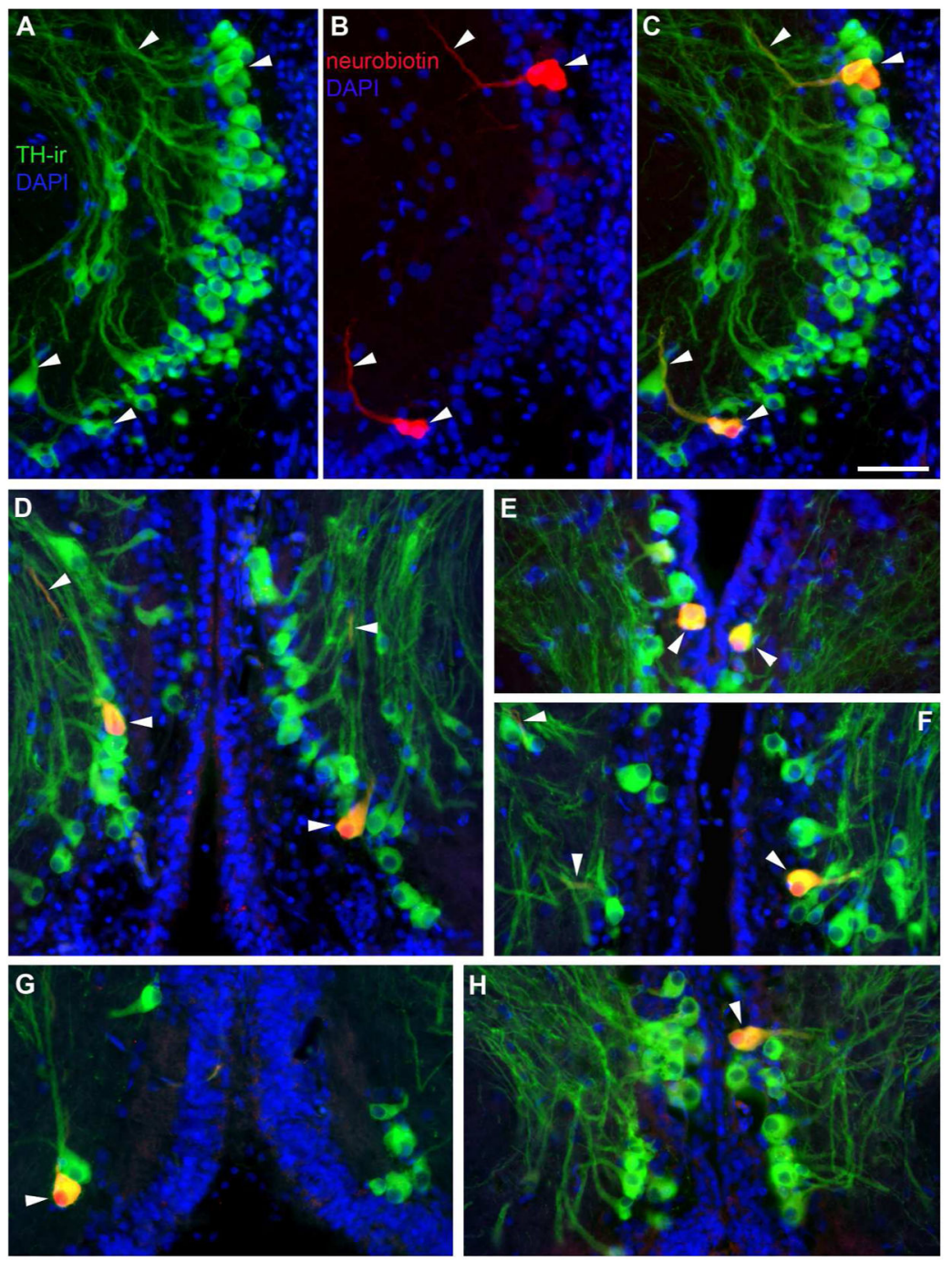

Figure 14.

Neurobiotin backfills of the saccule combined with TH immunofluorescence identify source of TH-ir efferents to the saccular epithelium as a small population of large, pear-shaped cells in the periventricular posterior tuberculum (TPp). A: TH-ir cells in the TPp just medial to the medial forebrain bundle and lateral and dorsal to the paraventricular organ. B: Three neurobiotin labeled-neurons (two adjacent cells on top) after a saccular backfill. C: Overlay of images in A and B. Arrowheads indicate same cells and filled axons. All neurobiotin backfilled cells in this region were also TH-ir. D-H: Additional examples of backfilled THir neurons (arrowheads, yellow overlay) throughout the TPp. Examples of bilateral filled cells in D and E are from unilateral saccular fills. See regional distribution in Figures 15 and 16. Scale bar $=50 \mu \mathrm{m}$ in all images. 

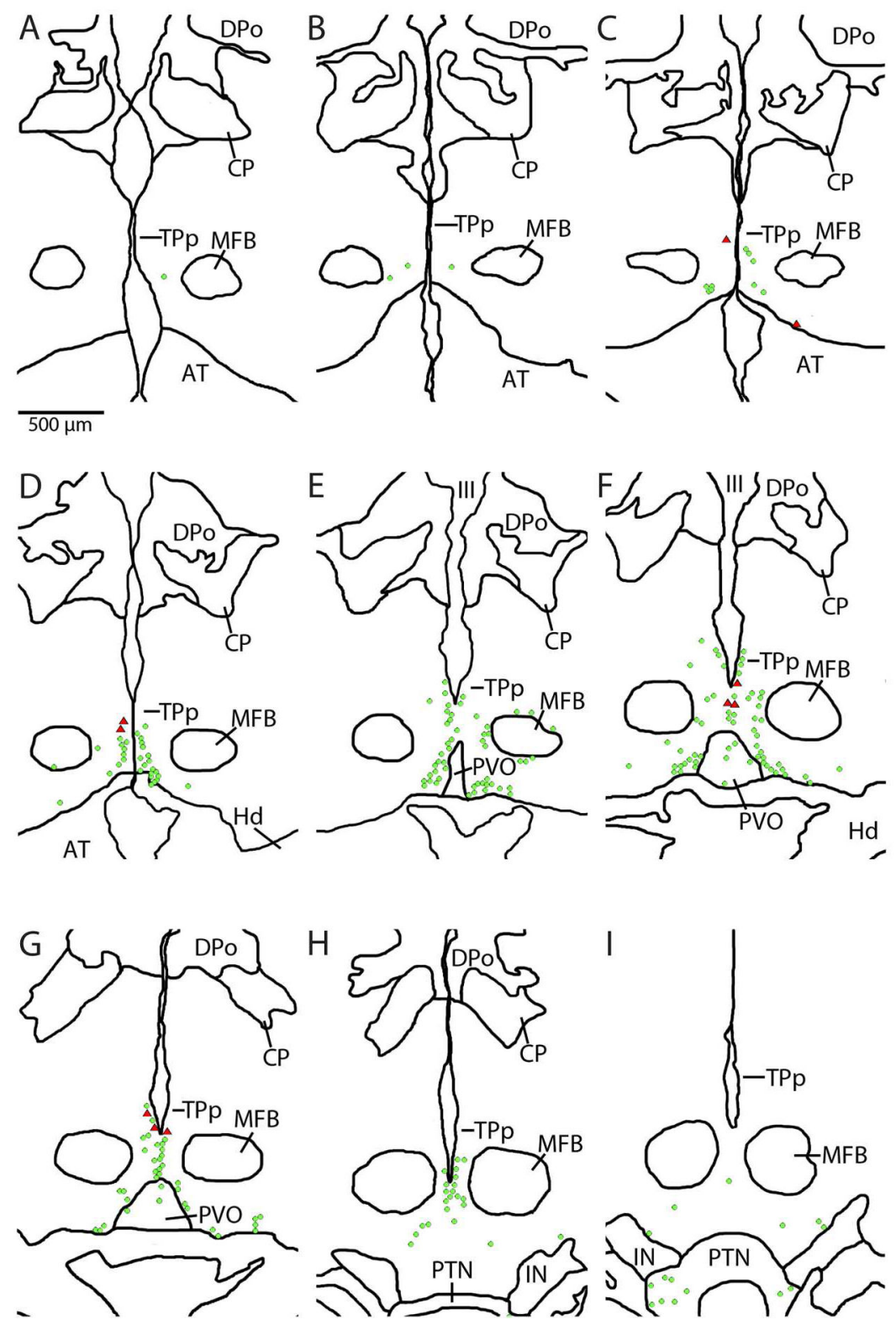

Figure 15.

Digital tracings of rostral-caudal series of sections depicting distribution of backfilled neurons also labeled by TH-ir (red triangles) in the posterior tuberculum of an individual after neurobiotin application on the saccular branch of the eighth nerve. Green circles indicate TH-ir neurons not backfilled. Backfilled cells were always TH-ir and were a small percentage of total population of $\mathrm{TH}$-ir neurons in this brain region. 

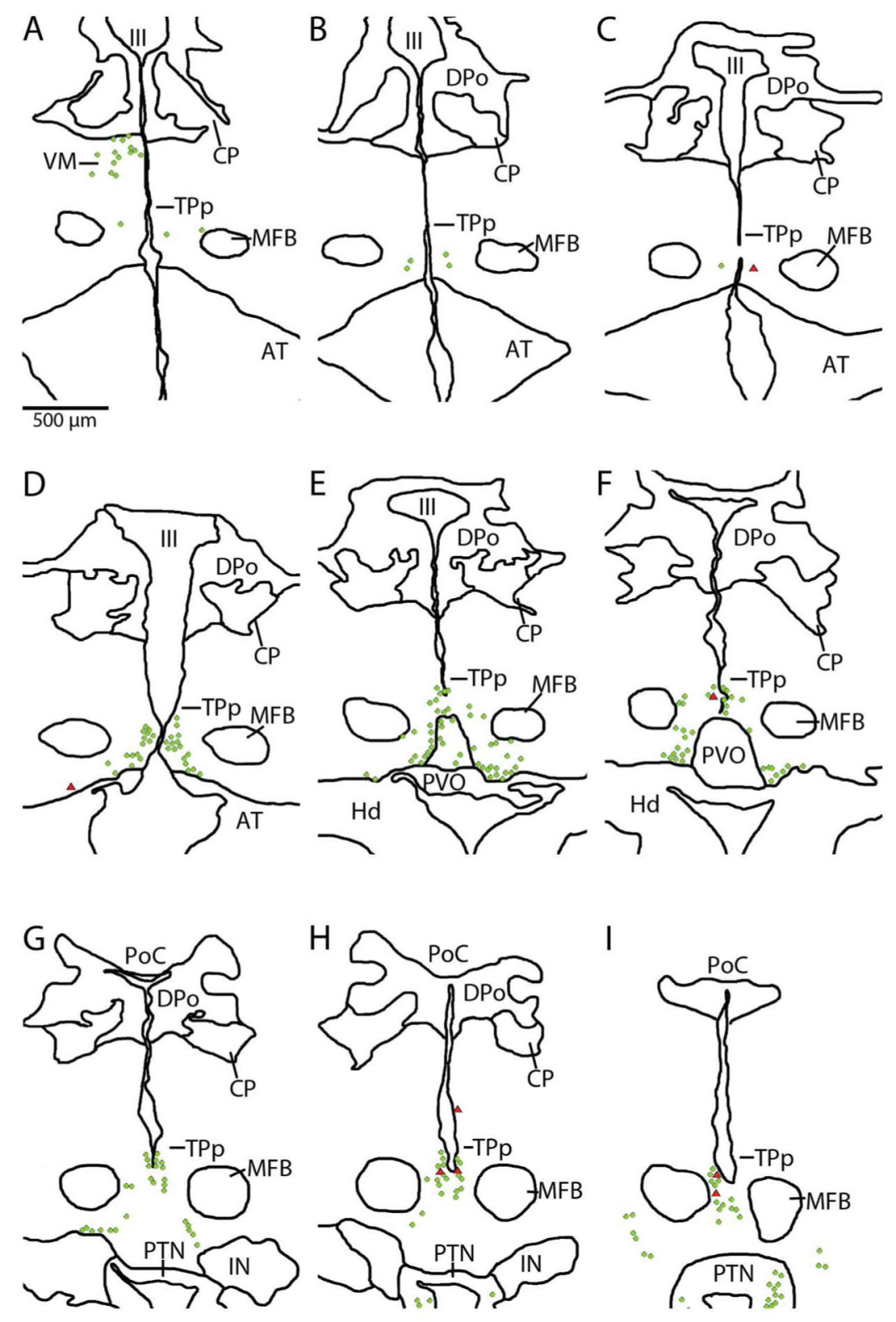

Figure 16.

Digital tracings of rostral-caudal series of sections depicting distribution of backfilled neurons also labeled by TH-ir (red triangles) in the posterior tuberculum of an individual after neurobiotin application on the saccular branch of the eighth nerve. Green circles indicate TH-ir neurons not backfilled. Backfilled cells were always TH-ir and were a small percentage of total population of $\mathrm{TH}$-ir neurons in this brain region. 


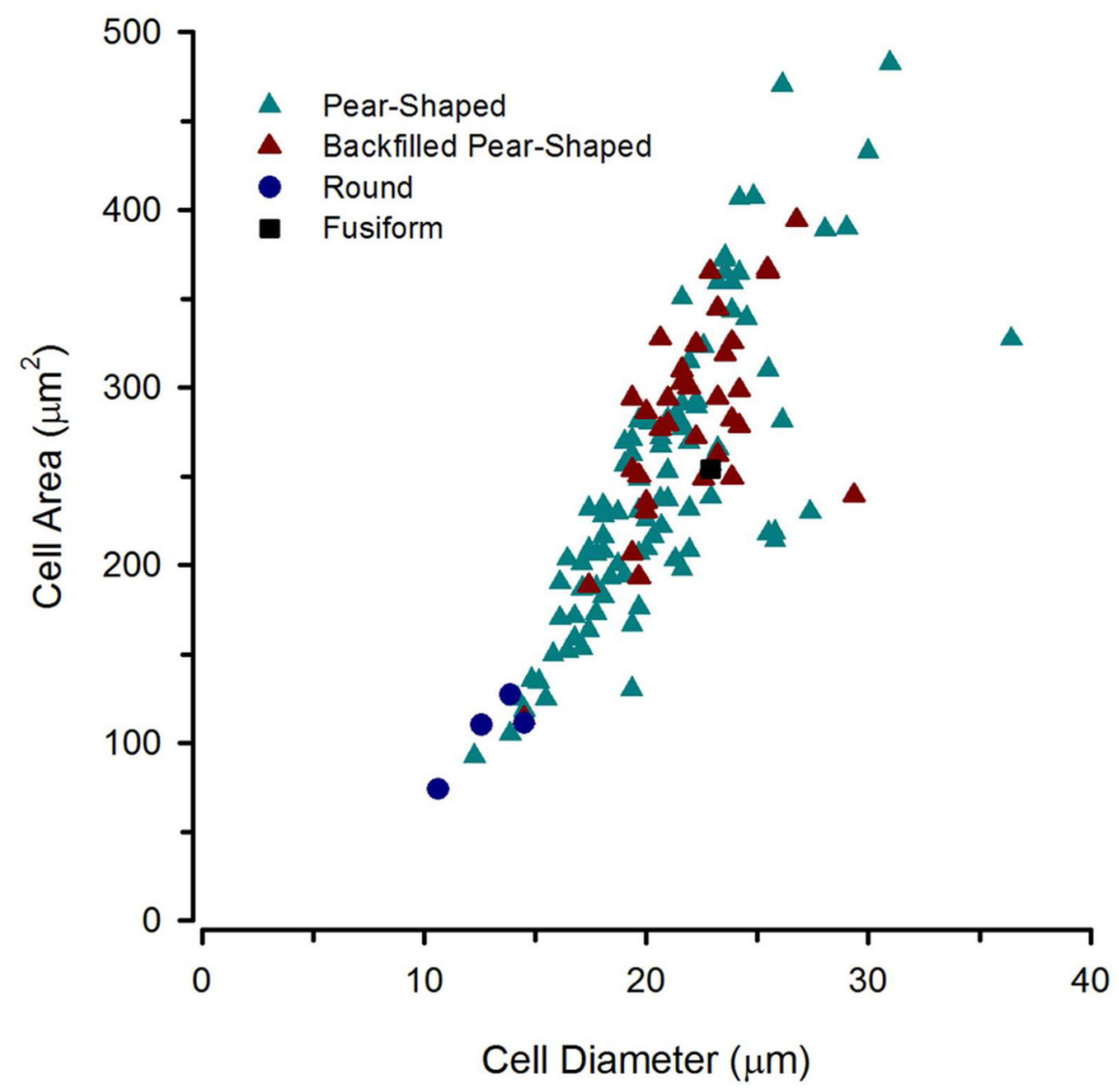

Figure 17.

Size and shape distribution of TH-ir neurons in the periventricular posterior tuberculum that were backfilled after neurobiotin application on the saccular branch of the eighth nerve (red triangles). These cells had an average soma diameter of $22 \mu \mathrm{m}$ and all were classified as pear-shaped. Measurements of other non-backfilled TH-ir neurons within the same sections were taken for comparison. 


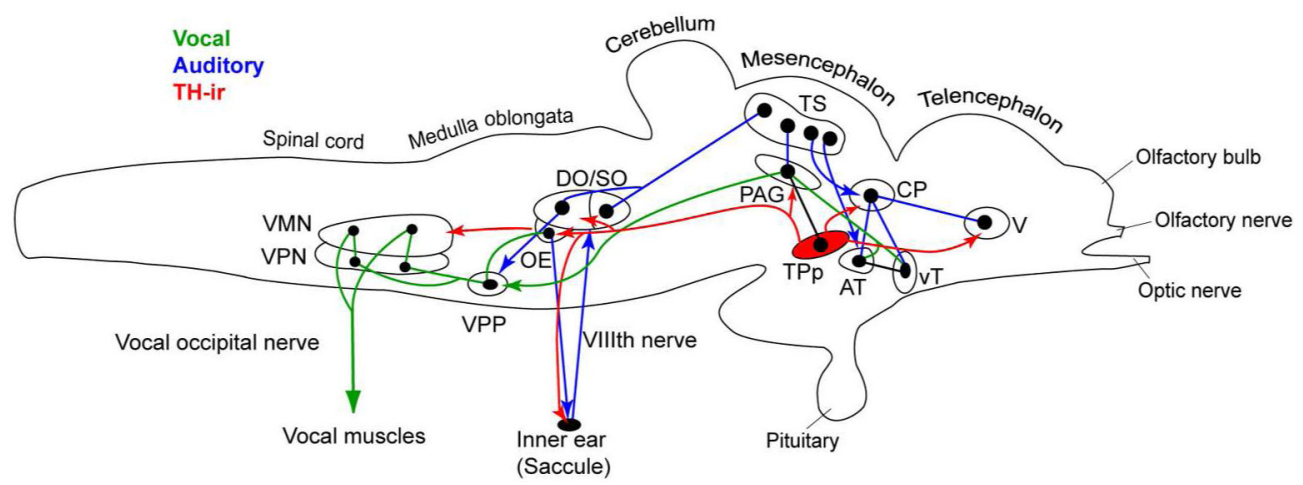

Figure 18.

Schematic sagittal view of the brain showing vocal motor (green), and central auditory (blue) systems in batrachoidid fish (midshipman and toadfish) (modified from Bass and McKibben, 2003; Kittelberger et al., 2006) with connectivity from large TH-ir neurons within periventricular posterior tuberculum (red, TPp, this study). Solid dots represent somata, and lines represent axonal projection pathways. Two connected dots indicate reciprocal connections. Descending vocal motor pathways (see Bass and Baker, 1990; Bass et al., 2000; 2001a; Bass et al., 1994; Fine and Perini, 1994; Goodson and Bass, 2002; Kittelberger et al., 2006; Remage-Healey and Bass, 2004). Preoptic (POA, not shown) and ventral (vT) and anterior (AT) tuberal nuclei in the hypothalamic forebrain project to the periaqueductal gray (PAG) in the midbrain which then connects to the vocal pattern generator (VPG) in the hindbrain-spinal cord. The VPG consists of vocal prepacemaker (VPP), pacemaker (VPN) and motor (VMN) nuclei. The VMN projects directly via occipital nerve roots to sound-producing muscle on the swim bladder. Central auditory system (see Bass et al., 2000; 2001a; Bass et al., 1994). Social vocalizations are detected by the inner ear which projects via the VIIIth nerve to descending (DO) and secondary (SO) octaval nuclei in the hindbrain and further to the auditory midbrain torus semicircularis (TS). Shown are nuclei interconnected with TS. The dorsal thalamic central posterior nucleus (CP) contains reciprocal connections with the ventral telencephalon $(\mathrm{V}$; includes supracommissural division) and anterior hypothalamus (AT/vT) (for nomenclature see Braford and Northcutt, 1983). TS and CP also connect to vocal motor nuclei in the forebrain (AT, vT, POA, not shown) and midbrain (PAG and isthmal/tegmentum, not shown), while auditory-recipient octaval nuclei in the hindbrain connect to the VPG via the VPP (also see Bass et al., 1994; Goodson and Bass, 2002). The octavolateralis efferent nucleus (OE) projects to the inner ear which includes the saccule, the main endorgan of hearing (Bass et al., 1994, 2000; Weeg et al., 2005). OE contains reciprocal connections with the VPP (Chagnaud et al., 2011) and receives projections from PAG (Kittelberger and Bass 2013, not shown). Large, pear-shaped TH-ir neurons from TPp send a massive dorsal turned descending tract into the hindbrain which appears to innervate DO, SO and OE and likely VMN. A branch of this tract exits the brain via the efferent tract in nVIII to the inner ear. Other targets of TPp TH-ir neurons include CP and PAG. The PAG and TPp are reciprocally connected (Kittelberger and Bass, 2013) but whether PAG projects onto TH-ir cells in TPp is not confirmed. TPp also has a 
robust ventral ascending $\mathrm{TH}$-ir projection although the exact innervation target in the ventral telencephalon (V) is undetermined. See above references for additional known connectivity. 


\section{Table 1}

Primary Antibodies Used

\begin{tabular}{ccc}
\hline Name & Immunogen & Manufacturer info \\
\hline anti-TH, clone LNC1 & Tyrosine hydroxylase purified from PC12 cells & $\begin{array}{c}\text { Millipore/Chemicon, MAB318, mouse } \\
\text { monoclonal }\end{array}$ \\
anti-TH & Native tyrosine hydroxylase from rat pheochromocytoma & Millipore/Chemicon, AB1542, sheep polyclonal \\
hair cell soma-1 (HCS-1) & Sensory epithelia from utricles of White Leghorn chicks & Dr. Jeffrey Corwin, mAb76, mouse monoclonal \\
& emulsified in RIBI adjuvant & \\
\hline
\end{tabular}

